\title{
SMALL SCALE REINFORCED CONCRETE MODELS
}



To: \$o P. MeIsuginIin, Director Joint Higlowsy Rerearch Rgeject

Tron: HoI0 Melhsel, Assiscent Director Jolut Hightray Regearcb project
July 12,1058

File: 7ohol2

Projecr: C-36-56L

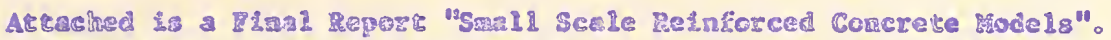

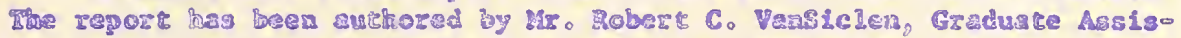
csnc on our staff, and ha the final report or the research spproved by

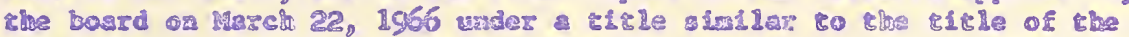
Inal Report. Profess9rs

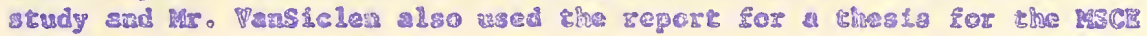
degrea.

Fithe report contalns date from tho ratertals used in congtructing tbe arall scrle beans and fron the testrig of the brans. Compriscrs

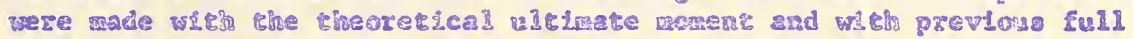
scale bearss. The regort is subshered for the record.

respectsulay suaraf

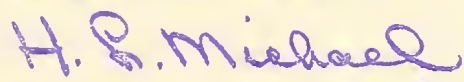

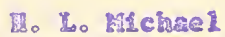

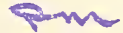

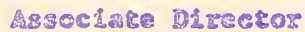

Fus: prex

Acterstraents

Copy: F。 \&。 Asbbracher

ข. IL. Dolch

츤

ข. Ho Aresco

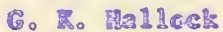

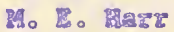

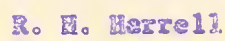

S. A. risuers

ฑ。. E。 Mrarvey

6. A. LRorst's

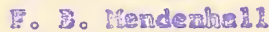

E. D. MIIes

ฎ. C. Dppenlฮmeะ
C. Fo Sebieler

‥ B. Bsott

๗。. Spewcer

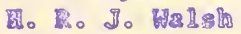

踏。 Wood

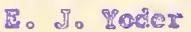


Digitized by the Internet Archive in 2011 with funding from

LYRASIS members and Sloan Foundation; Indiana Department of Transportation 


\section{ACKNOWLEDGIENTS}

Acknowledgment is made to the members of the Board of the Joint Highway Research Project and to Professor G. A. Leonards, Director, for appropriating funds for the project.

Special thanks is given to Professors Nartin J.

Gutzwiller and Robert H. Lee, major professors, for their patient guidance and advice.

The author also wishes to express appreciation to Mr. G. W. Foster and to Mr. W. B. Telfer, laboratory technicians, and to the several graduate students for their help in the $1 \mathrm{ab}$. Further, the author wishes to thank his wife for her encouragement and many hours of help. 


\section{TABLE OF CONTENTS}

Page

LIST OF TABLES....................... v

LIST OF FIGURES ....................... vi

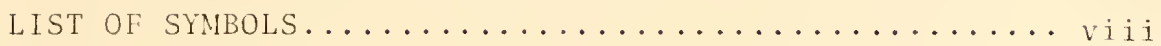

ABSTRACT $\ldots \ldots \ldots \ldots \ldots \ldots \ldots \ldots \ldots \ldots \ldots \ldots \ldots \ldots \ldots \ldots \ldots \ldots \ldots \ldots \ldots$

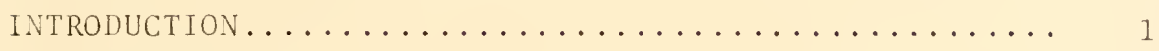

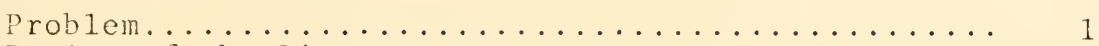

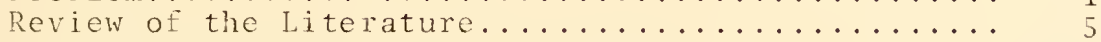

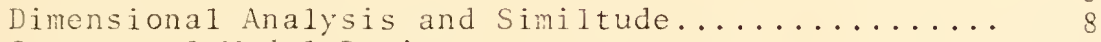

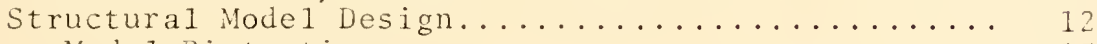

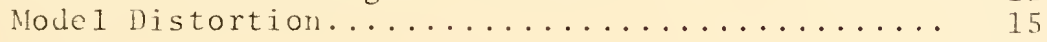

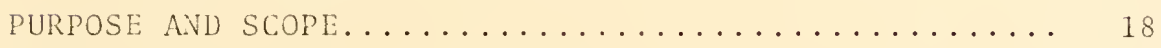

TEST SPECIMENS AND PRUCEDURES ................ 19

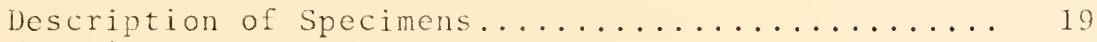

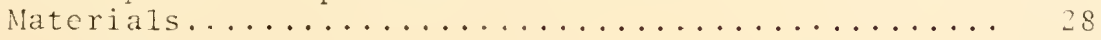

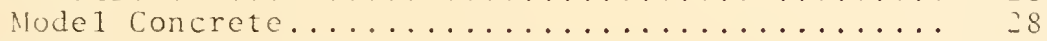

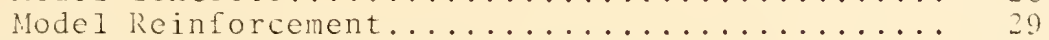

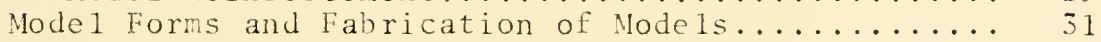

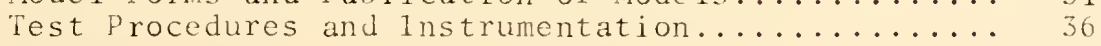

TEST RESULTS........................ 40

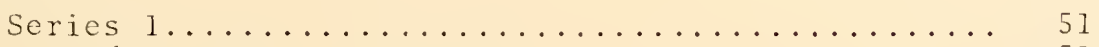

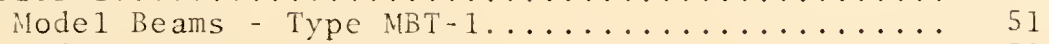

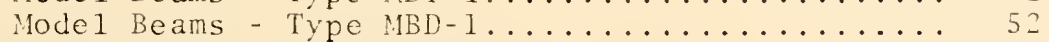

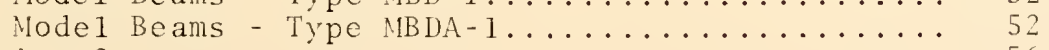

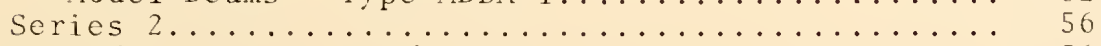

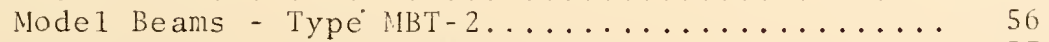

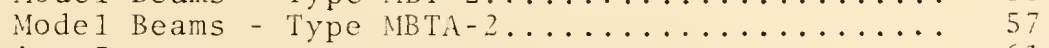

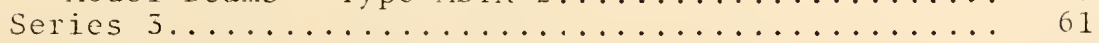

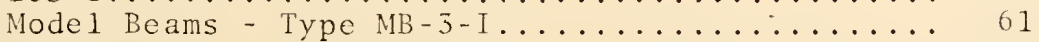

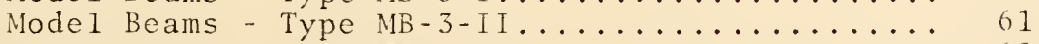

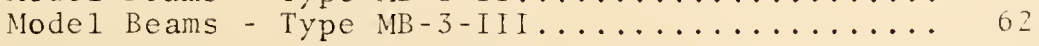


TABLE OF CONTENTS (continued)

Page

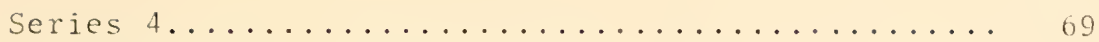

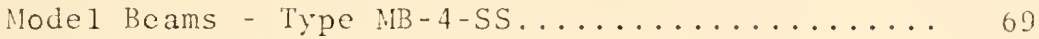

Node 1 Beams - Type $11 B-4-T \ldots \ldots \ldots \ldots \ldots \ldots \ldots$

DISCUSSION OF TEST RESULTS ............... 73

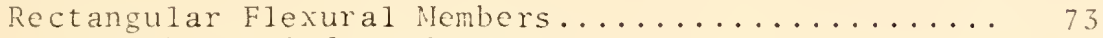

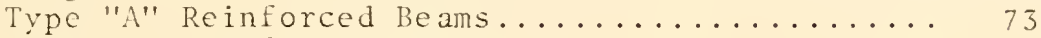

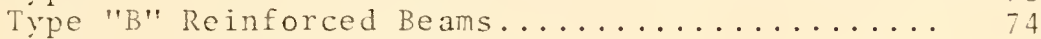

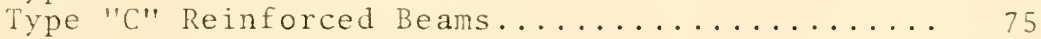

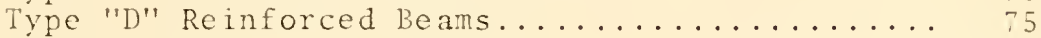

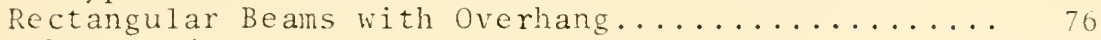

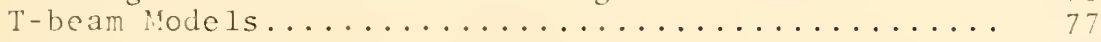

ANALYSIS OF TEST RESULTS ................ 79

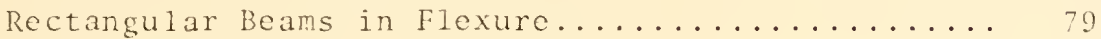

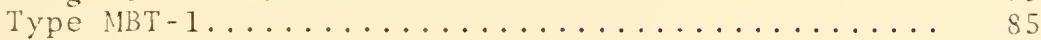

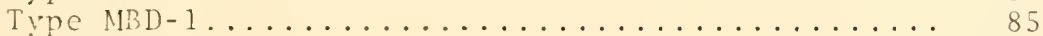

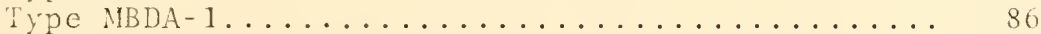

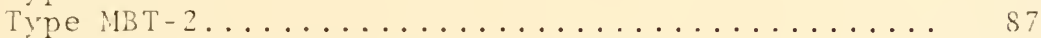

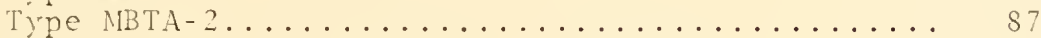

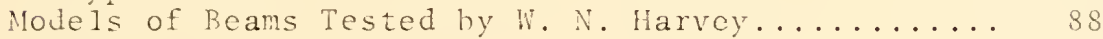

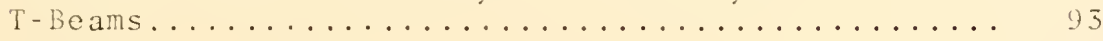

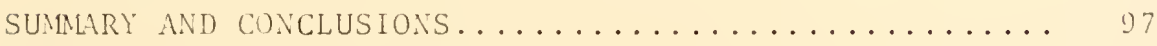

SUGGESTIONS FOR FURTHER RESEARCH.............. 100

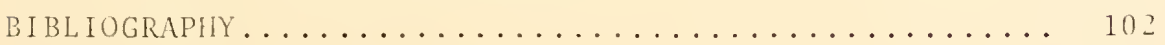

APPENIIIA A. MODEL CONCRETE................ 104

APPENIIX B. MODEL REINFORCEMENT ............... 110

APPENDIX C. SAMPLE CALCULATIONS .............. 120 


\section{LIST OF TABLES}

Tab le

Page

1. Properties of Test Specimens (Series 1)....... 22

2. Properties of Test Specimens (Series 2) ....... 23

3. Properties of Test Specimens (Series 3,4) ...... 24

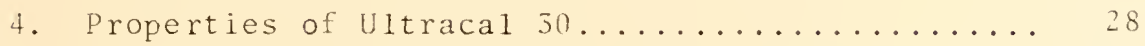

5. Properties of Longitudinal Nodel Reinforcement... 30

0. Properties of Web Reinforcement............. 31

7. Summary of Test Results (Series 1).......... 41

8. Sumary of Test Results (Series 2) .......... 42

9. Summary of Test Results (Series 3,4) ........ 43

10. Comparison of Test Results with U.S.D.
for Series $1 \ldots \ldots \ldots \ldots \ldots \ldots \ldots \ldots \ldots \ldots \ldots \ldots \ldots$

11. Comparison of Test Results with U.S.D.

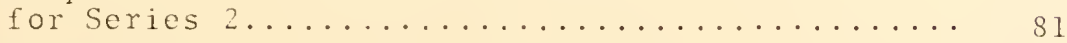

12. Comparison of Test Results for Scries 3

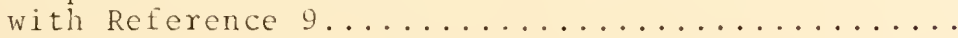

13. Comparison of Test Results for Series 4

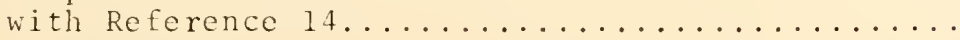


LIST OF FIGURES

Figure

Page

1. Stress-Strain Properties of Model and

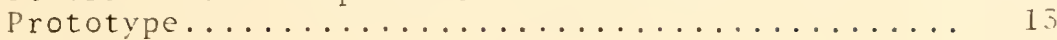

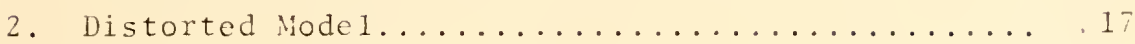

3. Cross-Section of Test Specimens (Series

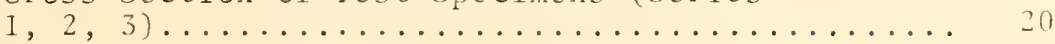

4. Cross-Section of Test Specimen (Series 4)...... II

5. Details of Specimens - Series $1,2 \ldots \ldots \ldots \ldots$

6. Details of Specimens - Series 5........... 20

7. Details of Specimens - Series 4........... ?

8. Plexiglas Forms with Reinforcement

(Series 1,2)..........................

9. Plexiglas Forms with Reinforcment

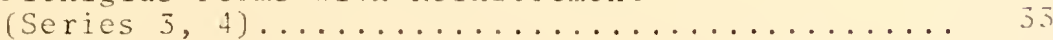

10. Cross-Section of Model T-Beam Forms......... 35

11. Beam Test Arrangement................ 37

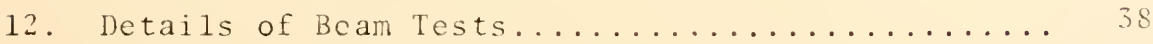

13. Tested Model Beams - Series 1.............. 44

14. Tested Model Beams - Series 1 (cont'd)........ 45

15. Tested Mode1 Beams - Series 2............. 46

16. Tested Hodel Beams - Series 2 (cont'd)....... 47

17. Tested Mode1 Beans - Series 3............. 48

18. Tested Model Beams - Series $4 \ldots \ldots \ldots \ldots \ldots \ldots \ldots$

19. Tested Model Beams - Series 4 (cont'd) ....... 50 


\section{LIST OF FIGURES (continued)}

Figure

Page

20. Sample Crack Pattern - Series 1 (MBT-1-4).... 54

21. Example of Load vs. Deflection - Series 1..... 55

22. Sample Crack Pattern - Series 2 (MBT-2-3)..... 59

23. Example of Load vs. Deflection - Series 2..... 60

24. Stirrup Steel Placement - Series 3..........6 64

25. Load vs. Deflection - Series 3............6 65

26. Load vs. Deflection - Series 3 (cont'd)...... 06

27. Load vs. Deflection - Series 3 (cont'd)...... 67

28. Load vs. Deflection - Series 3 (cont'd)....... 68

29. Load vs. Deflection - Series 4............ 71

30. Load vs. Deflection - Series 4 (cont'd)...... 72

Appendix

Figure

A-1. Cylinder Split Tension Test................ 100

A-2. Typical Stress-Strain Curve for Ultracal

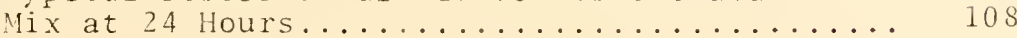

A-3. Time-Strength Curve for Model Concrete....... 109

B-1. Stress-Strain Curve for Type A Reinforcement.. 111

B-2. Stress-Strain Curve for Type B Reinforcement.. 11?

B-3. Stress-Strain Curve for Trpe C Reinforcoment.. 113

B-4. Stress-Strain Curve for Type D Reinforcement.. 114

B-5. Stress-Strain Diagram for Stirrup Stee1...... 115

B-6. Test Setup for Model Reinforcement.......... 110

B-7. Aluminum Clip Gage..................... 117

B-8. Annealing Racks..................... 119 


\section{LIST OF SYMBOLS}

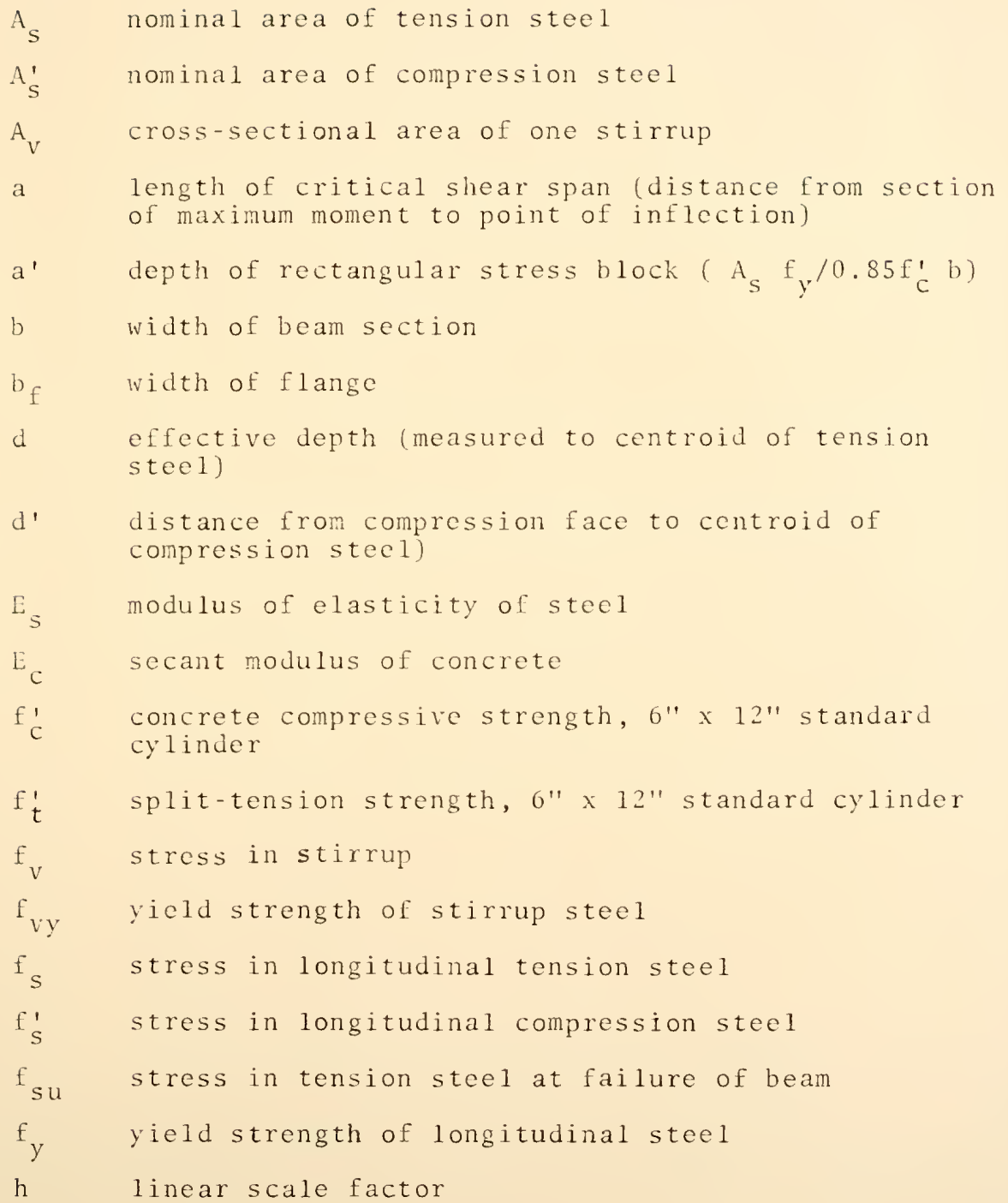




\section{LIST OF SYMBOLS (continued)}

$M_{S} \quad$ ultimate shear-compression moment

$\mathrm{M}_{\mathrm{u}}$ ultimate flexural moment

$M_{1}$ maximum negative moment

$\mathrm{M}_{2}$ maximum positive moment

m subscript for mode 1

$n \quad E_{S} / L_{C}$ modular ratio

$\mathrm{p} \quad \mathrm{A}_{\mathrm{S}} / \mathrm{bd}$ percentage longitudinal tension stee 1

P total 1oad

p subscript for prototype $\mathrm{P}_{1}, \mathrm{P}_{2}$ load on the overhang and load between supports,
respectively

$\mathrm{P}_{\mathrm{C}}$ total load at formation at diagonal tension crack

$\mathrm{P}_{\mathrm{u}}$ total load at failure

$\mathrm{r} \quad \mathrm{A}_{\mathrm{V}} / \mathrm{bs}$ - web reinforcement ratio

$s \quad$ horizontal spacing of stirrups

t total beam depth

$t_{1}$ depth of $f$ lange

V total shear at any section

$V_{\text {a }}$ shear in critical shear span

$V_{C}$ shear assigned to concrete (working stress design)

$V^{\prime}$ shear assigned to stirrups (working stress design)

$V \quad$ nominal shearing stress $=V / b j d$ or $V / b d$ as defined in text

$v_{c}$ portion of total shearing stress assigned to concrete or average shear at diagonal cracking

$v_{\mathrm{s}}$ portion of total shearing stress assigned to stirrups

$v_{u} \quad$ ultimate shear strength 


\section{LIST OF SYMBOLS (continued)}

$x$

stress scale factor

y

strain scale factor

$\alpha$

inclination of stirrups with respect to longitudinal axis

$\theta$ inclination of compression diagonal with respect to longitudinal axis

$\varepsilon_{c u} \quad$ strain at outermost compression fiber at failure

$\varepsilon_{\text {su }} \quad$ strain in tension steel at failure

$\pi \quad$ dimensionless quantity

S.C. shear-compression failure

1). T. diagonal tension failure

F.T. flexural tension failure

MII strain in micro-inches per inch 


\section{ABSTRACT}

Van Siclen, Robert C., MSCE, Purdue University, August, 1968. SMALL SCALE REINFORCED CONCRETE MODELS. Major Professors: M. J. Gutzwiller and R. H. Lee.

This research project is an experimental study on the feasibility of using small scale models to represent reinforced concrete beams. The specific objectives were:

1. to establish model techniques and materials applicable to small scale beams.

2. to compare model test results with standard theory and previous test results from larger scale beams.

In order to accomplish the objectives of the research, fifty-three model beams of different sizes and shapes were used. Cylinders were used to determine model concrete properties.

The specimens of Series 1 and 2 were simply-supported rectangular beams. The variables used in these two series were amount and type of reinforcing as well as the crosssectional area of the beams. Four types of model reinforcing were utilized, namely: threaded rod, annealed and unannealed, and deformed wire, annealed and unannealed. 
From the test data obtained from these specimens the test ultimate moment was compared with the theoretical ultimate moment as calculated using Ultimate Strength Theory. In general, correlation between test and theory was excellent, with most beams behaving as the theory predicted.

The models of Series 3 were intended to simulate some previous work done by W. N. Harvey. Results from these tests indicated that modeling of such beams is much more difficult. Although some of the beams did behave similar to their prototype, it was possible to establish that stirrup spacing affected beam strength. On the other hand, those beams of short shear span exhibited a size effect, with some failures occurring outside the shear span. The beams of Series 4 were models of beams tested by K. E. Wehr. These models were distorted having a slightly different steel percentage than their prototype specimens. The results of these tests indicated that with careful consideration a slight model distortion will not affect the results. 


\section{INTRODUCT ION}

\section{Problem}

The use of reinforced concrete throughout the various phases of life has become quite common. It is therefore important to understand the properties and conditions that control and influence the reactions of various concrete structures. Most of the recent experimental research has been done using large scale models. The models are scaleddown replicas of the reinforced concrete structures used in the field with the model concrete and reinforcement being cxactly the same as that of the prototype.

When using large scale models, it is often difficult to test more than a small number of specimens. Thus, if any problems develop in the manufacture or testing of the specimens, it can often involve a great deal of time, effort, and expense merely to carry out a relatively routine investigation. At the same time, such specimens require a large amount of floor space for pouring, curing, and testing. For the small laboratory, this could easily tie up the entire area. Also, one is faced with the problem of storing a large inventory of reinforcing bars, cement, and aggregate. Recently, the idea has been presented of the possibility of developing smaller scale models that will predict the 
same results as the field structures. Although the use of models is not a new concept in the field of reinforced concrete, it has only been in relatively recent years that the use of small-scale models has come into existence.

In working with such materials as steel or aluminum, one is dealing with a homogeneous material and this greatly alleviates the model similitude problem. The problem of working with reinforced concrete, or for that matter, any non-homogeneous material, is somewhat more difficult but the problem can be handled if proper techniques are used.

Recent interest has been shown in the use of plastic models for the elastic range of behavior in reinforced concrete. However, today ultimate strength design is becoming more and more accepted as the design technique for reinforced concrete. Plastic models do not adequately simulate the reinforced concrete members in the plastic design region. Consequently, the need has developed for model materials that act as the concrete in the inelastic area.

In analyzing reinforced concrete, there are two critical materials to consider, portland cement concrete and steel reinforcement. Furthemore, the concrete may be broken down into cement, water, and aggregate. Thus, it is necessary to deal with a relatively complex material.

The laws governing similtude place strict requirements on the relationship between model and prototype. The relation of the physical dimensions of the model and prototype 
must remain constant in order to insure complete similitude. If the concrete and steel that make up the reinforced concrete are treated as two materials that control the action of the reinforced concrete, then these two materials must maintain the scale ratios with their respective model counterpart. It is thus important to find materials which will maintain the same stress-strain factors.

As an example, the ideal relationship would be to use the same materials in the model as in the prototype specimen. This means that if one uses steel and concrete in the prototype, the same materials would be used in the model.

The difficulty in using this type of model lies in the problem of the concrete, when possibly a one inch aggregate would be used in a $1^{\prime \prime}$ by $2^{\prime \prime}$ specimen. If the aggregate size is reduced so that the maximum aggregate size is that of sand, the mixture compares to that of a mortar which may exhibit high shrinkage and crack during curing.

Thus, the problem of finding a material to replace the portland cement concrete becomes imperative. As soon as one is faced with this problem, it is then necessary to find a model material to replace the steel of the prototype. This problem can be somewhat alleviated by using a model material whose strength characteristics closely resemble those of the portland cement concrete, but also corresponding to the model properties and dimensions. 
The idea is to develop a model that is similar in a 11 respects, right down to deformations on the model reinforcing bar. In designing large scale concrete members, forms made from wood are usually used for the making of the beams, however, with the use of plexiglas for making the mode 1 forms it is possible to develop beams that have smoother surfaces. This is important in maintaining a uniform cross section for the model specimens and eliminating any surface defects that could affect the strength of the model.

Another problem of importance is that of the bond strength of the concrete and steel of the prototype and that of the model concrete and its reinforcement material. In regular reinforced concrete beams, the reinforcing bars are deformed to increase the bonding strength of the concrete to steel. However, in the case of the models it is difficult to locate wire or small diameter bars that are deformed. Correlation between model and prototype bond strengths is extremely important if model failures due to bond stress are to be prevented.

The model size must be large enough to allow for ease in measuring the deformations of the model. For strain gages to be mounted in the reinforcing material it is necessary to have reinforcing bars large enough so that the smallest gages made can easily be mounted on the reinforcement. On the other hand, it is important that small enough models be made, so that the prototype scale is reduced 
substantial1y.

One of the major difficulties that confront present day reinforced concrete modellers is the lack of proper equipment and established techniques. When a large scale model is used, most structural 1 aboratories are set up to provide a means for testing the concrete and steel properties. But when the scale of the model is reduced to a small-scale model, then one is faced with an almost untouched area.

In order to utilize proper model materials, it is necessary to obtain properties of the model concrete such as the compressive strength, the tensile strength, and stress-strain relationship. Similar information is needed for the reinforcement. Testing of the model materials inrolves equipment and techniques that are not standard in 1 aboratories.

\section{Review of the Literature}

Yodels were one of the carliest design methods employed by designers. Although such models often did not behave as the actual structure being designed, nevertheless, the large factors of safety used in design and the simplicity of structures allowed for their use. With the development of the science of mathematics, especially dimensional analysis and similitude, the engineer began to realize the need for developing models that more closely followed the actual field structures. 
As the use of reinforced concrete became common, large scale models were used to test beams, columns, and slabs, in order to obtain a working knowledge of such members. Even today such model methods are commonly accepted (9, 14 . Although highly valuable, in many cases, it has been necessary to devote more time to the actual manufacture of such specimens than to consideration of the problem. At the same time, it is often necessary to make rather broad simplifications as to the actual conditions that exist in the field.

In recent years the possibility of developing smallscale reinforced concrete models has come into light with the increased use of reinforced concrete for varied and more complex structures. A great deal of model work has been done in Europe using mortar-type models, where cheaper labor costs make the manufacture of models very popular $(5,4,7)$. At the same time, in this country, emphasis has been placed on the use of plastics for reinforced concrete models.

Models of reinforced concrete structures made from materials such as plastics, whose performance can be correlated only in the elastic range, are somewhat limited in their usage. Although they do provide a good check on basic working stress design techniques, results from tests are used mainly as a means for simplifying the analytical work involved in more complex structures (4). 
With the increased use of ultimate strength design techniques the need for models to simulate the reinforced concrete in the non-elastic region has become evident (4, 12, 15). Along these lines, two different model types have evolved. These may be called the portland cement models and the gypsum or plaster type models.

There are advantages and disadvantages to using either type model. The portland cement models have the advantage of being riade from the same material as the prototype specimen. However, with the use of a scaled-down aggregate in the model, one is faced with using a material as different from actual reinforced concrete as plaster (15). At the same time, there is no gain in the required curing time necessary to produce the model specimen. In the case of gypsum models, in actuality a completely different type of material is being used to represent the prototype concrete. This immediately has a negative effect on its acceptance by many members of the concrete profession. But, at the same time, the gypsum type model can be tested very rapidly after pouring and requires little curing $(4,5,15)$. The time element is very important in any research experiment. By using plaster-reinforced mode1s, large numbers of beams have been tested in very short periods of time $(5,15)$. Present emphasis in model research is on developing models that will be accepted as valid for design purposes. The use of such a design technique offers many unique 
advantages. It allows the observer to obtain a great deal of information about the structure he will eventually build in the field (7). The model can be completely destroyed and several others tested before there actually is any work begun at the construction site.

This idea of developing a model has already been applied in many different industries, especially the aircraft industry, where the nature of aircraft structures has necessitated the testing of smali-scale models. Also, in the area of hydraulic structures, much effort has been made to use models in dam work (11).

\section{Dimensional Analysis and Similitude}

Before attempting to establish any model relationships it is important to understand the general concepts of dimensional analysis and similitude theory. Dimensional analysis is that branch of mathematics which deals with dimensionally homogeneous equations, equations which have forms independent of the fundamental units of measurement. On the other hand, the theory of similtude establishes those relationships necessary to permit reliable predictions to be made from observations on models, and the type of relationship existing among the variables involved in any physical phenomenon in order that the most pertinent data mya be obtained (13).

In essence, dimensional analysis leads directly to the theory of similtude. By establishing equations which are 
independent of any units of measurement it is possible to relate a phenomenon occurring in one thing to the same one occurring in another; thus, the model-prototype relationship.

Buckingham's Theorem states that the number of independent dimensionless groups is equal to the number of all quantities which are of importance for the process 1ess the number of primary quantities (8). To illustrate this theorem consider a very simple example in which three quantities are important to the problem; force, stress, and crosssectional area. In this case the two primary quantities are length, L, and force, F. Thus, by Buckingham's Theorem the number of dimensionless groups should be $(3-2)=1$.

Force is given in units of F, while stress has units of $F / L^{2}$ and cross-sectional area units of $L^{2}$. The obvious relation between these threc variahles is that stress equals the force divided by the cross-sectional area, or in equation form:

$$
\sigma=P / A
$$

Here both sides of the equation have the same dimensions, $\mathrm{F} / \mathrm{L}^{2}$, and the equation is dimensionally homogeneous.

Now consider another separate situation in which the same equation is valid. In this case, however, the area has been reduced proportionally. By the theory of similitude it is possible to establish the resulting stress in the second case, by knowing the values of the quantities in 
the previous example. No matter how one of the quantities in case two is changed from casc one, it is still possible, according to similitude theory, to relate the equation governing one to the equation governing the other.

It is important here to remember that no other quantity plays any part in either example one or two. If, for example, width and length rather than just cross-sectional area play an important role, the area is replaced by these two governing quantities. From Buckingham's Theory the number of dimensionless groups is $(4-2)=2$. These two groups are

$$
\frac{\sigma w l}{\Gamma} \text { and } \frac{W}{\ell}
$$

The new cases, three and four, are now governel by these two equations:

$$
\sigma=\frac{P}{\mathrm{~W} \ell} \text { and } \mathrm{w}=\mathrm{k} \ell
$$

where $k$ is a dinensionless number. In order to relate the phenomenon occurring in case three to that in case four it is necessary that both the preceding relations hold, rather than just the one equation for cases one and two. Thus, increasing the number of variables affecting the problem, the number of restrictions are increased.

By calling case one the model and case two the prototype, the model-prototype relationship is developed. Similarly, the relationship between cases three and four is 
developed by applying the additional restriction that the length remain proportional to the width.

Returning to the basic idea of dimensional analysis, it is important to mention the two systems of measurement common to stress analysis. These are the force-length-time and the mass-length-time systems. Since force and mass are related, it is possible to use either system, remembering that:

$$
\text { force }=\text { mass } x \text { acceleration }
$$

or in dimensional units,

$$
(F)=(M)\left(L / T^{2}\right)
$$

When dealing with a static problem it is advantangeous to use the F-L-T system of units, since only the units of force and length come into play.

Although from the previous examples the ideal of dimensional analysis and similitude may appear highly simple, this is not the case. In the first place, rarely are the variables affecting a phenomenon so few and obviously related to one another. On the contrary, often the variables having an effect on a particular situation are large in number and related in a complex manner. At this stage it becomes necessary to carefully consider the importance of the part each variable plays in affecting the phenomenon. Those variables of little importance must often be neglected 
if the phenomenon is to be duplicated with any degree of success.

Prediction of a given phenomenon in a prototype test is dependent on an accurate interpretation of the test results. This involves both understanding the phenomenon and the relation between model and prototype. At the same time the accuracy of the model test work is highly important, for in many cases, the model is of a reduced scale from that of the prototype. Any error in such work could easily magnify many times when determining the effect on the prototype.

\section{Structura1 Mode1 Design}

In the case of a structural model, concern is chiefly with the behavior of a structure under various loading conditions. The reaction of the structure to these conditions can normally be stated in terms of stresses and strains.

For simplicity, consider the case of a prototype structure that is made from a homogeneous and isotropic material such as stee1. Assume the model must be constructed of a material having slightly different stress-strain properties than the prototype material. Properties of the model and prototype materials are shown in Figure 1.

Stresses and strains in the model are related to those in the prototype by the factors $x$ and $y$, repsectively, and can be expressed in equation form as: 


$$
\begin{aligned}
& x f_{m}=f_{p} \\
& y \epsilon_{m}=\varepsilon_{p}
\end{aligned}
$$

If the model and prototype material were identically the same, then the values of $x$ and $y$ would be unity.

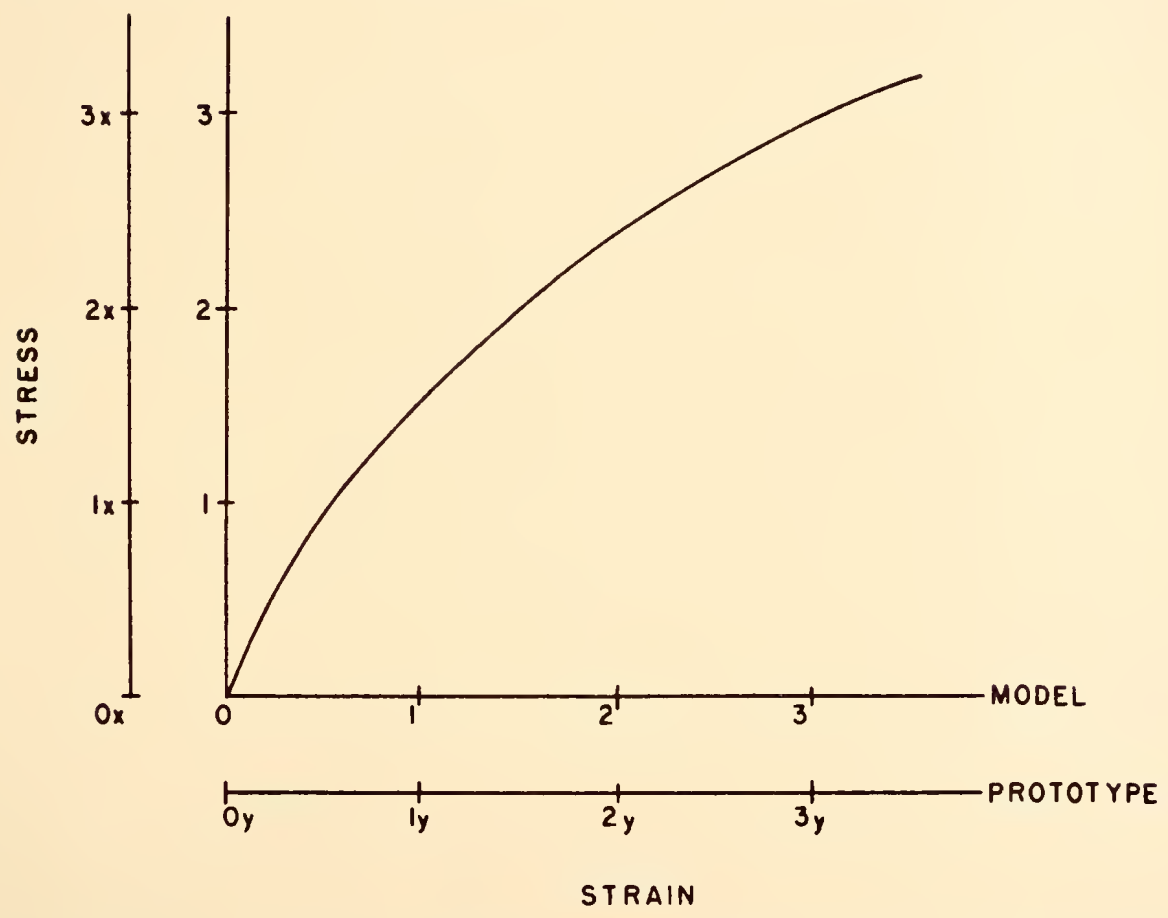

Figure 1. Stress-Strain Properties of Model and Prototype.

In order to maintain model similitude it is necessary that the values of $x$ and $y$ be constants. Thus the stressstrain properties of the model must take on the general shape of that of the prototype. As an exception to this statement, 
it is possible to utilize a model material for a prototype structure in which the factors $x$ and $y$ are not constant throughout the entire range of the stress-strain diagram. However, any experiments done on the model must be done in the region where these factors are constant. An example of such a model method is the use of a plastic model to represent a reinforced concrete prototype structure at low loads.

Having the relations between the stresses and strains in the model and prototype, it is then possible to develop relationships between the various loads and reactions of the system in terms of the geometry of the model and prototype. A linear scale factor relating the linear dimensions of model to prototype is then defined as $h$, such that the following geometric relationships hold:

$$
\begin{aligned}
& I_{p}=h_{m} \\
& A_{p}=h^{2} A_{m} \\
& I_{p}=h^{4} I_{m}
\end{aligned}
$$

Combining Equations (1) and (2) with relations from the laws of statics, the following relationships hold:

$$
\begin{gathered}
f_{m}=F_{m} / A_{m} \text { and } f_{p}=F_{p} / A_{m} h^{2} \\
\therefore \quad F_{p}=x F_{m} h^{2}
\end{gathered}
$$




$$
\begin{gathered}
f_{m}=\frac{M_{m} C_{m}}{I_{m}} f_{p}=\frac{M_{p} C_{p}}{I_{p}} \\
\therefore M_{p}=M_{m}\left(x h^{3}\right)
\end{gathered}
$$

and

$$
\begin{aligned}
& \varepsilon_{m}=\Delta_{m} / 1_{m} \quad \varepsilon_{p}=\Delta_{p} / 1 p \\
& \therefore \quad \Delta_{m}=\Delta_{p} / y h
\end{aligned}
$$

In order that the above relations hold exactly for a material such as reinforced concrete, the model concrete and reinforcement must both have the same scale factors, $x$ and $y$, as the prototype concrete and steel (4). When model materials have the same stress-strain factors $x$ and $y$ as their respective prototype materials, it is possible to develop exact scaled-down models.

\section{Mode 1 l)istortion}

Whenever any similitude condition is violated, the resulting structural model is a distorted one. This type of model is often used due to the complex nature of many structures. In general, loading conditions and the reaction of the structure to them can be divided into two groups, those of primary and those of secondary importance.

As an example of this type of model, consider the case of an axially loaded column. In order to test the column in the laboratory, a column having the same cross-sectional 
area hut half the length, is manufactured. By changing the length of the column and not the other geometric propertics, the design conditions have been violated. Although the model is a distorted one, it is still possible to obtain a relatively good estimate of the critical load of the prototype column.

Another example of a distorted model would be a reinforced concrete beam in which the reinforcement arca of both the model and prototype are proportional by the square of the linear scale factor, h, but where the number of reinforcement bars in the model differs from those in the prototype. This is shown in Figure 2. The advantages of this type of distortion is that it allows the modeller to utilize a larger bar in the small-scale model (7). Such a distortion is possible when hond stress is not an important consideration.

It is more difficult in working with reinforced concrete models to carry out reasonable model distortion than with homogeneous and isotropic materials. For this reason, in most cases it is advisable to maintain an undistorted model. 


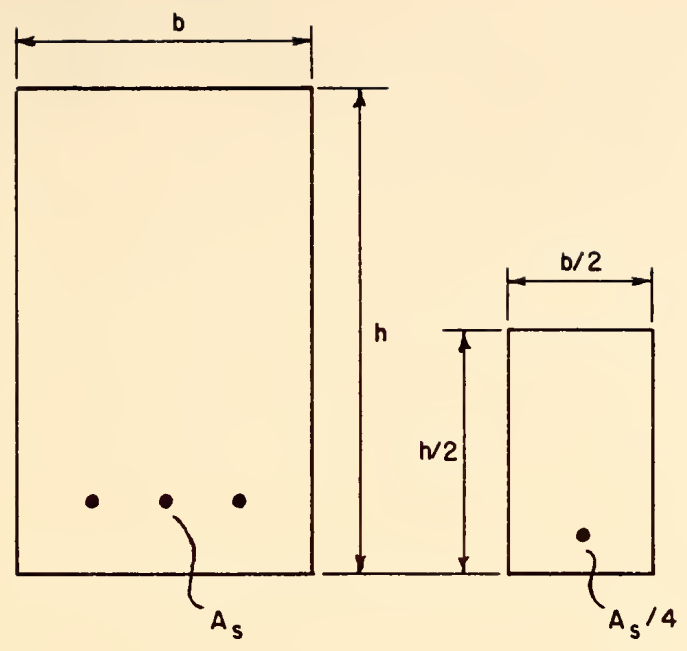

FIGURE 2. DISTORTED MODEL 


\section{PURPOSE A.ND SCOPE}

The objective of this research was to develop a small model that adequately represents a reinforced concrete beam, having the same geometrical shape. This involved solution of the following problems:

1. Materials had to be found for use as the model concrete and reinforcing.

2. A suitable linear model scale had to be selected.

3. Tests had to be performed to determine the relationship of modei to prototyne.

The model and prototype specimens were beams of rectangular and T-beam cross-section. The first model specimens were rectangular and were tested in flexure to determine the ultimate load and failure pattern. Then both rectangular and $\mathrm{T}$-beam models were tested to determine the effect of shear span-to-depth ratios and amounts of web reinforcement.

It was the intent of this work, combined with other recent findings in small model research, to provide a means whereby eventually the use of small models for reinforced concrete research will become accepted practice. 


\section{TEST SPECIMENS AND PROCEDURLS}

\section{Description of Specimens}

There were four series of beams. The first and second series were simply-supported rectangular beams tested with equal loads at the third points of the span. The third series was a simply-supported rectangular beam with an overhang at one end. The final series of beams consisted of T-beams tested in the same manner as beams in Series 1, 2, and 3 .

Beams in Series 3 were scaled-down models of rectangular beams tested by $\boldsymbol{N}$. $N$. Harvey (9), while those in Series 4 were models of T-beams tested by $k$. E. Wehr (14). All loads were delivered to the heans through knife edges. With the exception of those $\mathrm{T}$-beams tested in flexure and having a variable flange width, the cross-section for each series of beams remained the same.

Figures 3 , and 4 show details of beam cross-sections and Tables 1, 2, and 3 provide properties of each beam tested. Shear and moment variations, and specimen details can be seen in Figures 5, 6, and 7 . 


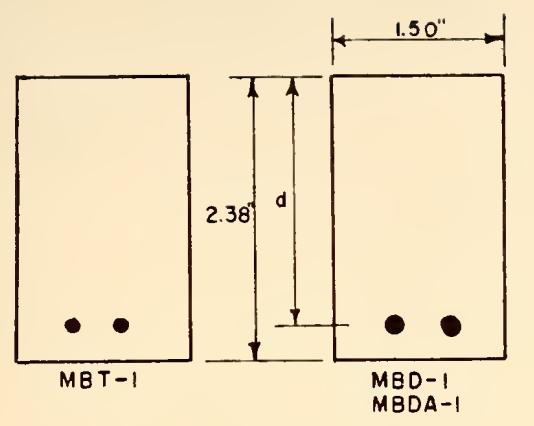

\begin{tabular}{|c|c|} 
SERIES I \\
\begin{tabular}{|c|c|}
\hline TYPE & REINFORCING \\
\hline$M B T-1$ & $I T, 2 T$, or 3T \\
\hline$M B D-1$ & $1 D, 2 D$, or 3D \\
\hline$M B D A-1$ & IDA, 2DA, or 3DA \\
\hline
\end{tabular}
\end{tabular}

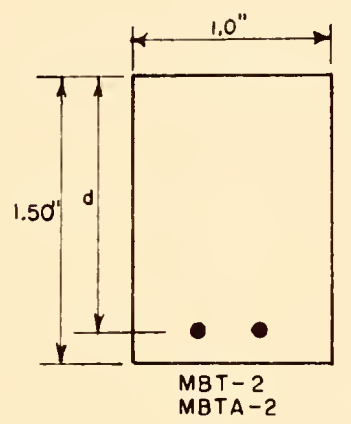

SERIES 2

\begin{tabular}{|l|l|}
\hline TYPE & REINFORCING \\
\hline$M B T-2$ & IT, 2T, or $3 T$ \\
\hline$M B T A-2$ & ITA,2TA, or 3TA \\
\hline
\end{tabular}

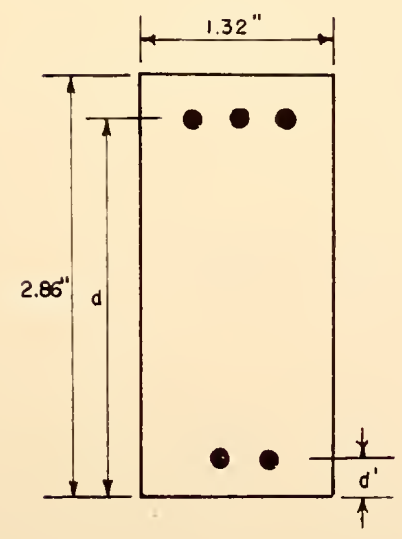

SERIES 3

ALL TYPES :

TOP - 3 DA

BOTTOM- 2DA

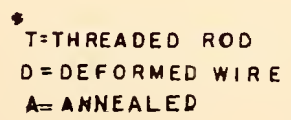

FIGURE 3. CROSS-SECTION OF TEST SPECIMENS (SERIES I,2, 8.3) 


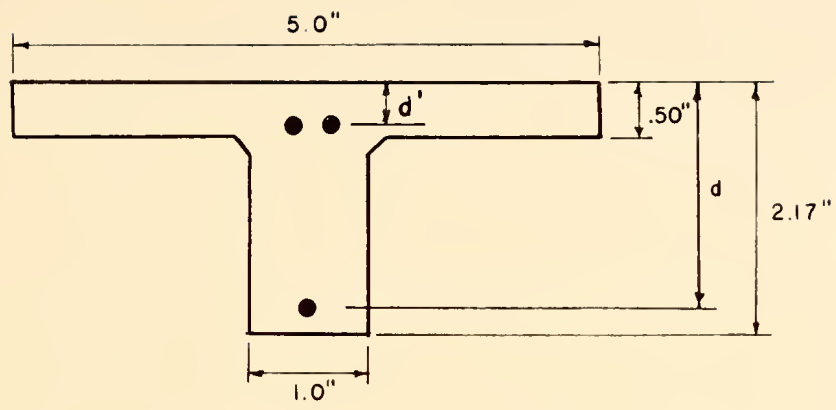

BEAM TYPE MB-4-I-

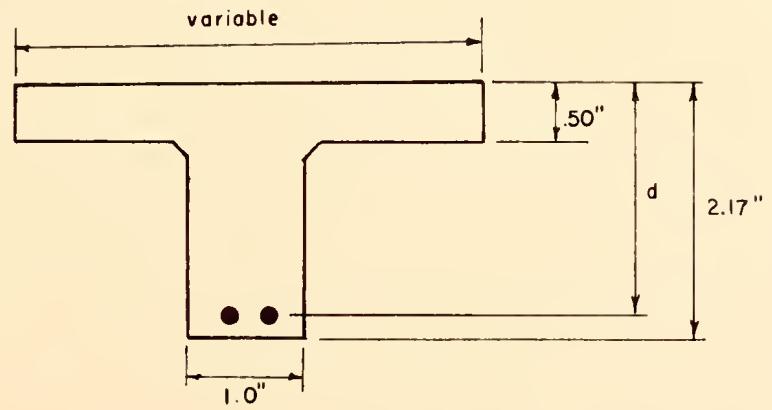

BEAM TYPE MB-4-SS-

FIGURE 4. CROSS-SECTION OF TEST SPECIMENS (SERIES 4) 


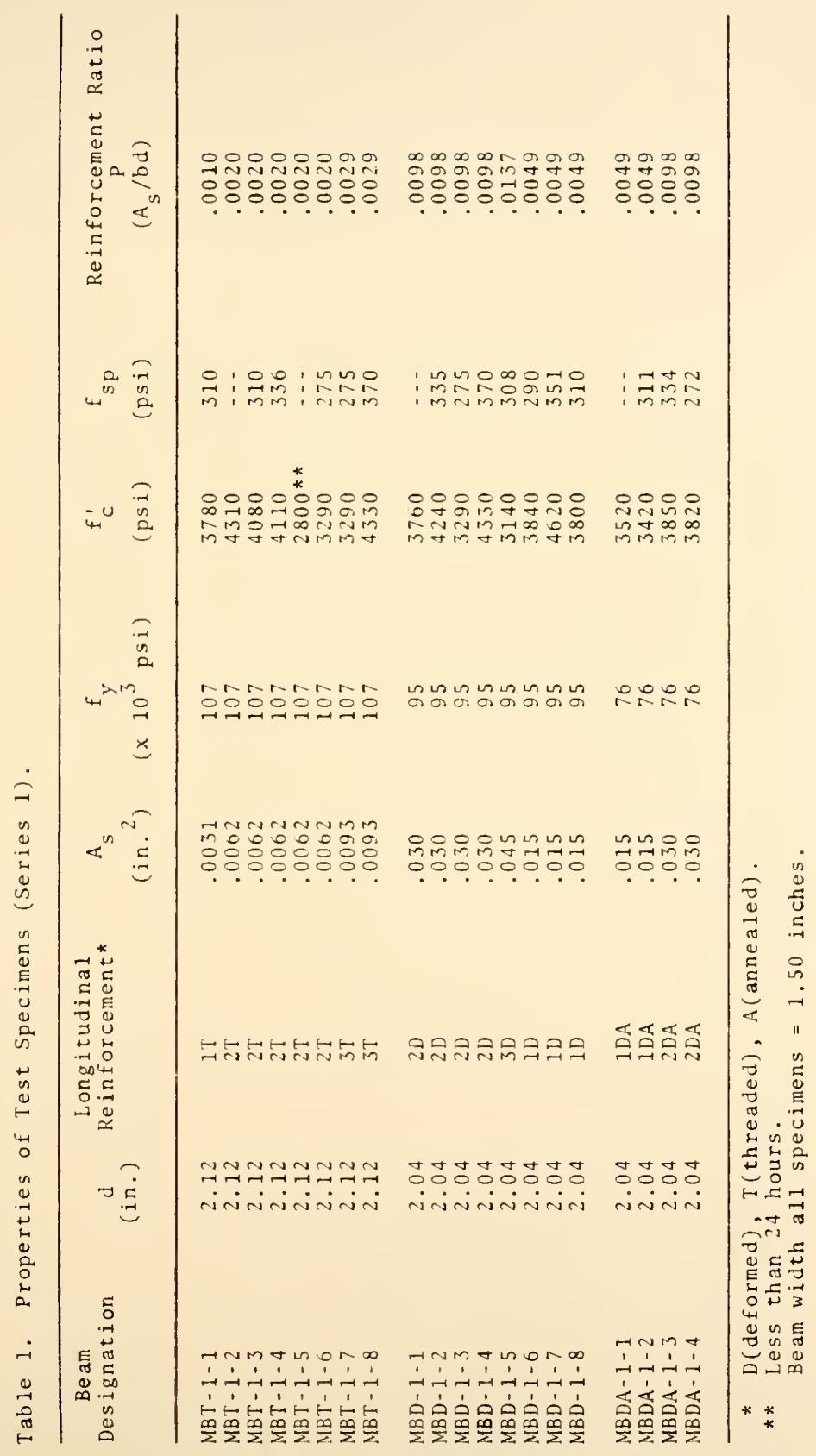




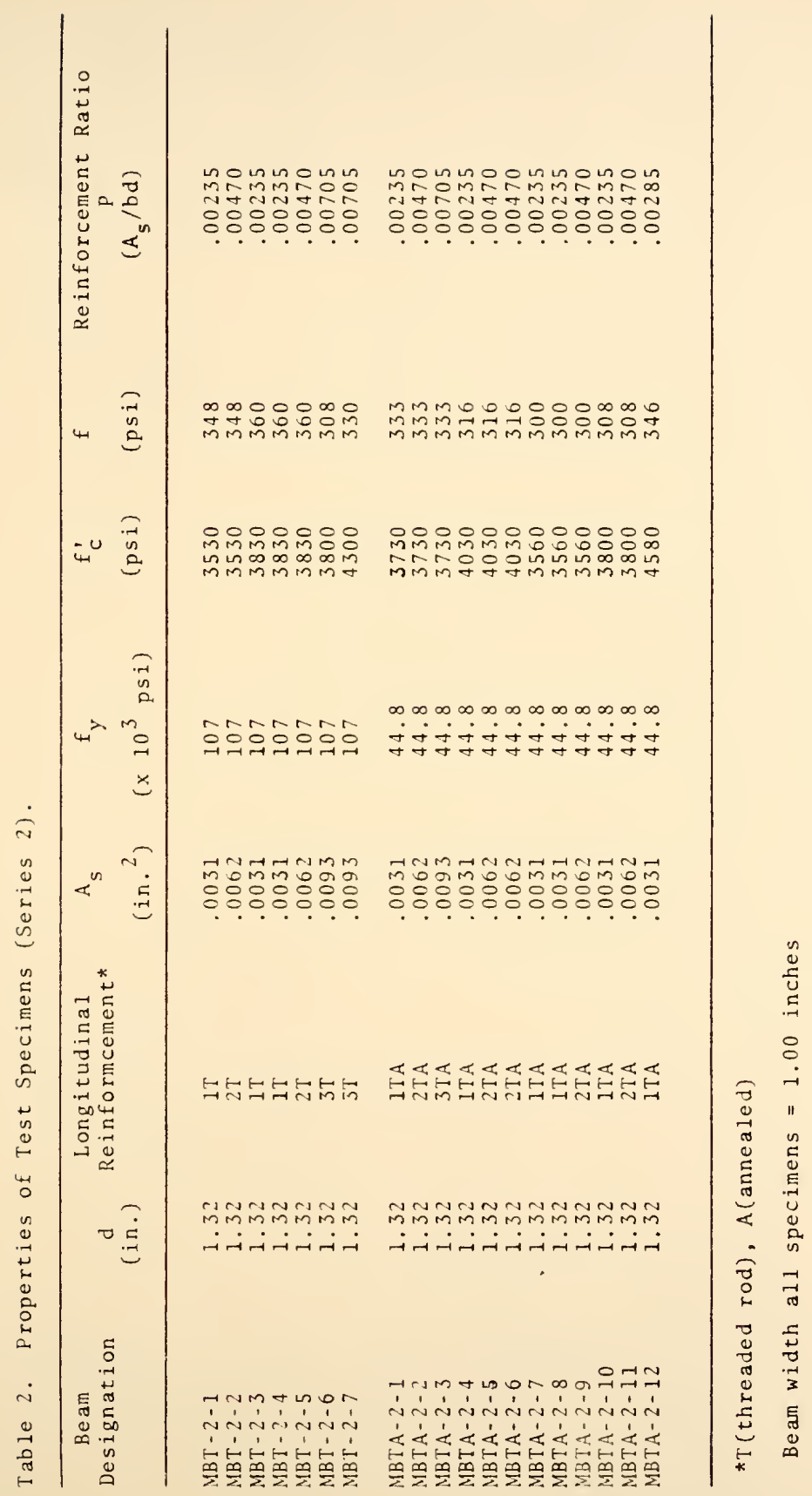




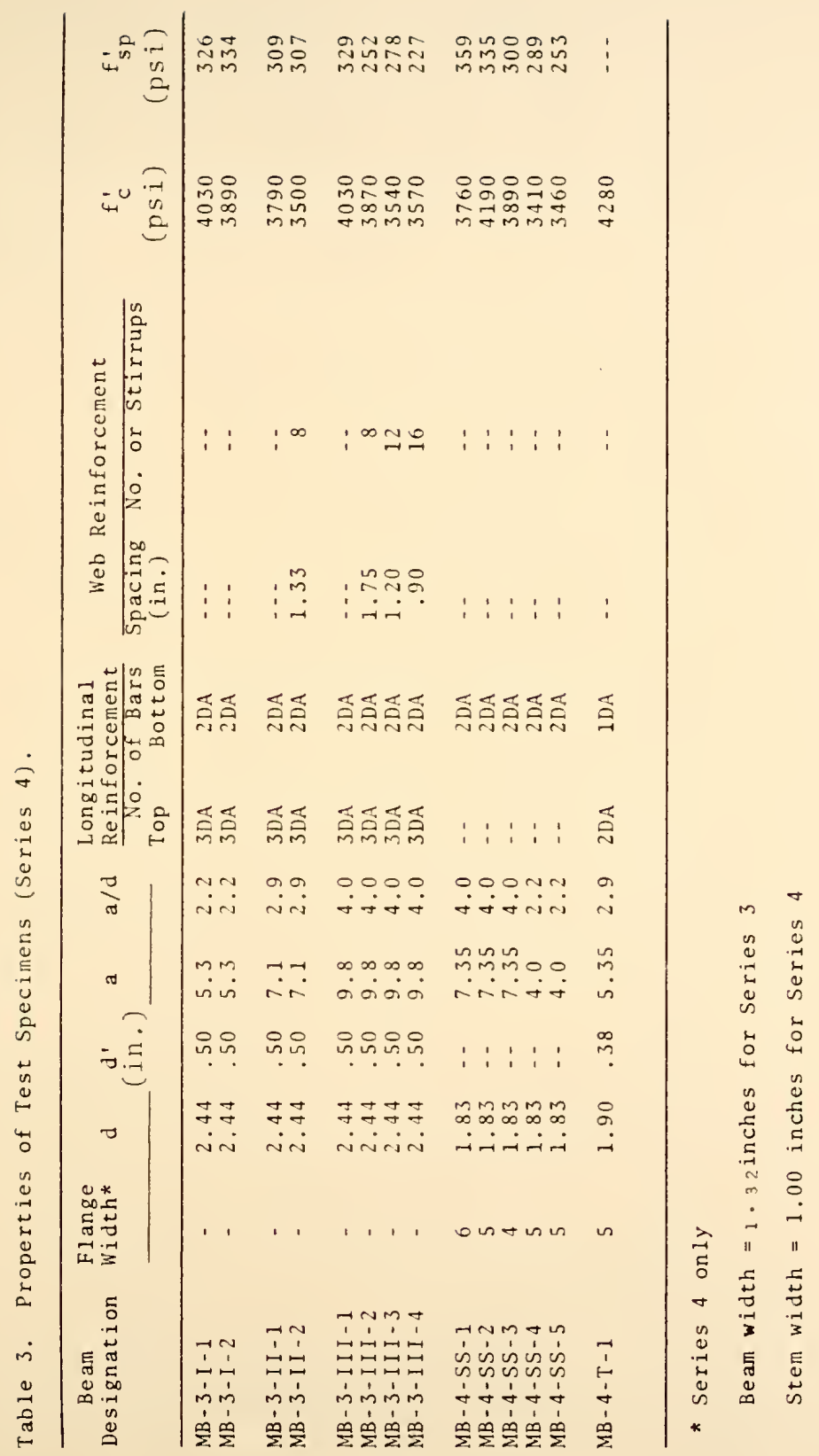



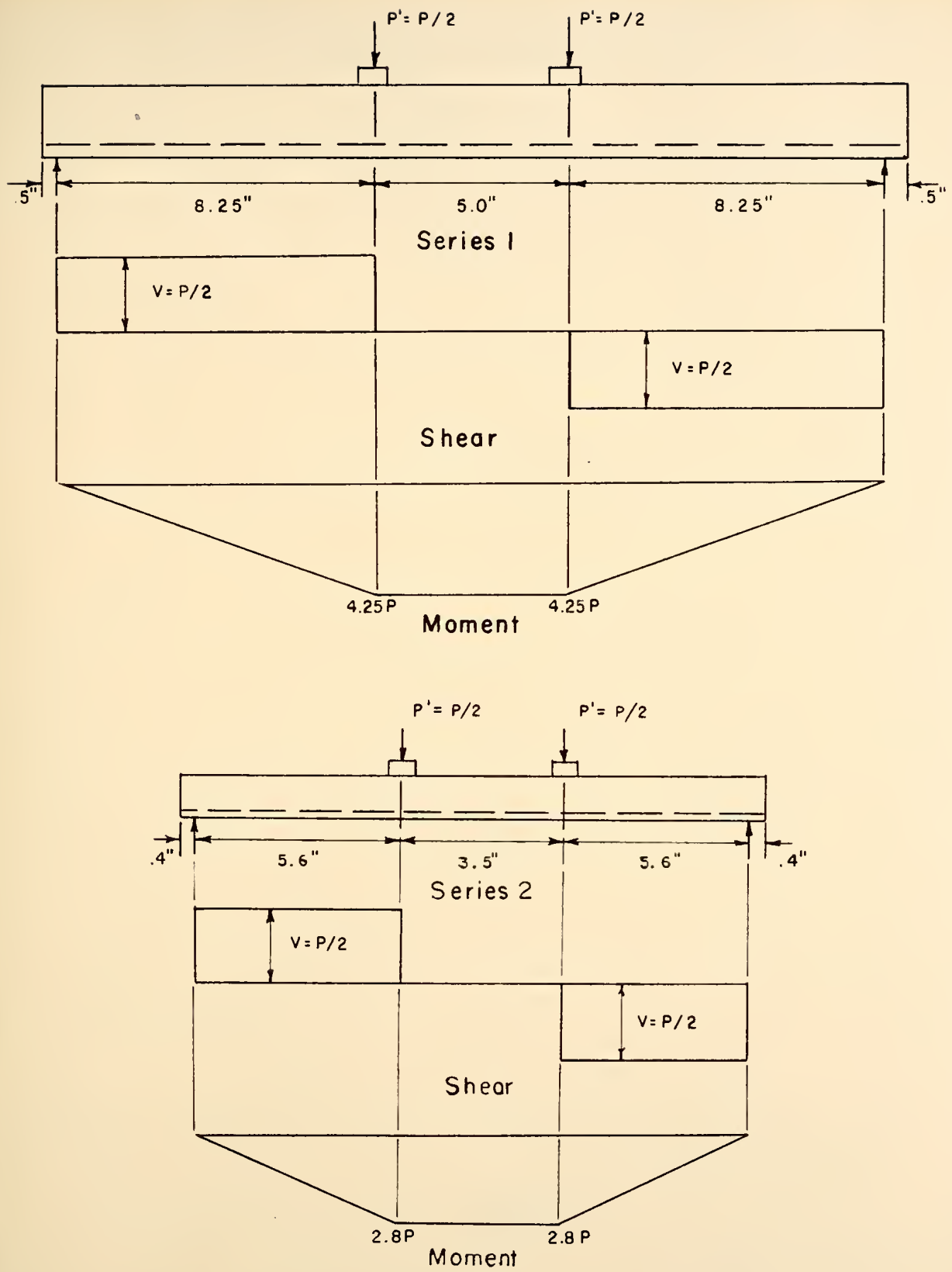

FIGURE 5. DETAILS OF SPECIMENS - SERIES 182 


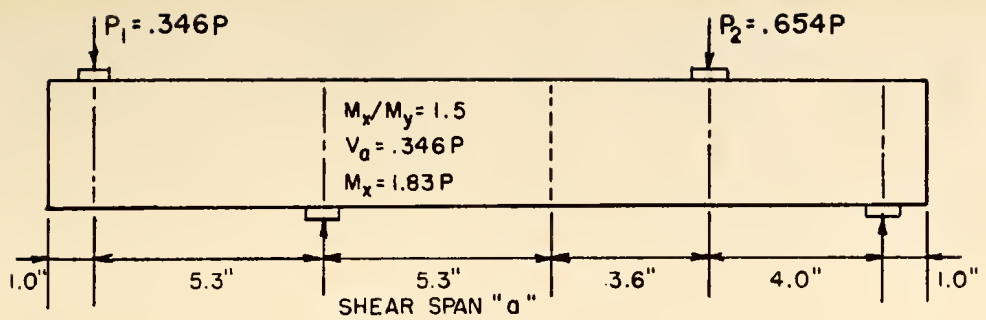

TYPE I

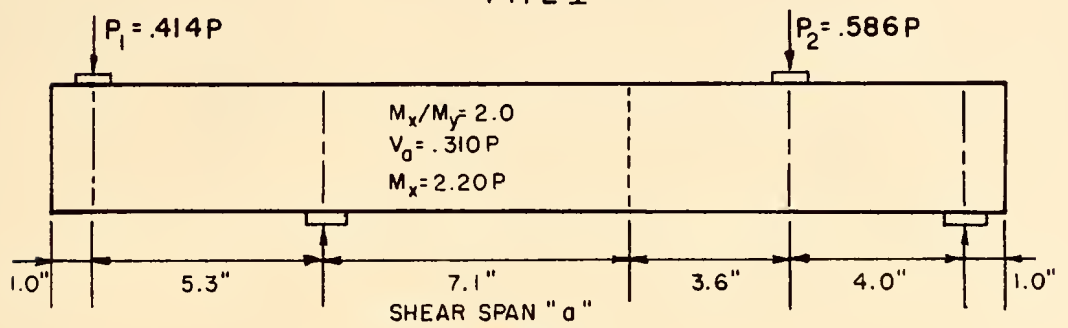

TYPE II

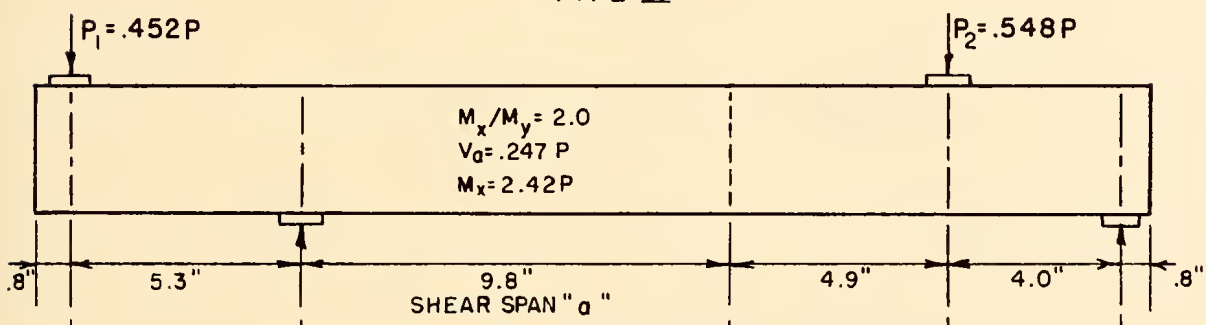

TYPE III

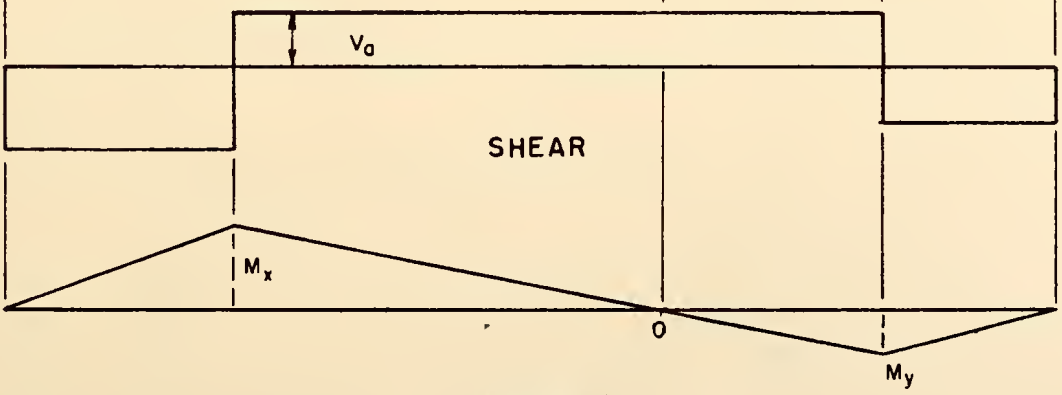

MOMENT

FIGURE 6. DETAILS OF SPECIMENS - SERIES 3 

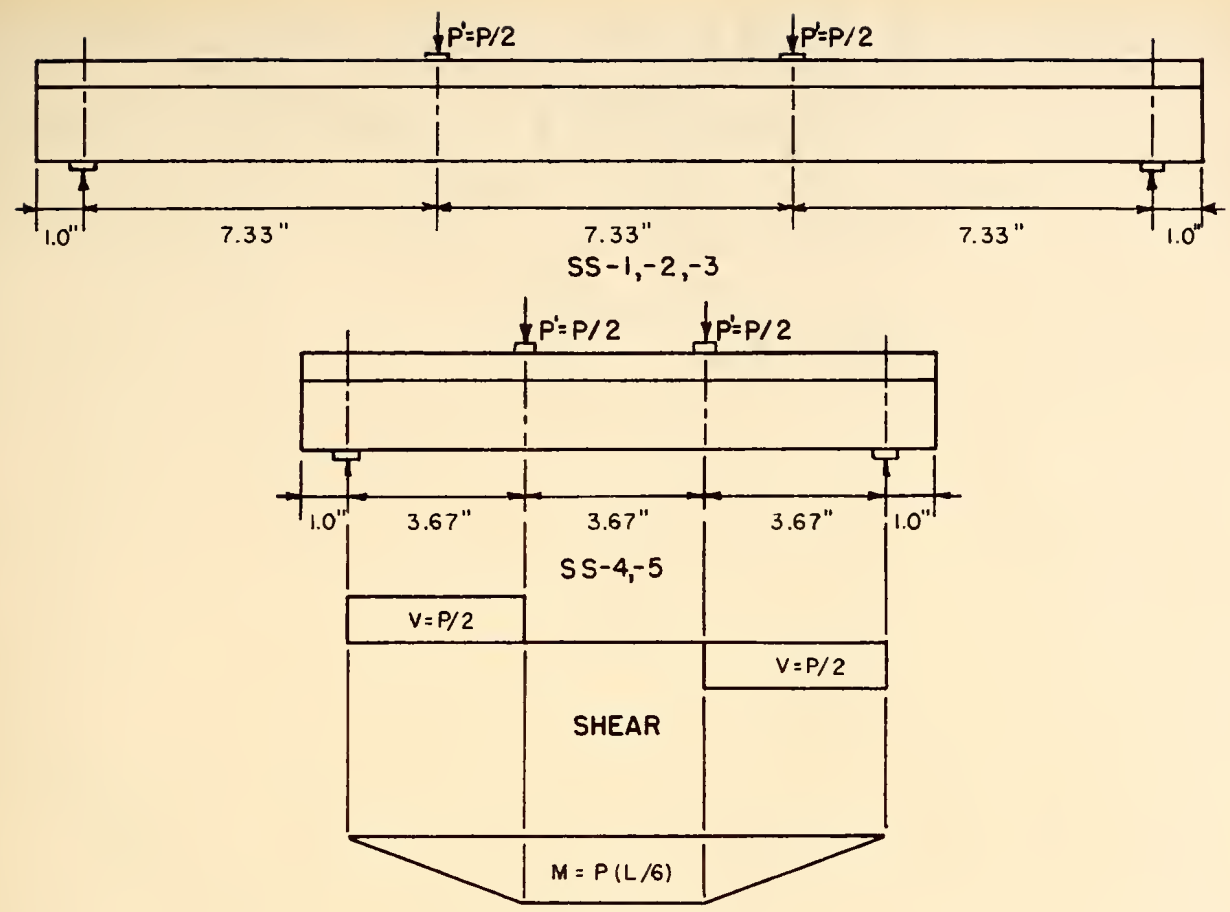

MOMENT

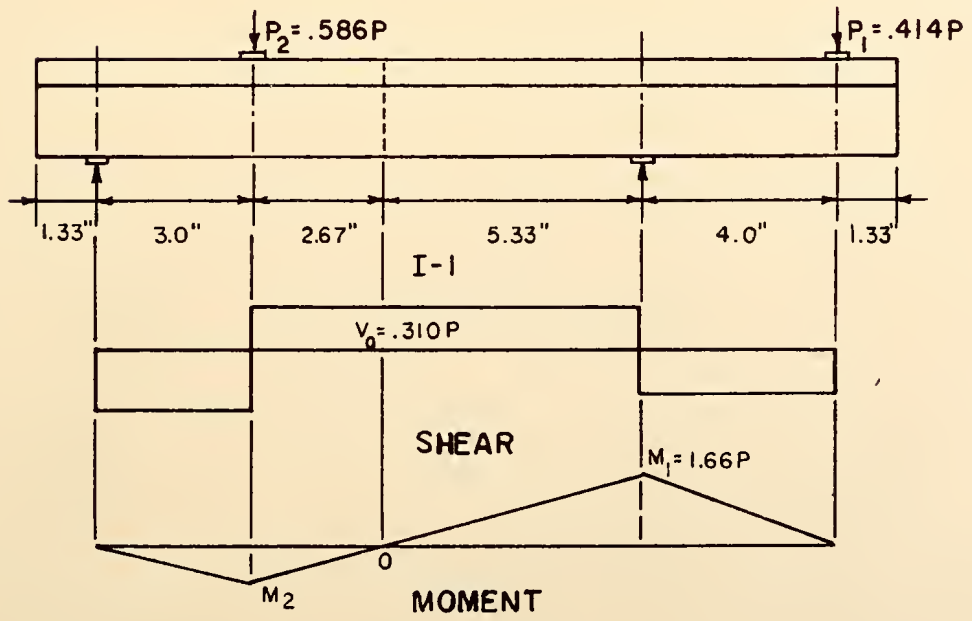

FIGURE 7. DETAILS OF SPECIMEN S - SERIES 4 


\section{Materials}

Model Concrete

The concrete used in all experimental models in this project was made from $75 \%$ U1tracal $30,25 \%$ graded Ottawa Sand measured by weight, and had a water/Ultracal ratio of 30. U1tracal 30 is the trade name for a product of the United States Gypsum Company and exhibits the properties shown in Table 4, for a mix having a water/U1tracal ratio of 38 .

Table 4. Properties of Ultracal 30.

Wet Comprehensive Strength

Dry Comprehensive Strength

Wet Tensile Strength

Coefficient of Thermal Expansion

Modulus of E1asticity
3000 to 3500 psi
6800 to 7800 psi
470 to $550 \mathrm{psi}$
$0.000010 \mathrm{in} / \mathrm{in} /{ }^{\circ} \mathrm{F}$
$2.5 \times 10^{6} \mathrm{lbs} / \mathrm{sq}$ in

A11 properties for the model concrete were determined using 2" $x$ 4" cylinders. A detailed discussion of compresstion and split tension tests is given in Appendix A. The average compressive strength for the concrete at 24 hours was 3800 psi, while the average split tensile strength was about 320 psi.

In general, the concrete compressive strength was found to increase markedly within the first 24 hours and then to 
level off. This is shown in Figure $A-3$ of Appendix $A$. Since the concrete displayed these characteristics, it was possible to test all beams within 24 to 48 hours after casting and obtain fairly consistent concrete strengths.

In order to determine the properties of the mix, 4 cylinders were normally poured with each batch, three were capped and tested in compression, the remaining one was tested in split-tension. Stress-strain properties for the mix were determined by the methods explained in Appendix A. A typical stress-strain curve for the mix is shown in Figure A-2. The average modulus of elasticity of the concrete was found to be $2.7 \times 10^{6}$ psi using the initial tangent modulus.

\section{Mode 1 Reinforcement}

There were four basic types of steel reinforcement used in the model specimens, as indicated in Table 5 .

Although little difficulty was found in obtaining the threaded steel rod, the relative cost of such reinforcement was prohibitive. On the other hand, the deformed wire was extremely difficult to obtain commercially. The deformed wire used in this research was provided with the compliments of the United States Steel Corporation.

Annealing of the threaded rod was done at Purdue University. The annealing oven was a gas type with an extreme maximum temperature of $3000^{\circ} \mathrm{F}$. During the annealing of the reinforcement, a small amount of tension was applied to the 
Table 5. Properties of Longitudinal Model Reinforcement.

Type of Reinforcement

Yield Ultimate

Strength Strength

(psi) (psi)
A. Threaded rod (high-strength)
$107,000 \quad 121,000$
B. Threaded rod (annealed)
$44,800 \quad 52,000$
C. Deformed bars (high-strength)
95,000
131,000
D. Deformed bars (annealed)
76,000
87,000

bars so that warping would not occur. This was done by using the apparatus shown in Figure B-9 of Appendix B.

The threaded rod was heated to a temperature of $1300^{\circ} \mathrm{F}$, held at that temperature for one hour and then allowed to cool slowly. The annealed rod was then tested to obtain the stress-strain properties as shown in Figure B-2 of Appendix B.

Since one deformed wire was obtained in a 100 lb. coil, it was necessary to have the wire straightened. After this was accomplished, a portion of the wire was annealed.

After a series of annealing tests on small lengths of the deformed wire, it was decided that an annealing temperature of $1050^{\circ} \mathrm{F}$ and a time of 2 hours was most suitable. Properties of this material are shown in Figure B-4 of Appendix B.

The properties of the web reinforcement are shown in Table 6 and Figure B-5 of Appendix B. The wire used for this purpose had a diameter of 0.050 inches. 
Table 6. Properties of Web Reinforcement.

$\begin{array}{ll}\text { Yield Stress } & 44,000 \mathrm{psi} \\ \text { Ultimate Strength } & 72,400 \mathrm{psi} \\ \text { Modulus of Elasticity } & 28.8 \times 10^{6} \mathrm{psi}\end{array}$

Properties of the steel reinforcement were determined with an instrumented aluminum c-clamp which was developed for measuring the load-strain properties for small strands of deformed wire. Stress-strain curves are plotted in Appendix $B$ and a detailed discussion of the tensile tests are given there.

\section{Model Forms and Fabrication of Models}

Forms for model specimens were made using one-quarter to five-eighths inch thick sheets of clear plexiglas. These were made as shown in Figures 8 and 9. Forms were designed to manufacture either one, two or three beam models at one time. The forms were constructed in such a manner that they could be easily taken apart and cleaned upon removal of the model specimen. The use of plexiglas allowed for a very smooth model surface and the elimination of any surface defects.

Plexiglas is relatively easy to work with and inexpensive to obtain. Because of its clarity, it is possible to remove any air bubbles that occur during placing of the concrete. Due to the smooth surface of the plexiglas, the model 


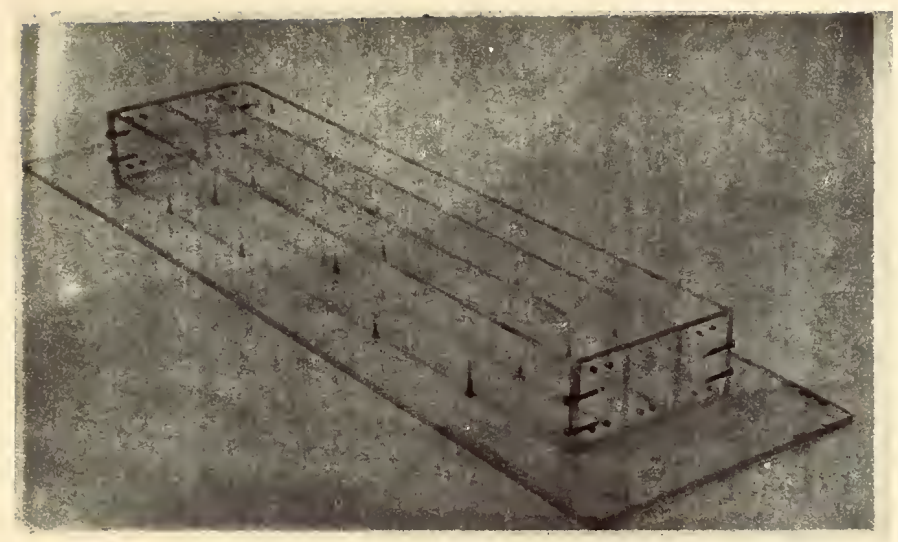

Series 1

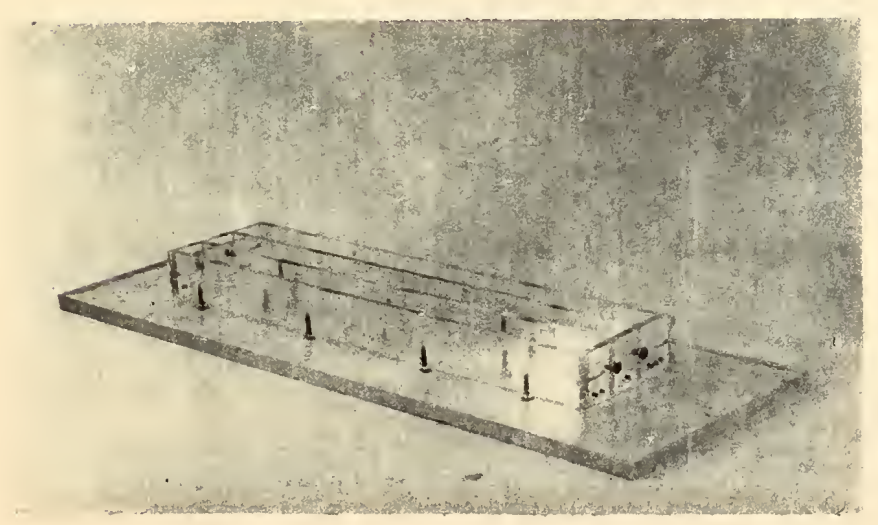

Series 2

FIGURE 8. PLEXIGLAS FORMS WITH REINFORCEMENT 


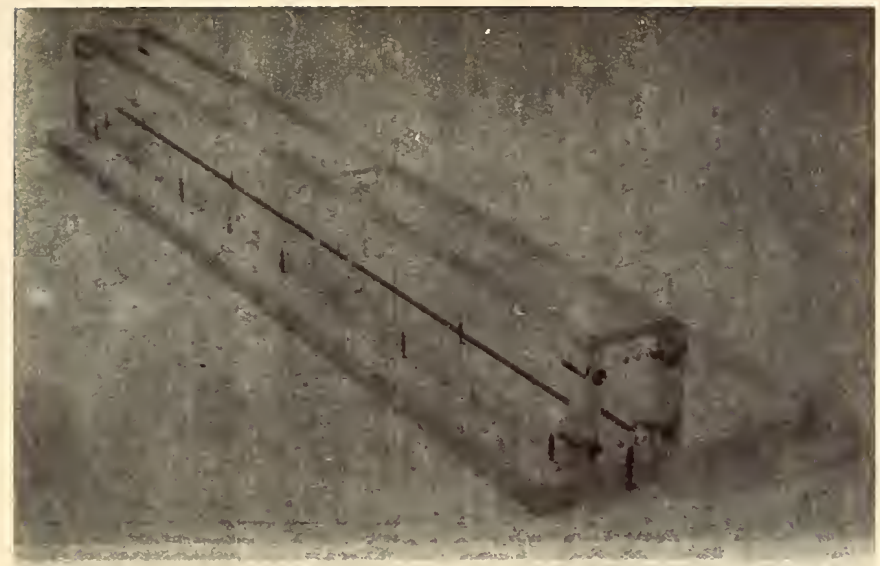

Series 3

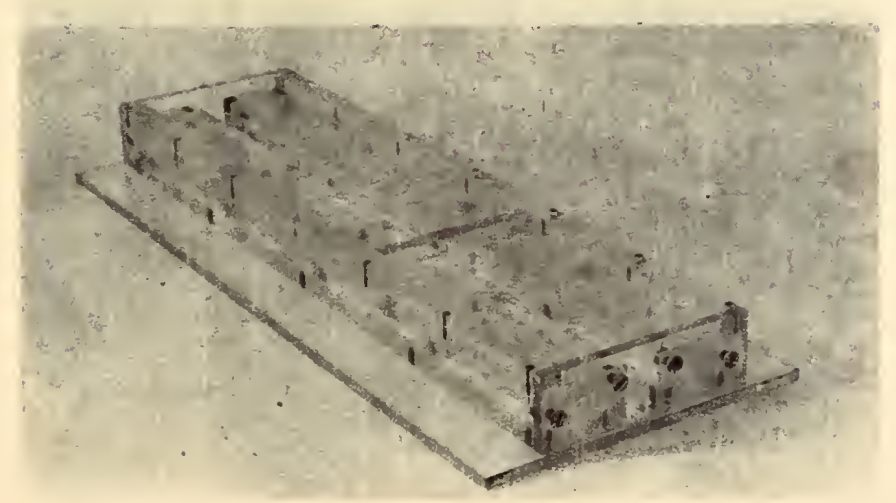

Series 4

FIGURE 9. PLEXIGLAS FORMS WITH REINFORCEMENT (con't) 
beam does not, adhere to the forms, thus eliminating the need for any release agent which could affect the concrete properties near the surface of the model.

In utilizing plexiglas care must be taken not to scratch the surface as this could easily produce deformities on the model specimens. Construction of the forms for Series 1 and 2 was done using a jigsaw and a router set up especially for making plastic models. The router allowed for very accurate and smooth edges. However, even greater accuracy was possible by machine milling the forms and this was done in manufacturing the forms for Series 3 and 4.

All of the model forms were carefully constructed to eliminate any spaces between adjoining members where marked amounts of water could be lost from the model concrete mixture. To further assure that no water was lost through form joints, the outside of the forms was carefully covered with petroleum jelly. Plexiglas is not water-absorptive and water content of the mix was not affected by the forms themselves.

The end plates of each model form could be exchanged so that various steel reinforcement combinations could be used. In this manner, it was possible to utilize the same forms for several different steel combinations. In order to eliminate any sag in the reinforcement at midspan, a slight amount of tension was applied to the reinforcement bars. This was done by threading each of the bars at the 
ends and tightening nuts on each end of the bar. After the model concrete was poured, this initial tensile stress was removed.

Since the T-beam model of Series 4 had to have both a varying flange width and specimen length, it was necessary to devise a form as pictured in Figure 9 and shown in cross-section in Figure 10.

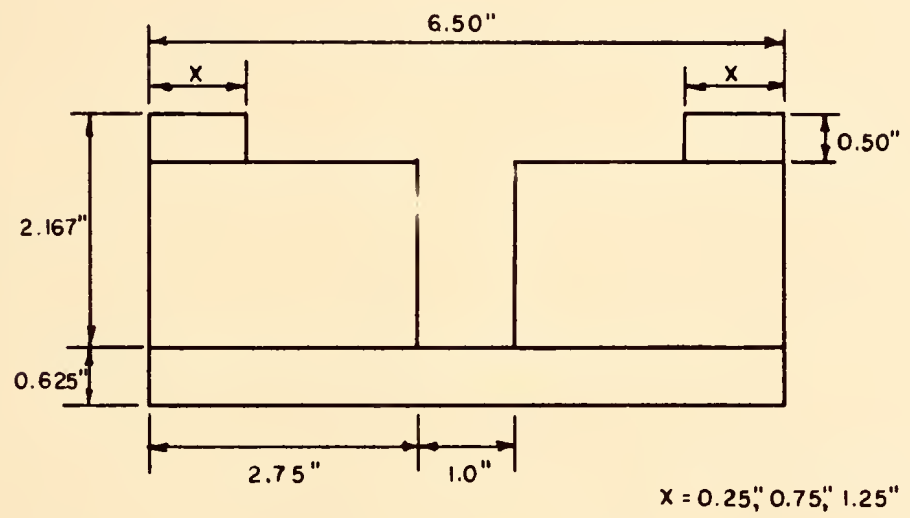

Figure 10. Cross-Section of Model T-Beam Forms.

All parts of this form were machine milled to obtain the highest degree of accuracy possible. The entire form can be taken apart and the upper plexiglas pieces are interchangeable, thus changing the beam flange width. At each end of the form there is a stationary end plate and within the model there is a movable end plate. The beam length can be changed by moving the portable end plate. The maximum specimen length of 24 inches is obtained by removing the movable plate. 
Test Procedures and Instrumentation

All beam tests with the exception of Series, 2 were performed using a Baldwin universal testing machine with a TateEmery load indicator. The maximum load capacity of this machine is $120,000 \mathrm{lbs}$. and the load indicator has three load ranges as below:

Lower range 0-1200 1bs.

Middle range 0-12,000 1bs.

Upper range $0-120,000$ 1bs . load increment $1 \mathrm{lb}$. load increment 10 lbs. load increment 100 lbs.

The beams of Series 2 were tested on the same machine used for the cylinder tests, an Emery universal testing machine. This machine has a maximum load capacity of 60,000 lbs. and three load ranges as below:

Lower range $0-3,0001 \mathrm{bs}$. load increment 5 lbs.

Middle range $0-15,000$ lbs. load increment 20 1bs. Upper range 0-60,000 1bs. load increment 100 lbs.

View of the beam test arrangements and the details of the beam test are shown in Figures 11 and 12 , respectively. Initially the sides of the beam specimens in Series 1 were gridded to provide a means for estimating the crack propagation under various loads. However, due to the size of the beams, it appeared to be of little advantage to grid the sides of these beams. For the later tests, dial gages with 0.0001 inch accuracy were used to measure beam deflection. .

The properties of the model concrete of each beam were determined by testing at least four cylinders for each 


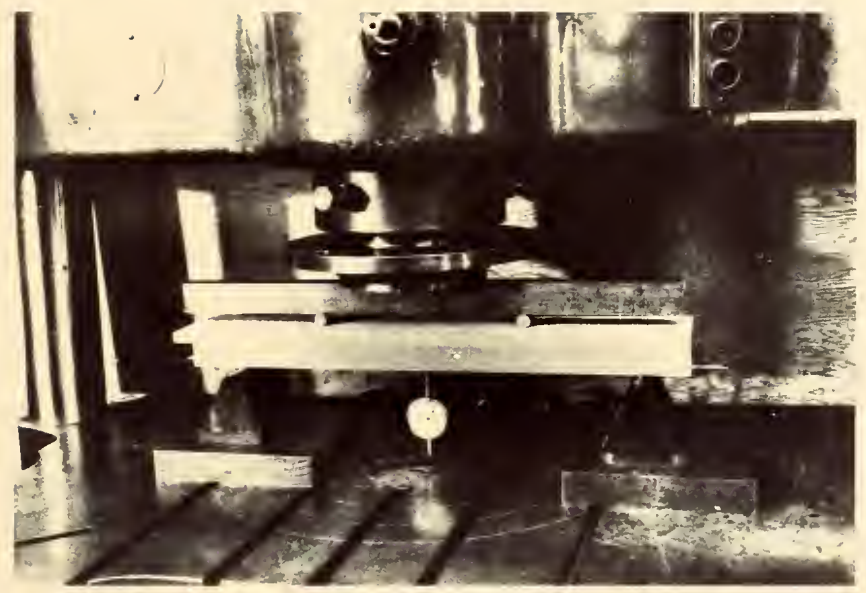



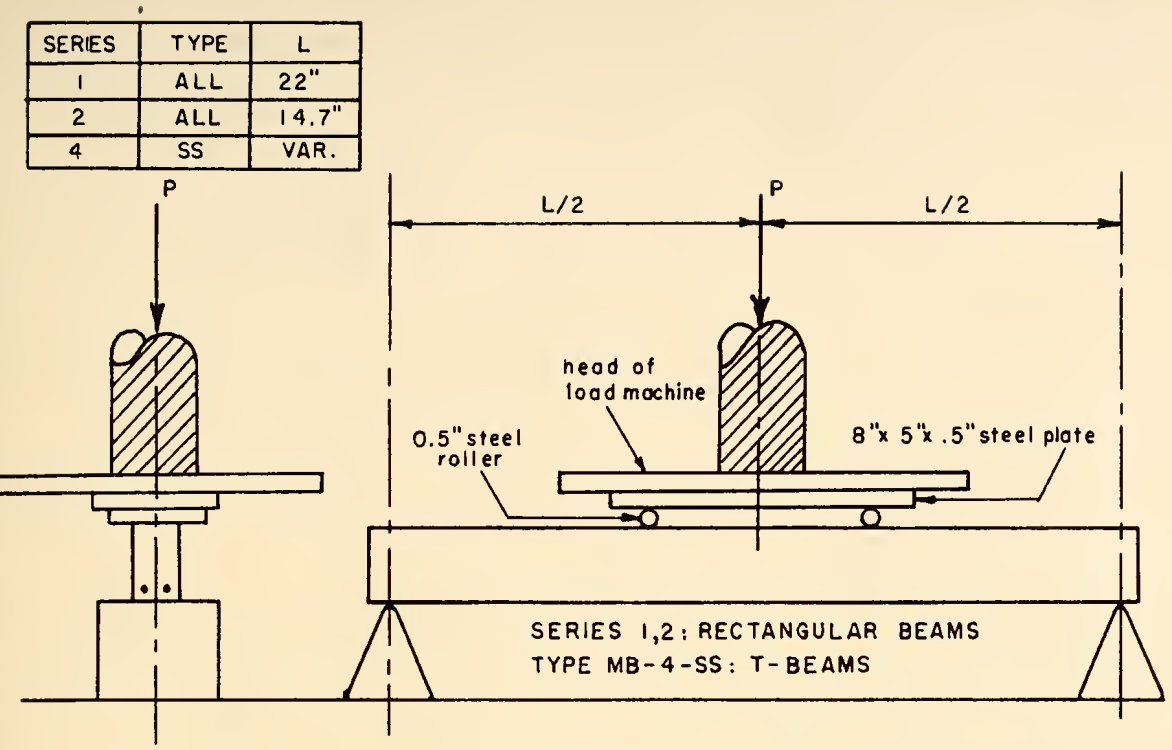

SERIES 1,2 and TYPE MB- 4 -SS

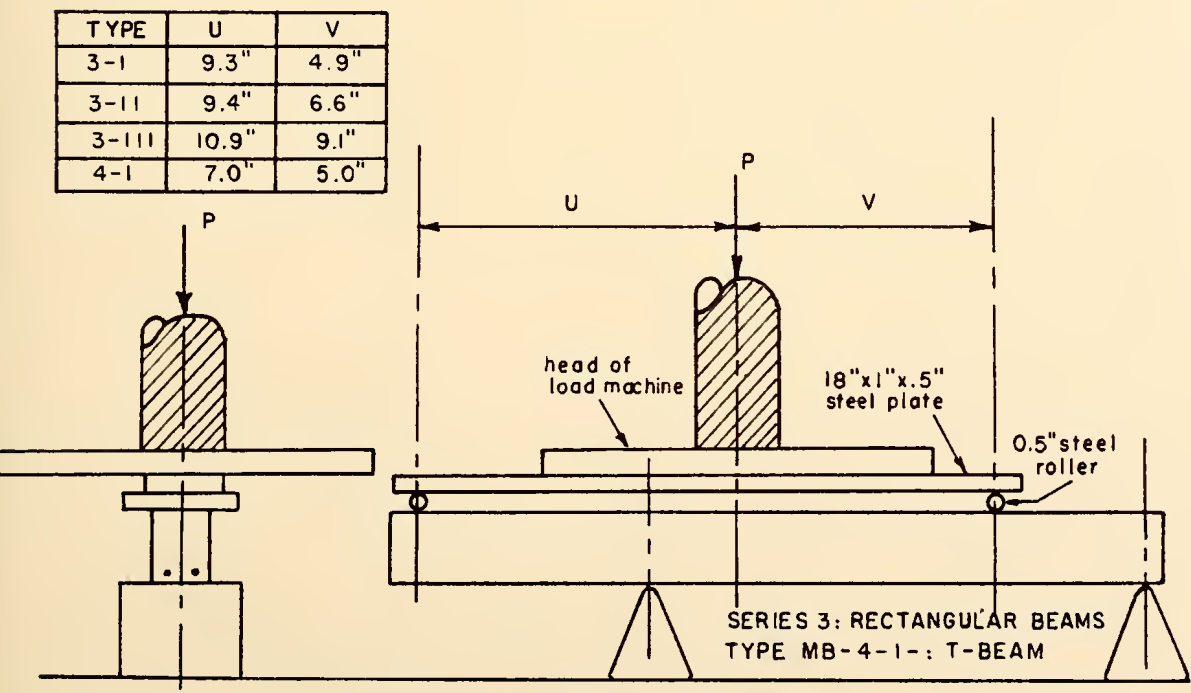

SERIES 3 and TYPE MB-4-I

FIGURE 12. DETAILS OF BEAM TESTS. 
batch. Three cylinders were tested in compression and one in split-tension. 


\section{TEST RESULTS}

A summary of all the pertinent test results from the beam tests is given in Tables 7,8 , and 9 . Pictures of the specimens after test are shown in Figures 13 through 19. For beams from each series deflection curves were plotted and these curves appear in Figures 21, 23, and 25 through 30. As a further aid in understanding the results of the beam tests, Figures 20 and 22 provide a close-up view of the typical cracking patterns of various model beams from Series 1 and 2 .

A short discussion is provided for each bean series. Each discussion relates the various types of beams which were tested in each series, their failure types, and the way in which they failed. At the same time any problems or complications which occurred during testing are discussed.

A11 loads mentioned in this section are the loads coming from the testing machine.

The model beams tested here exhibited the same types of failures that occur in the larger scale beams. In most cases it was possible to detect initial cracking of the member when it occurred. The surface smoothness of the model permitted easy identification of the rather minute cracks. 
Table 7. Summary of Test Results (Series 1).

\begin{tabular}{|c|c|c|c|c|}
\hline $\begin{array}{c}\text { Beam } \\
\text { Designation }\end{array}$ & $\begin{array}{c}\text { Ultimate } \\
\text { Load } \\
\mathrm{P}_{\mathrm{u}} \\
\text { (lbs.) }\end{array}$ & $\begin{array}{c}\text { Ultimate } \\
\text { Moment } \\
\mathrm{M}_{\mathrm{u}} \\
\text { (in-1bs) }\end{array}$ & $\begin{array}{c}\text { Mode } \\
\text { of } \\
\text { Failure* }\end{array}$ & Remarks \\
\hline 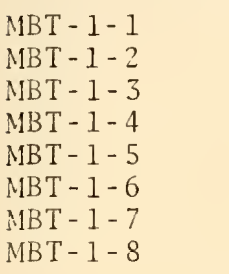 & $\begin{array}{l}230 \\
385 \\
376 \\
377 \\
354 \\
372 \\
491 \\
515\end{array}$ & $\begin{array}{r}978 \\
1631 \\
1598 \\
1602 \\
1505 \\
1581 \\
2087 \\
2189\end{array}$ & $\begin{array}{l}\text { F.T. } \\
F \cdot T \cdot \\
\text { F.T. } \\
\text { F.T. } \\
\text { F.T. } \\
\text { F.T. } \\
\text { S.C. } \\
\text { S.C. }\end{array}$ & \\
\hline $\begin{array}{l}\text { MBD }-1-1 \\
\text { MBD }-1-2 \\
\text { MBD }-1-3 \\
M B D-1-4 \\
\text { MBD }-1-5 \\
\text { MBD - } 1-6 \\
\text { MBD - } 1-7 \\
M B D-1-8\end{array}$ & $\begin{array}{r}980 \\
1075 \\
752 \\
1157 \\
730 \\
760 \\
720 \\
510\end{array}$ & $\begin{array}{l}3430 \\
4569 \\
3196 \\
4917 \\
3103 \\
3230 \\
3060 \\
2168\end{array}$ & $\begin{array}{l}\text { D.T. } \\
\text { S.C. } \\
\text { U.T. } \\
\text { S.C. } \\
\text { D.T. } \\
\text { F.T. } \\
\text { F.T. } \\
\text { S.C. }\end{array}$ & Bond Failure \\
\hline $\begin{array}{l}\text { MBDA - } 1-1 \\
\text { MBDA - } 1-2 \\
\text { MBDA - }-3 \\
\text { MBDA - } 1-4\end{array}$ & $\begin{array}{r}630 \\
665 \\
1028 \\
1115\end{array}$ & $\begin{array}{l}2680 \\
2830 \\
4360 \\
4730\end{array}$ & $\begin{array}{l}\text { F.T. } \\
\text { S.C. } \\
\text { S.C. } \\
\text { S.C. }\end{array}$ & \\
\hline
\end{tabular}

* F.T. - Flexural Tension

D.T. - Diagonal Tension

S.C. - Shear Compression 
Table 8. Summary of Test Results (Series 2).

\begin{tabular}{|c|c|c|c|c|}
\hline $\begin{array}{c}\text { Beam } \\
\text { Designation }\end{array}$ & $\begin{array}{c}\text { U1t imate } \\
\text { Load } \\
\mathrm{P}_{\mathrm{u}} \\
(1 \mathrm{bs})\end{array}$ & $\begin{array}{c}\text { U1timate } \\
\text { Moment } \\
M_{u} \\
\text { (in-1bs) }\end{array}$ & $\begin{array}{l}\text { Mode } \\
\text { of } \\
\text { Failure* }\end{array}$ & Remarks \\
\hline $\begin{array}{l}\text { MBT }-2-1 \\
\text { MBT }-2-2 \\
\text { MBT - } 2-3 \\
\text { MBT - } 2-4 \\
\text { MBT }-2-5 \\
\text { MBT }-2-6 \\
\text { MBT }-2-7\end{array}$ & $\begin{array}{l}170 \\
298 \\
175 \\
165 \\
245 \\
315 \\
250\end{array}$ & $\begin{array}{l}476 \\
834 \\
490 \\
462 \\
686 \\
882 \\
980\end{array}$ & $\begin{array}{l}\text { F.T. } \\
\text { S.C. } \\
\text { F.T. } \\
\text { F.T. } \\
\text { D.T. } \\
\text { D.T. } \\
\text { D.T. }\end{array}$ & Bond Failure \\
\hline 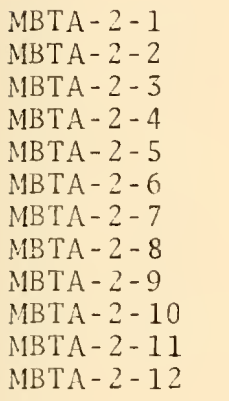 & $\begin{array}{r}82 \\
142 \\
207 \\
94 \\
144 \\
138 \\
89 \\
90 \\
150 \\
109 \\
148 \\
100\end{array}$ & $\begin{array}{l}230 \\
388 \\
580 \\
263 \\
403 \\
386 \\
249 \\
252 \\
420 \\
305 \\
414 \\
280\end{array}$ & $\begin{array}{l}\text { F.T. } \\
F \cdot T . \\
F \cdot T . \\
F \cdot T . \\
F \cdot T . \\
F \cdot T . \\
F \cdot T . \\
F \cdot T . \\
F \cdot T . \\
F \cdot T . \\
F \cdot T . \\
F \cdot T .\end{array}$ & \\
\hline
\end{tabular}

* F.T. - Flexural Tension

D.T. - Diagonal Tension

S.C. - Shear Compression 
Table 9. Sumnary of Test Results (Series 3, 4).

\begin{tabular}{|c|c|c|c|c|}
\hline $\begin{array}{c}\text { Beam } \\
\text { Designation }\end{array}$ & $\begin{array}{c}\text { Diagonal } \\
\text { Cracking } \\
\text { Pc } \\
(1 \mathrm{bs})\end{array}$ & $\begin{array}{c}\text { Ultimate } \\
\text { Load } \\
\mathrm{P}_{u} \\
(1 b s)\end{array}$ & $\begin{array}{l}\text { Mode } \\
\text { of } \\
\text { Failure* }\end{array}$ & Remarks \\
\hline $\begin{array}{l}M B-3-I-1 \\
M B-3-I-2\end{array}$ & $\begin{array}{l}-- \\
--\end{array}$ & $\begin{array}{l}3000 \\
2200\end{array}$ & $\begin{array}{l}\text { D.T. } \\
\text { D.T. }\end{array}$ & \\
\hline $\begin{array}{l}M B-3-I I-1 \\
M B-3-I I-2\end{array}$ & $\begin{array}{c}2020 \\
--\end{array}$ & $\begin{array}{l}2020 \\
2250\end{array}$ & $\begin{array}{l}\text { D.T. } \\
\text { D.T. }\end{array}$ & \\
\hline $\begin{array}{l}M B-3-I \text { I I - } 1 \\
M B-3-I \text { I I - } \\
M B-3-I \text { I I - } \\
M B-3-I \text { I I }-4\end{array}$ & $\begin{array}{l}2210 \\
1990 \\
2470 \\
2700\end{array}$ & $\begin{array}{l}2210 \\
2710 \\
2470 \\
2700\end{array}$ & $\begin{array}{l}\text { D.T. } \\
\text { D.T. } \\
\text { D.T. } \\
\text { D.T. }\end{array}$ & \\
\hline $\begin{array}{l}M B-4-S S-1 \\
M B-4-S S-2 \\
M B-4-S S-3 \\
M B-4-S S-4 \\
M B-4-S S-5\end{array}$ & $\begin{array}{l}659 \\
655 \\
560 \\
800 \\
--\end{array}$ & $\begin{array}{r}639 \\
655 \\
560 \\
1050 \\
1640\end{array}$ & $\begin{array}{l}\text { D.T. } \\
\text { D.T. } \\
\text { D.T. } \\
\text { D.T. } \\
\text { D.T. }\end{array}$ & \\
\hline$M B-4-T-1$ & - & 1980 & F.T. & Steel Yielding \\
\hline
\end{tabular}

* F.T. - Flexural Tension

D.T. - Diagonal Tension 
$M B T-1-1-$

$M B T=1-2$

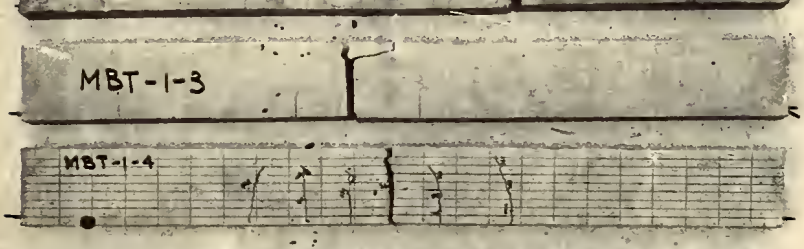

MBI-1-5

FIGURE 13. TESTED MODEL BEAMS - SERIES I 

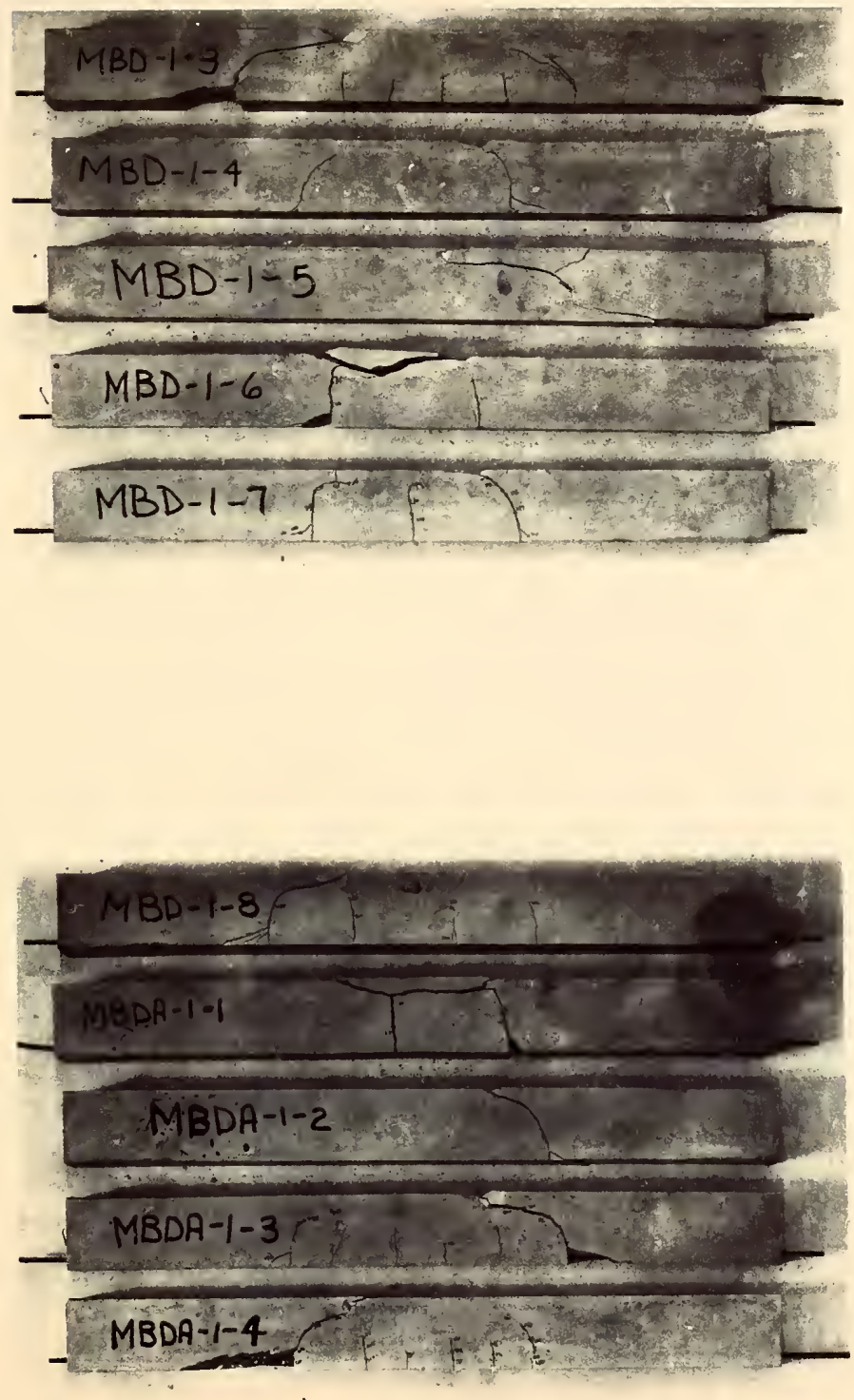

FIGURE 14. TESTED MODEL BEAMS - SERIES I (con' 1 ) 


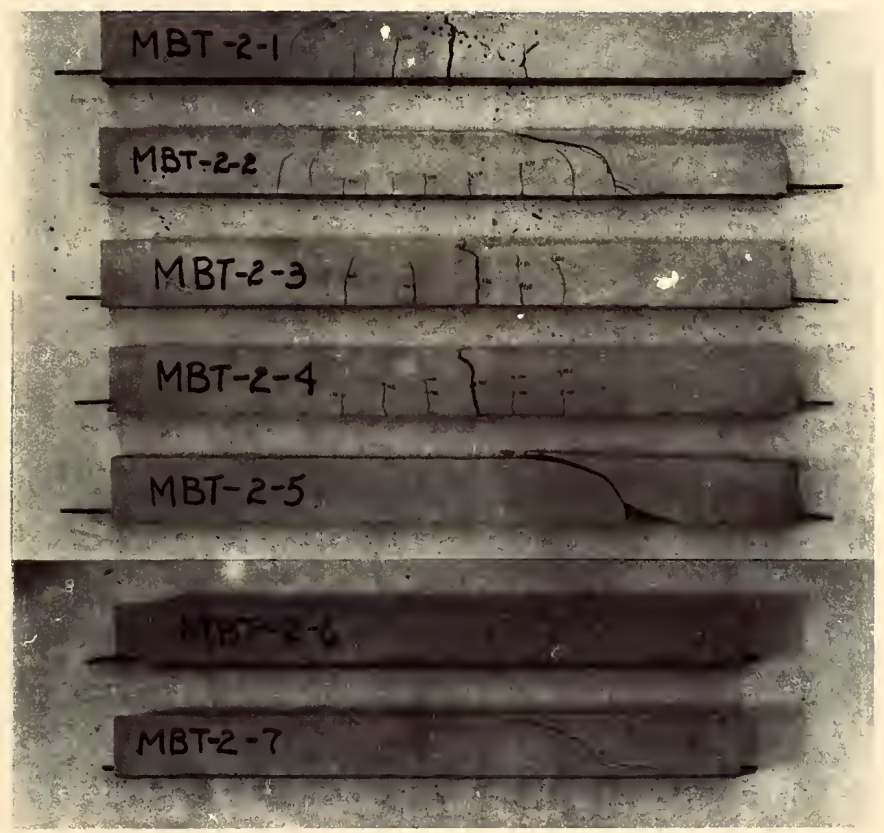

FIGURE 15. TESTED MODEL BEAMS - SERIES 2 

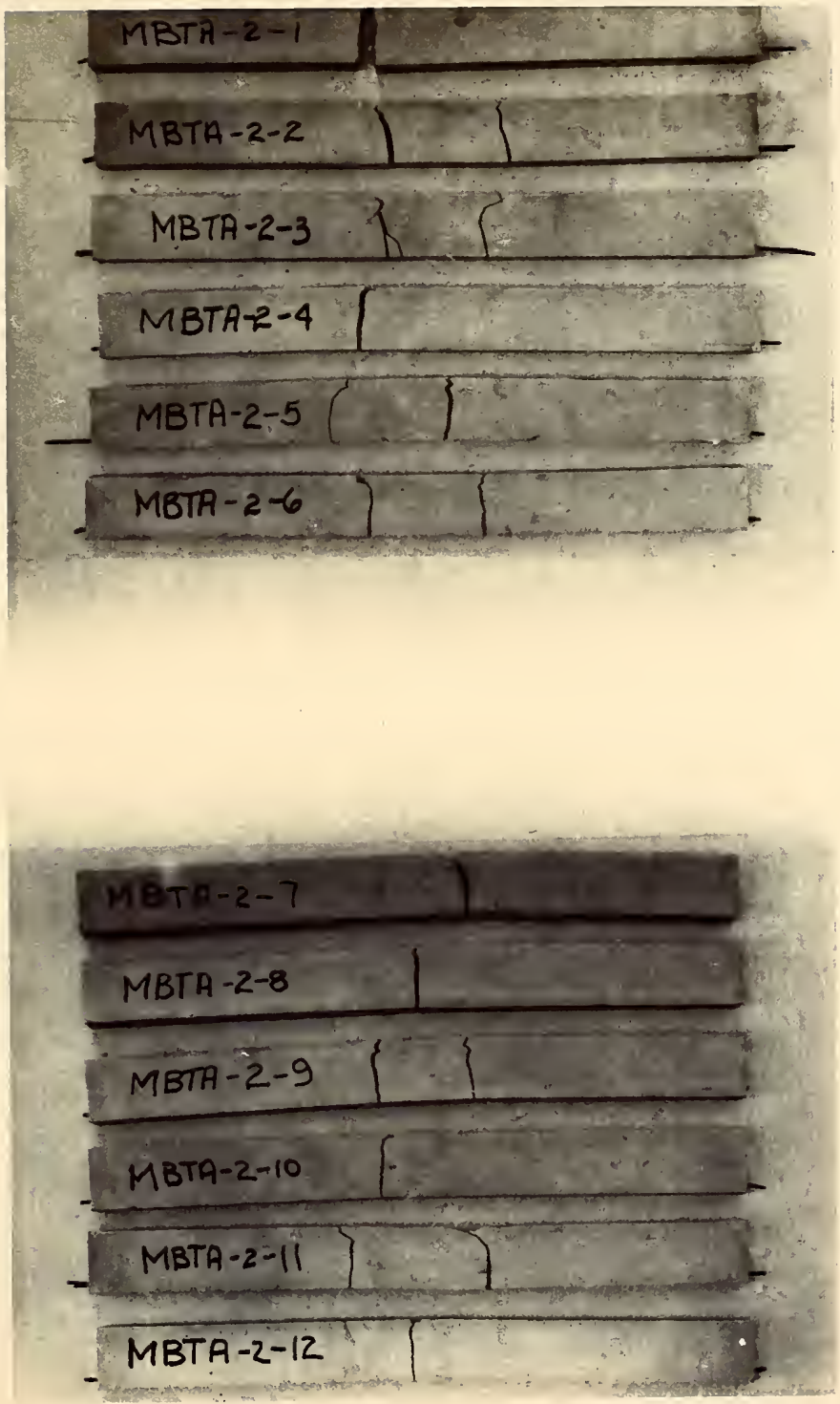

FIGURE 16. TESTED MODEL BEAMS - SERIES 2 (con't) 

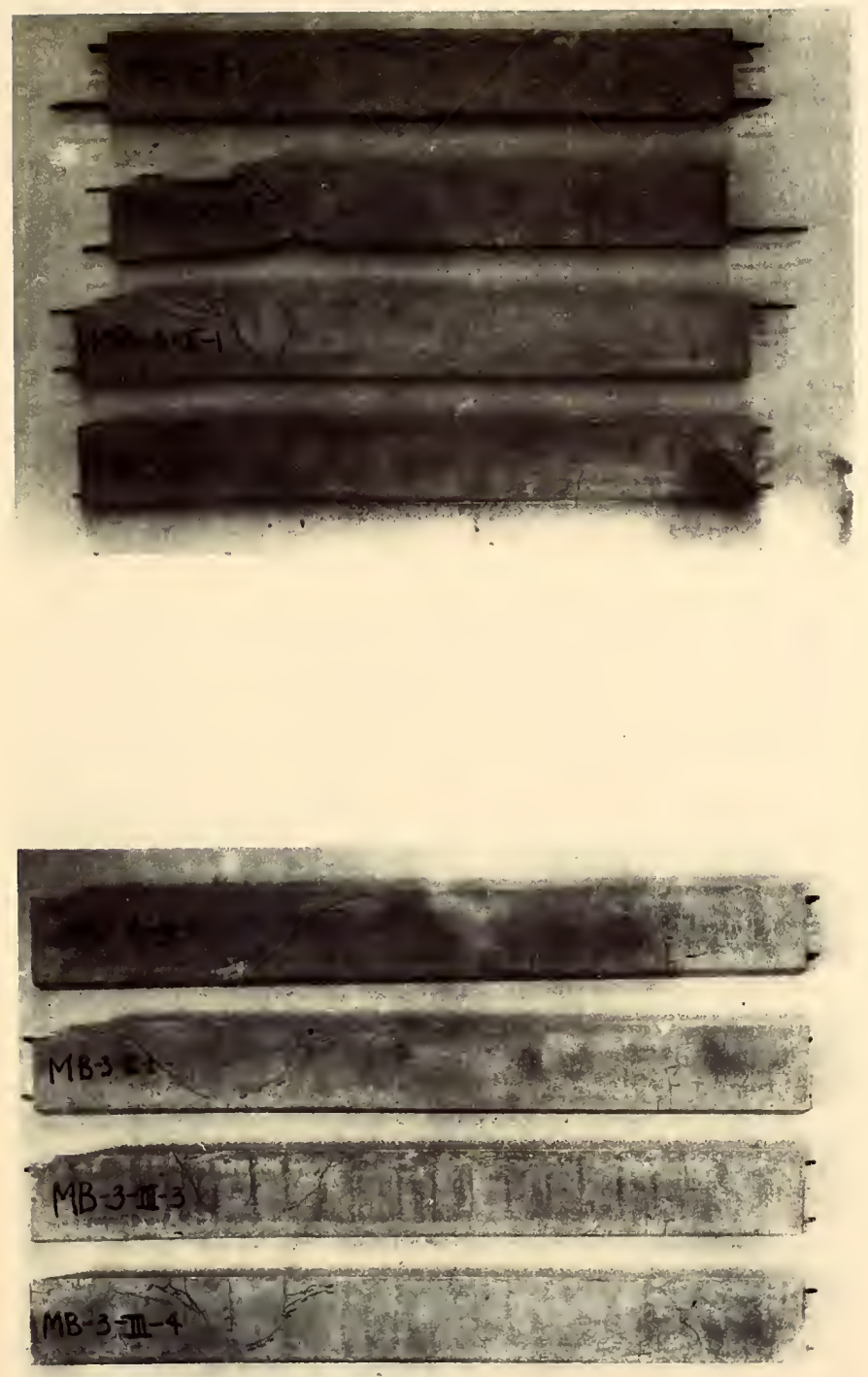

FIGURE 17. TESTED MODEL BEAMS - SERIES 3 

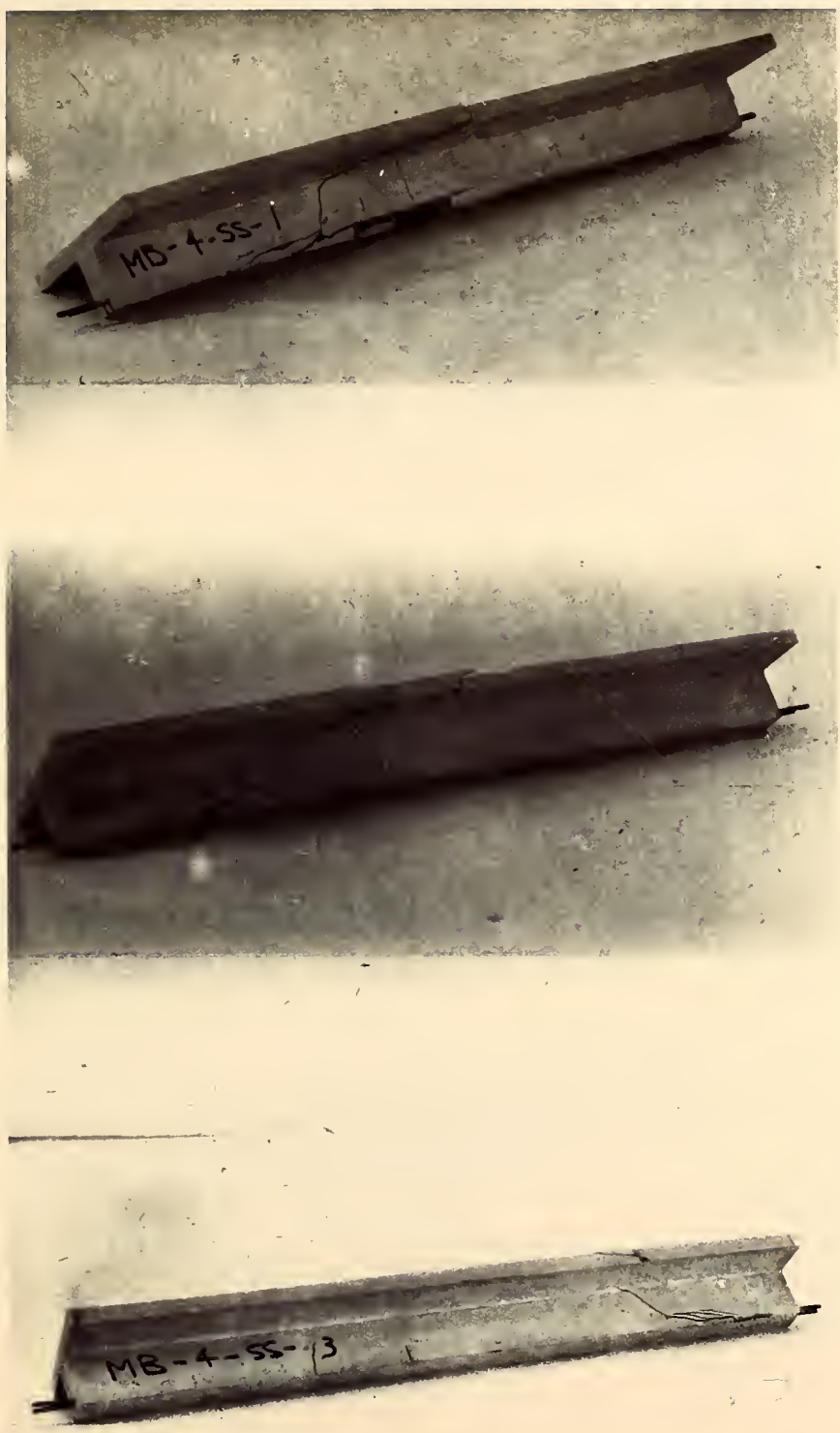

FIGURE 18. TESTED MODEL BEAMS-SERIES 4 
50 


\section{Series 1}

The model beams in this series were all simply-supported having a span length of 22 inches. Equal concentrated loads were applied to each specimen at 8.5 inches from the two end supports. The shear span-to-depth ratio (a/d) was greater than 4.0 with exception of beam MBD-1-1 where a/d was slightly less than 4.0 .

\section{Model Beams - Type MBT-1}

All beams of this type contained high strength threaded steel rod, each beam having either one, two, or three bars for longitudinal reinforcement. In each case the beams failed in either flexure or combined shear-flexure with eventual fracture of the reinforcement. At approximately two-thirds of the ultimate load, flexural cracks began to form in the region between the two loads. This can be seen in the example cracking pattern shown in Figure 20.

As the cracks formed in the beam, the extension of the cracks was marked at various load levels. In some cases cracks formed in the shear span, starting out vertically and eventually propagating at a $45^{\circ}$ angle toward the load. Final failure of the members was obtained when the cracks reached the top surface of the concrete, almost always directly below one or both of the loads.

In all cases, these beams exhibited excellent bond strength with no splitting off of the concrete from the steel reinforcement. As would be expected the crack spacing 
of these beams was relatively small with a large number of cracks appearing. Crack spacing appeared to decrease with an increased number of reinforcement bars.

Figure 21 shows the deflection of the center-1ine of a typical beam specimen of this type as it was loaded to failure. In all cases the deflection of the beams was visi ble to the naked eye before failure took place.

\section{Mode 1 Beams - Type MBD-1}

The beams of this type were reinforced with high strength deformed steel wire, the number of bars being either one, two or three. In general the failure load was less than that expected from flexural theory and beams failed in diagonal-tension with splitting of the cement from the steel. The first beam of this type showed extremely poor bond, with no cracking until the diagonal tension crack formed even though fairly high loads had been applied. After failure, it appeared that the concrete had filled all of the indentations in the wire and that the bars then acted almost like smooth bars. In the remaining beams tested the bars were roughened with emery paper and rotated in the forms just after the concrete had been poured. This seemed to increase the bonding strength of the concrete and steel.

\section{Model Beams - Type MBDA-1}

This type of beam was reinforced with either one or two bars of annealed deformed steel wire. A total of four such beams were tested. Beams MBDA-1-1 and MBDA-1-2 contained 
the same amount of reinforcing, however MBDA-1-1 failed with the extension of a tension crack that turned $90^{\circ}$ and resulted in the type of failure shown in Figure 14, while MBDA-1-2 failed with formation of a diagonal crack beneath the load point. In both cases the ultimate load capacity was approximately the same.

In the case of the two remaining specimens the amount of reinforcing steel was doubled. These beams exhibited considerably more cracking before actual failure. In both cases the final failure came with the formation of the diagonal crack and some splitting of the concrete from the stee 1 . 

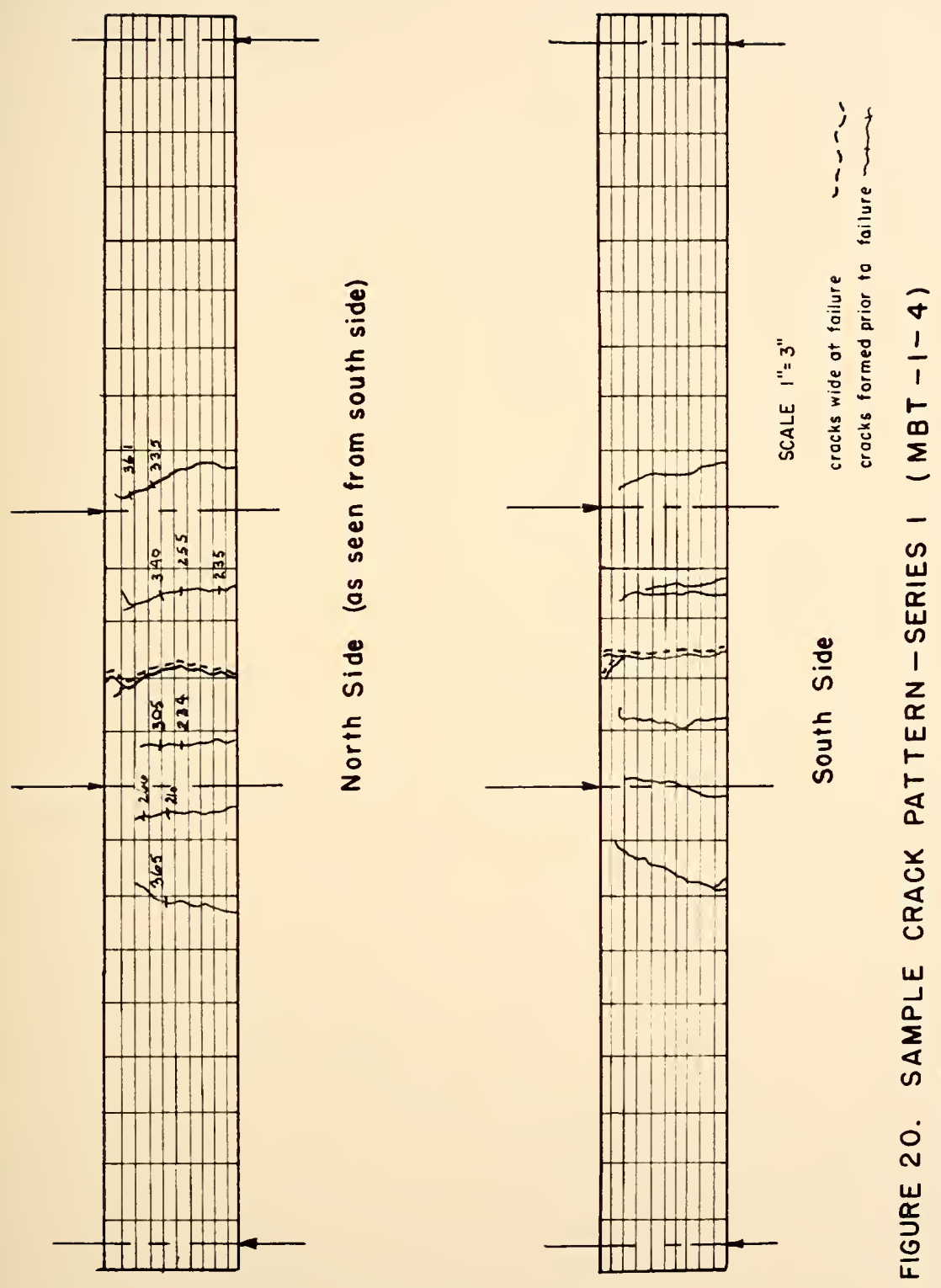

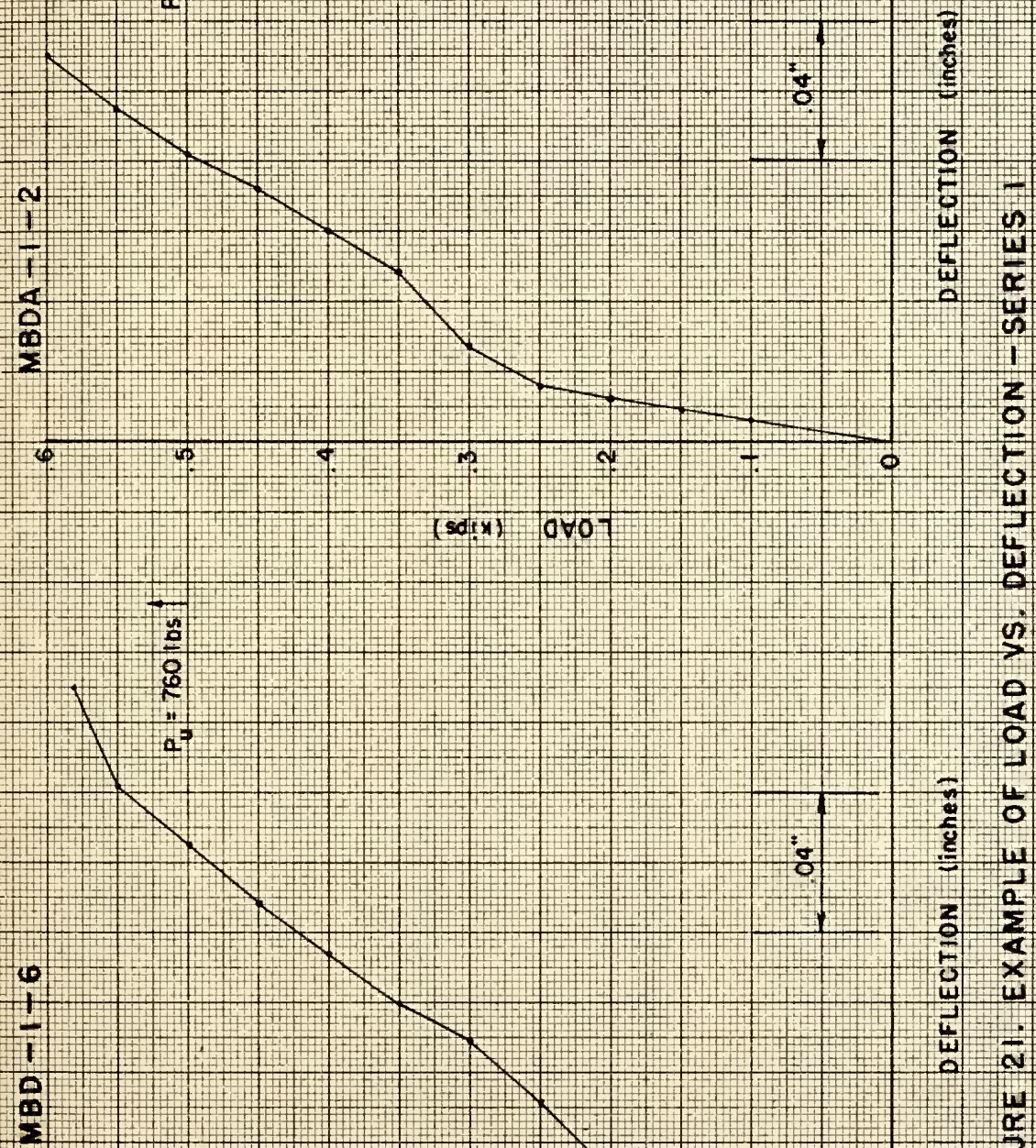


\section{Series 2}

This series consisted entirely of simply-supported model beams tested in pure flexure, having a smaller scale than those tested in Series 1. Each beam span was 14.7" in length. At 5.6" from each support two equal concentrated loads were applied. For all specimens in this series the shear span-to-depth ratio was greater than 4.0. Both the amount and type of reinforcement was varied in this series, no compression reinforcement being provided.

\section{Model Beans - Type MBT-2}

High strength threaded steel rod was used for reinforcement in all beams of this type. The number of reinforcement rods was varied from one to three. In most cases the beams failed in flexure, with the exception of beams MBT-2-5 and MBT-2-6 which failed with the formation of the diagonal tension crack. In the case of beam MBT-2-6, the flexural cracks had already cxtended to near the top of the compression zone when the diagonal crack formed.

At approximately two-thirds of the ultimate load visible flexural cracks began to appear. These cracks were initailly within the region of pure flexure, but as the load was increased some cracks formed within the two shear spans. A typical example of this type of cracking pattern can be seen in Figure 22.

At various load levels, crack extensions were marked. For those beams that failed in flexure, it was possible to 
follow the crack extensions until failure. Primarily, those cracks between the two load points remained vertical, while those cracks within the shear spans began vertically and then propagated at an approximate $45^{\circ}$ angle toward the load points. All failures occurred when the cracks extended to near the top of the compression zone and in most cases this occurred directly below one of the two load points. Final failure came with the breaking of the steel reinforcement.

\section{Model Beams - Type MBTA-2}

For the model beams of this type, annealed threaded steel rod was used for the longitudinal reinforcement. Either one, two, or three reinforcement rods were used in these beams. In all cases the beam exhibited flexural-type failures.

Prior to failure, the beams exhibited little cracking whatsoever. In the case of those beams haring one reinforcement rod only, one crack formed and that was immediately before the beams failed. In the case of those beams having two or three reinforcing rods the model beams did exhibit some cracking before the actual failure, however in only one case did more than 2 cracks actually form (Beam MBTA-2-3).

There were no cracks formed within either shear span. In general, failure cracks did not confine themselves to the regions below the load points, but were, instead, scattered within the region of pure bending. All cracks propagated vertically toward the top of the compression zone. 
The steel reinforcement bars elongated markedly and the cracks often appeared to be as much as one-sixteenth inch in width before the steel failed.

Typical curves for the deflection at the center-line of two beams of Series 2 are shown in Figure 23. 

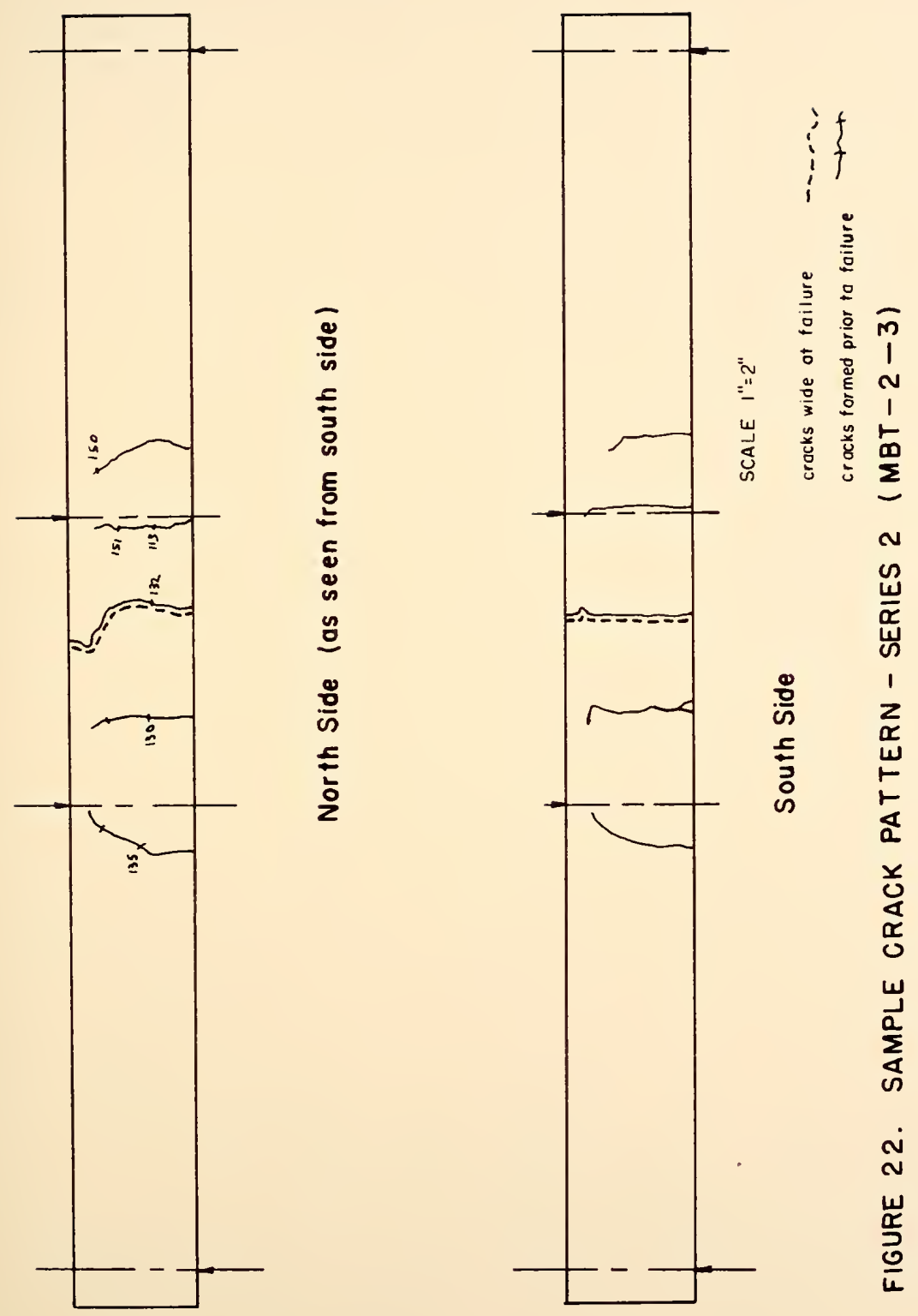

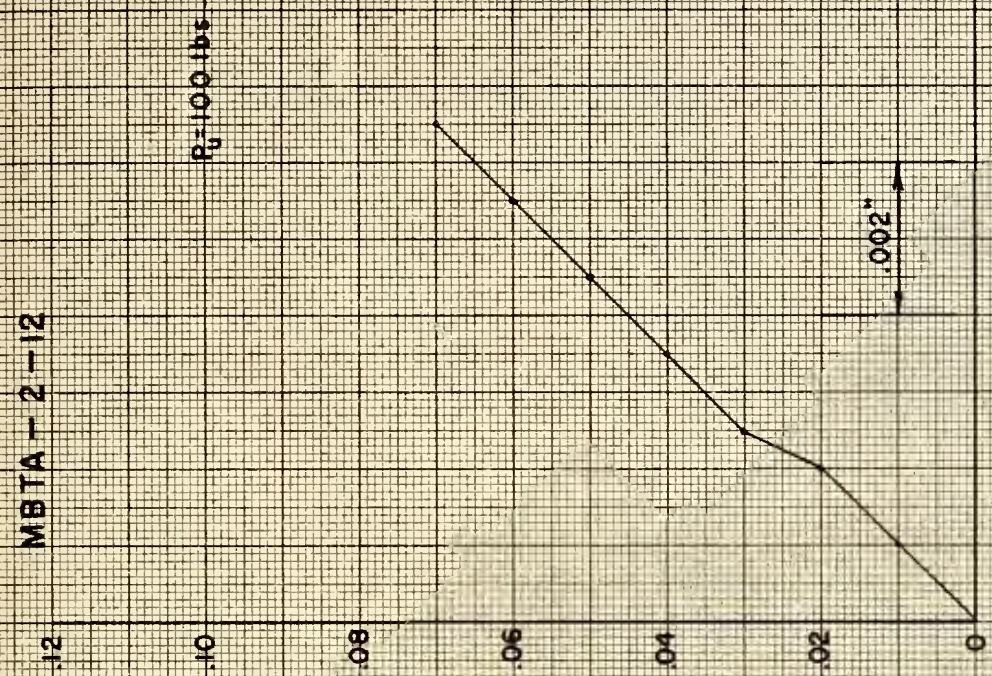

(x) $0 \times 07$
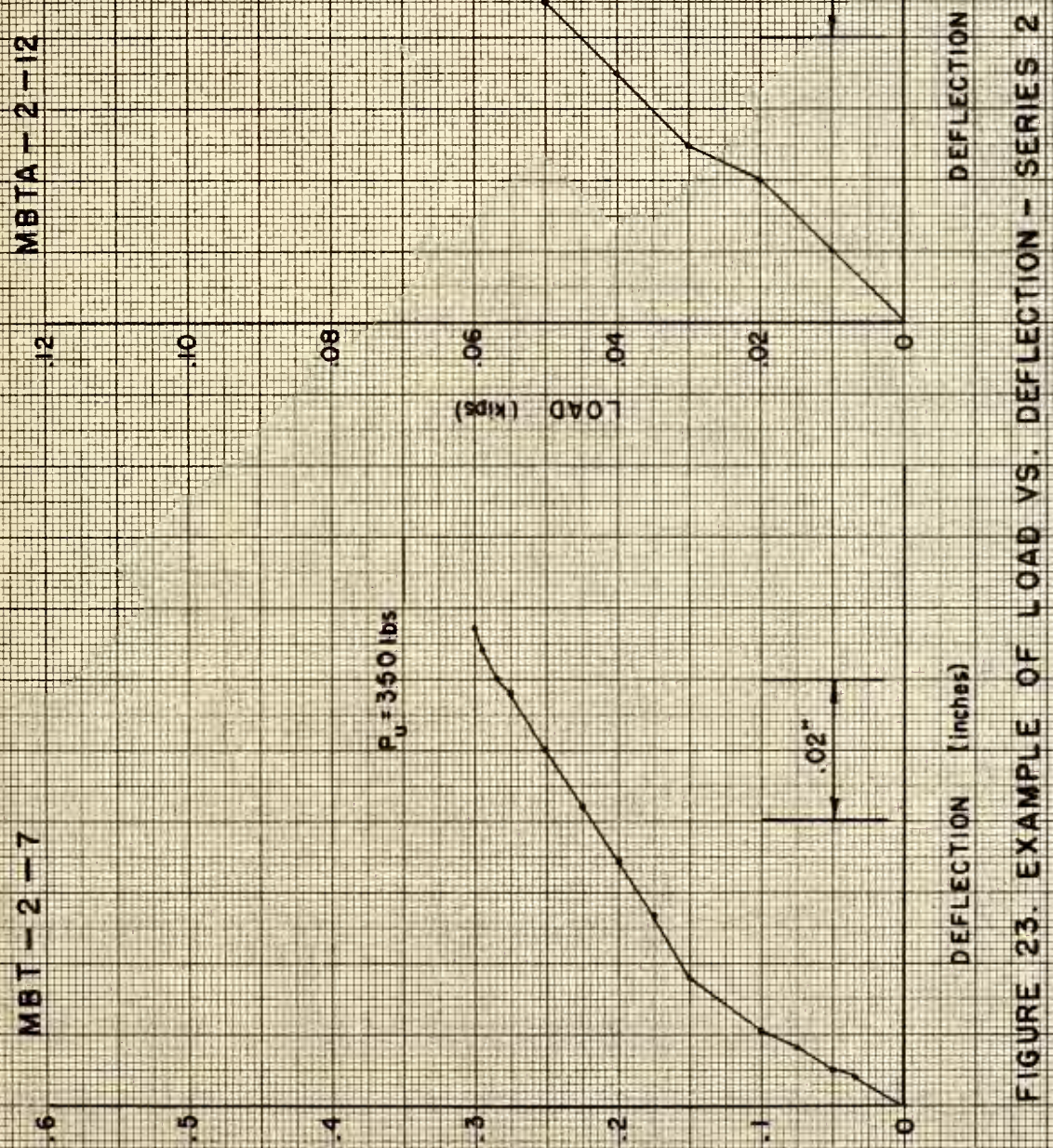


\section{Series 3}

These model beams were scaled-down models of beams tested previously by $W$. N. Harvey (9). All were simplysupported with an overhang. For each beam type there was a different a/d ratio.

\section{Model Beams - Type MB-3-I}

Two beams of this type were tested. Both beams had an a/d of 2.2 and contained no stirrup steel within the shear span. In both cases the failure came with the formation of a diagonal crack.

Beam MB-3-I-1 failed at a load of 3000 lbs., exhibiting an extensive crack pattern similar to the prototype heams. Ultimate failure came with crushing at the interior support. Failure occurred both within the shear span and in the exterior span simultaneously.

Beam MB-3-I-2 failed at 2200 lbs. in the overhang. Although this beam was exact 1 y the same as MB-3-I-1, nevertheless it failed at a much lower load. Prior to formation of the diagonal crack, little cracking was observed, most being confined to the overhang. Failure occurred in the overhang with marked deformation of the steel. No diagonal crack formed within the shear span.

$$
\text { Model Beams - Type MB-3-II }
$$

Two beams of this type were tested with an a/d ratio of 2.9. Beain MB-3-II-1 contained no stirrup steel within 
the shear span, while MB-5-II-2 had stirrups as shown in Figure 24. The deflection curves for both beams are shown in Figure 25 .

For beam :B-3-II-1 the first crack appeared at 780 lbs. which accounts for the large increase in the beam deflection between 700 1bs. and 800 1bs. The dial gage measuring the deflection was removed at 1700 lbs. 1oad. At 2210 lhs. the diagonal crack formed in the overhang. There was very little cracking in the shear span.

In the sccond beam, $V B$ - J-II-2, initial cracking occurred at 920 lbs. liere, the crack pattern was much more elaborate witls a large number of cracks forming in both the shear span and the overhang. Failure came with the formation of the diengal crack at 2250 lbs. The railure occurred chiefly within the shear span.

\section{Model Beams - Type MB-3-III}

Four beams of this type were tested. The a/d ratio for these beams was 4.0. Stirrup steel in the shear span raried from none in Nis-5-III- 1 to one stirrup cvery 0.9 inch in MB-3-III-4 as shown in Figure 24. The deflection curves for these beams are shown in Figures 26 and 27 .

Beam MB-3-III-1 cracked initially at a load of 890 bs. Relatively few cracks formed before the diagonal crack which came at a load of 2210 lbs. The diagonal crack formed within the shear span as can be secn in Figure 17 . 
For beam MB-5-III-2 cracking came at 490 lbs. of load. In this case cracking was more extensive than for the previous beam. At approximately 2000 1bs. a large crack opened up within the overhang. However, the beam sustained load until diagonal cracks formed both in the shear span and orcrhang. A large number of cracks formed along the tension stecl within the shear span. Just after the formation of the diagonal cracks the region of the beam directly under the overhand load point cracked off. The ultimate load Was 2710 16s.

The next beam, $M B-3-I I I-3$, cracked initially at a 10 ad of $890 \mathrm{lbs}$. N1though there was cracking within the shear span, actual failure came with the wideming of cracks within the overhang. The failure load was 2470 1bs. at which the concrete bencath the overhang load point broke off. Only slight cracking occurred below the interior load point. The final beam of this type, MB-3-III-4, contained the largest amount of stirrup reintorcement. For this beam tine initial cracking loal was 910 lbs. and the ultimate load 2700 1bs. Here, failure occurred in the overhang. As an exception to the other beams of this type, a large crack formed within the exterior span, extending to the interior load point. 


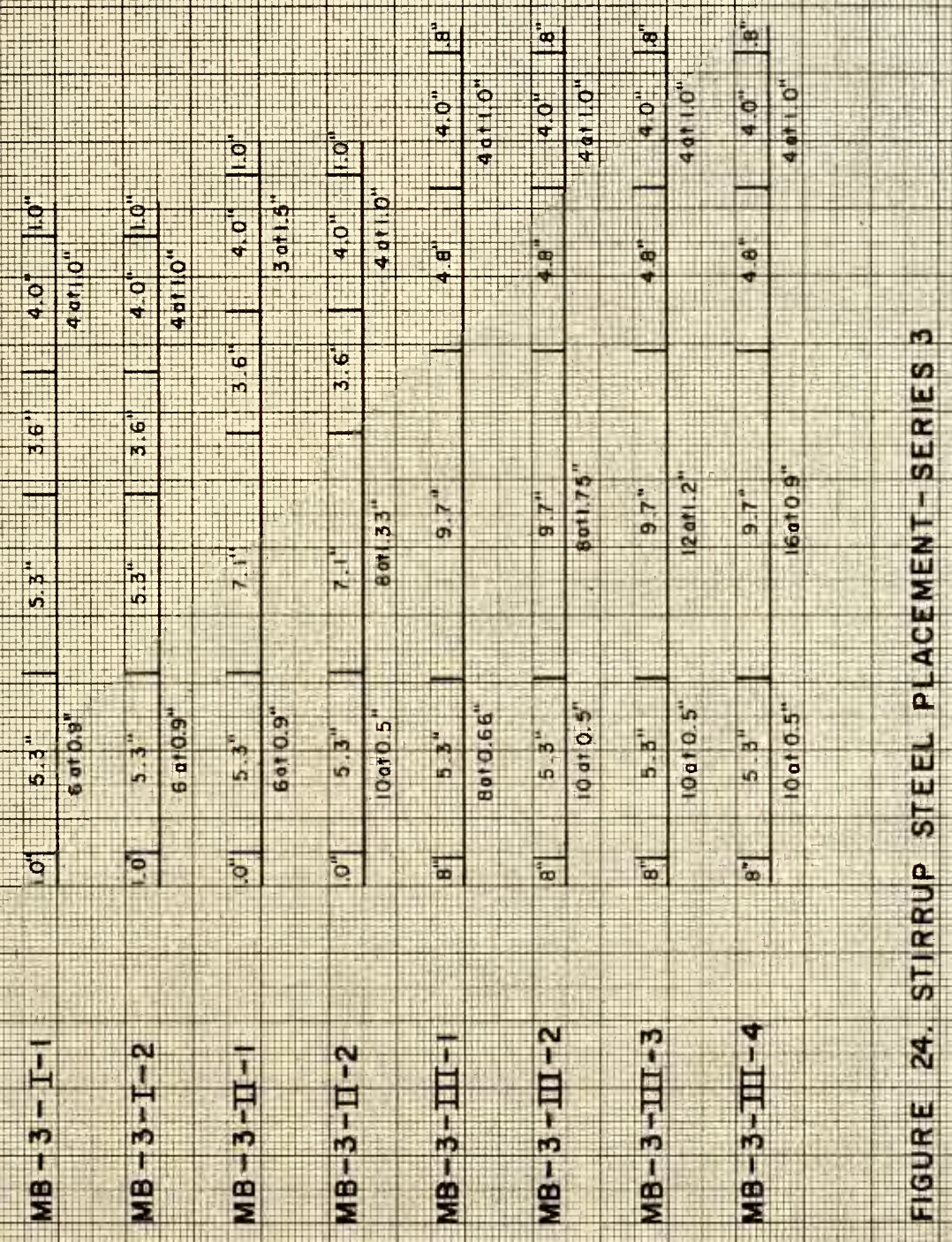




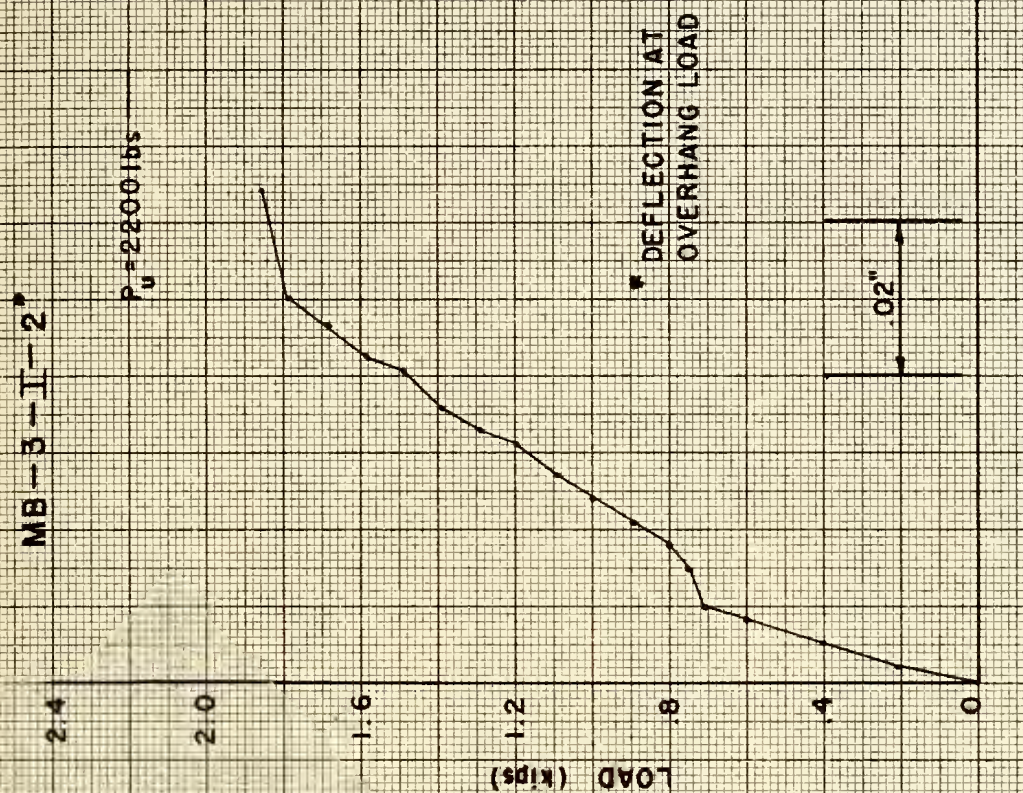

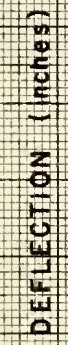

1
1
1
1
$m$
$m$
$z$

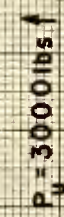

(sdin) 0ro
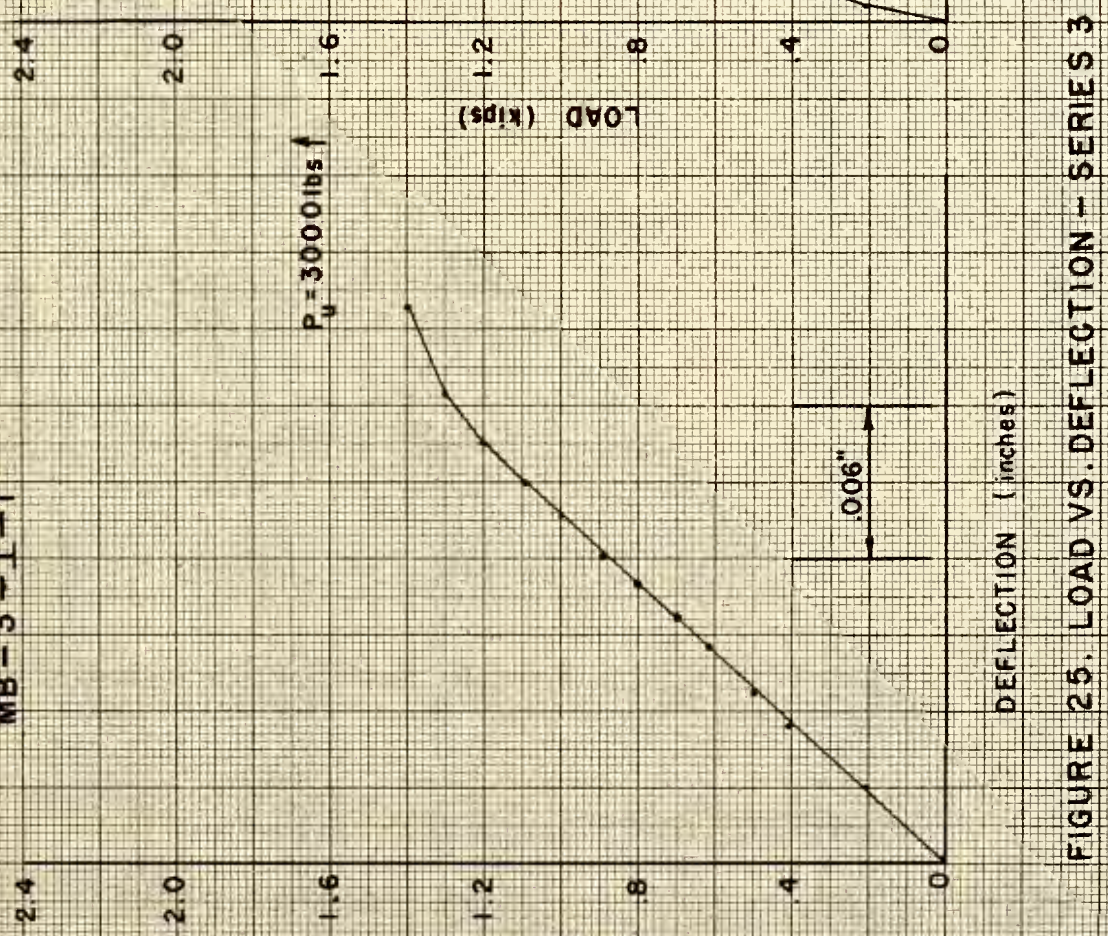

(sdix) avo7 


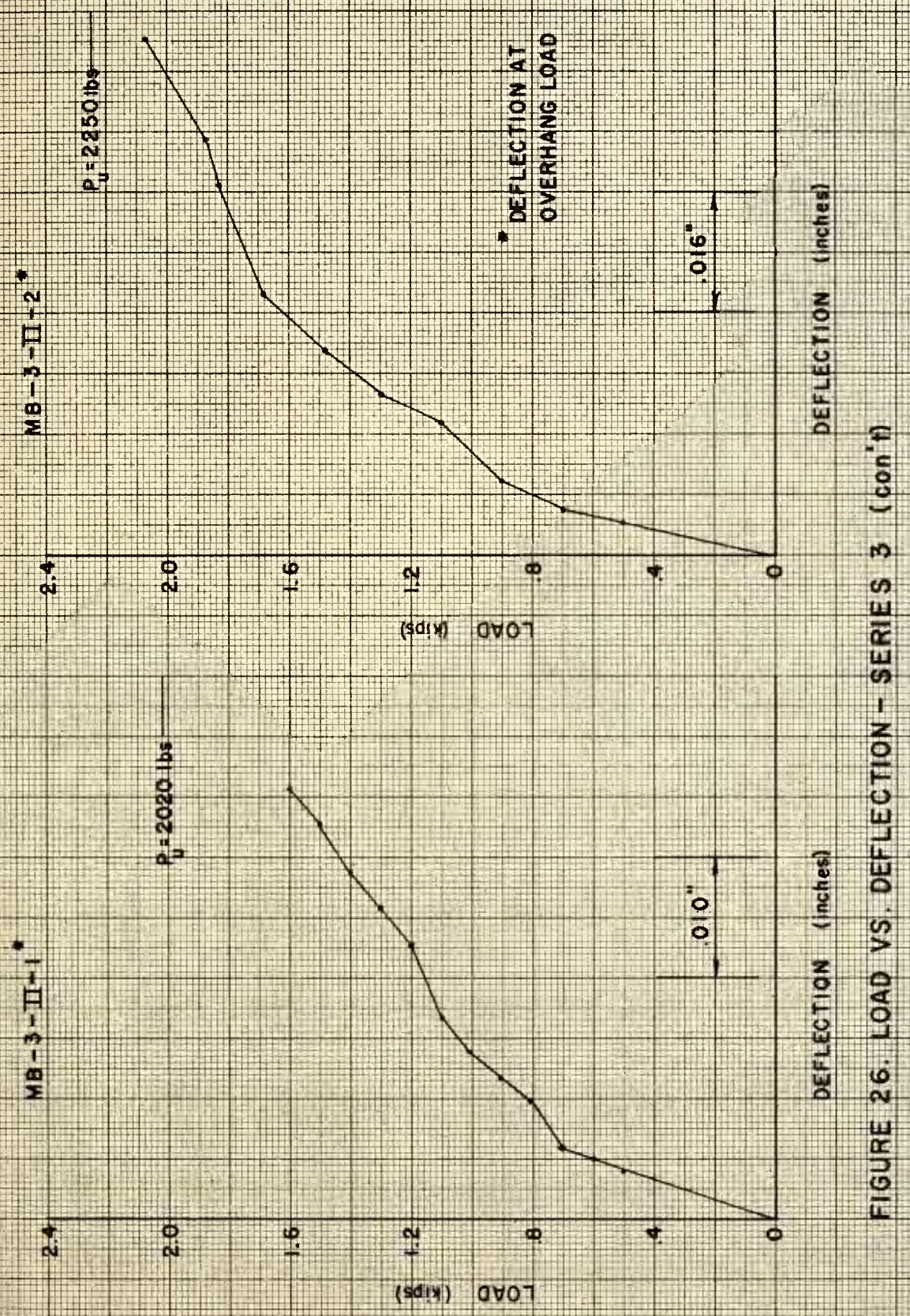



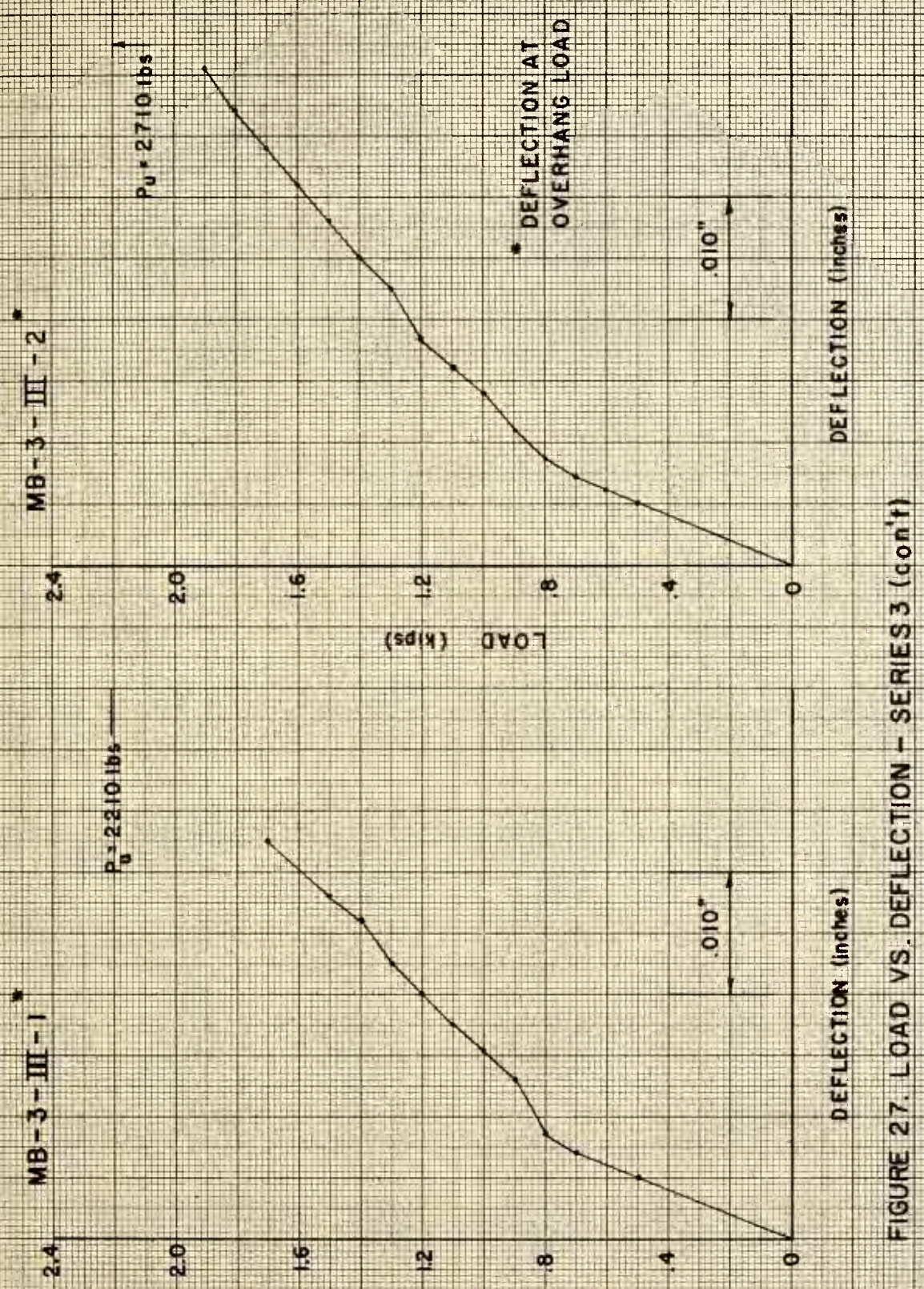

(sdix) 0007 
These model beams were scaled-down T-beams similar to those tested previously by K. E. Wehr (14). With the exception of beam MB-4-I-1, the beams of this series were simply-supported with equal loads applicd at the third points. Beam MB-4-I-1 was simply-supported with an overhang. The beams of this series are shown in Figures 18 and 19 .

\section{Mode 1 Beams - Type MB-4-SS}

Five beams of this type were tested. Both the a/d and flange width were varied. The first three beams had an a/d of 4.0 while the flange width varied from 6 in. to 4 in. The last two beams had a flange width of $5 \mathrm{in}$. While the a/d was 2.2.

Beam MB-4-SS-1, having a flange width of 0 in. cracked initially at a load of 355 lbs. Extensive tension cracks formed between the load points. Failure cane at an ultimate load of 639 lbs. with the formation of the diagonal crack. Splitting of the concrete took place along the reinforeing steel.

The beams, MB-4-SS-2 and MB-4-SS-3, with 5 inch and 4 inch flange widths respectively, failed in a manner similar to the first beam. The ultimate load for beam MB-4-SS-2 was 655 1bs. while for beam MB-4-SS-j the value was 560 lbs. Beam MB-4-SS-3 cxhibited very little cracking prior to the formation of the diagonal crack as indicated in Figure 18 . 
The deflection curves for these three beams are plotted in Figures 29 and 30 .

The last tivo beams of this type, MB-4-SS-4 and MB-4-SS-5, were identical. The first of these beams failed after the formation of the diagonal crack at an ultimate load of 1050 lbs., while the second failed at a load of 1640 1bs. These beams are shown in Figure 19.

\section{Mode 1 Beans - Type MB-4-T}

There was one beam of this type, MB-4-T-1. This beam is shown in I:igure 19 and the deflection curve in Figure 30. Initially the beam cracked at a load of 1090 lbs. Failure came at the overhang support with the extension of a vertical crack and yielding of the steel. The ultimate load was 1980 lbs. 


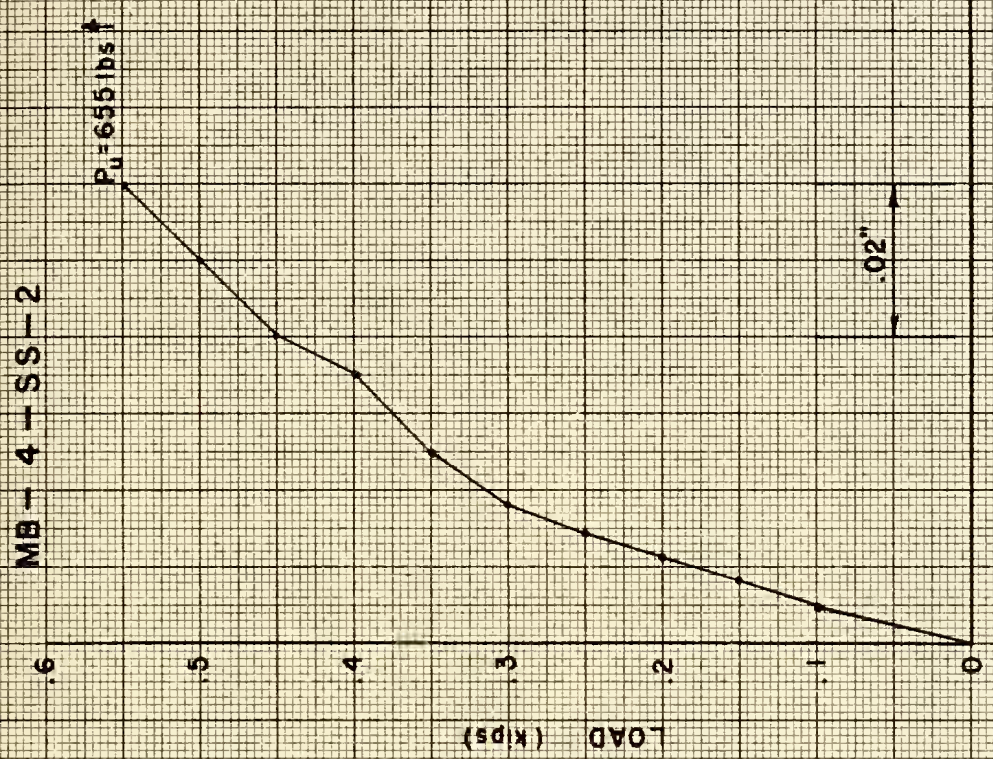

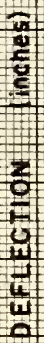

+1
$n$
0
$a$
0
$n$
$a^{2}$
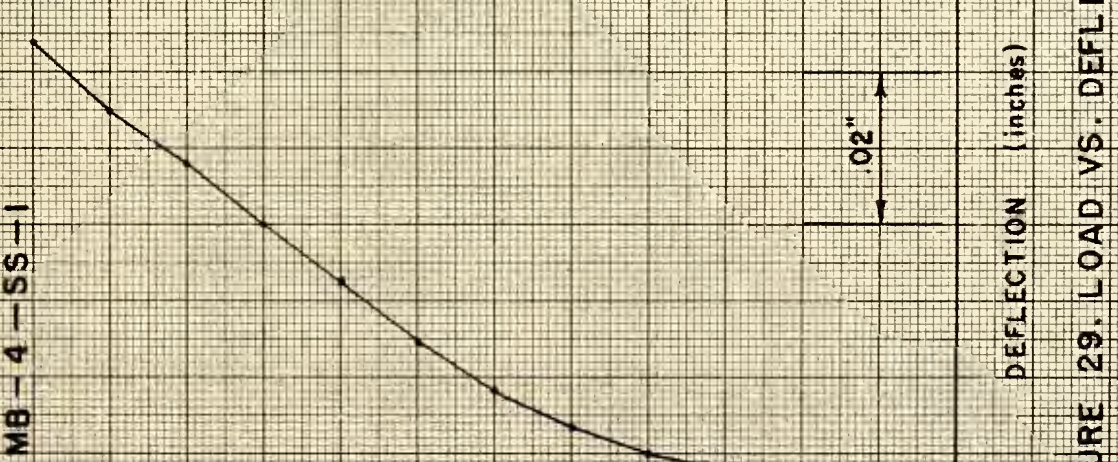

5
$\vdots$
$\vdots$
$\vdots$
$\vdots$
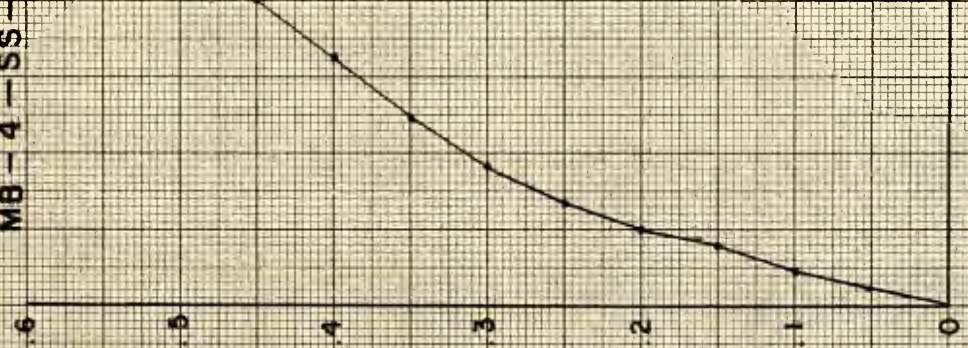

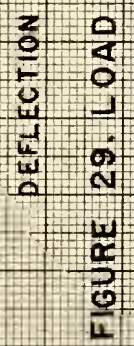



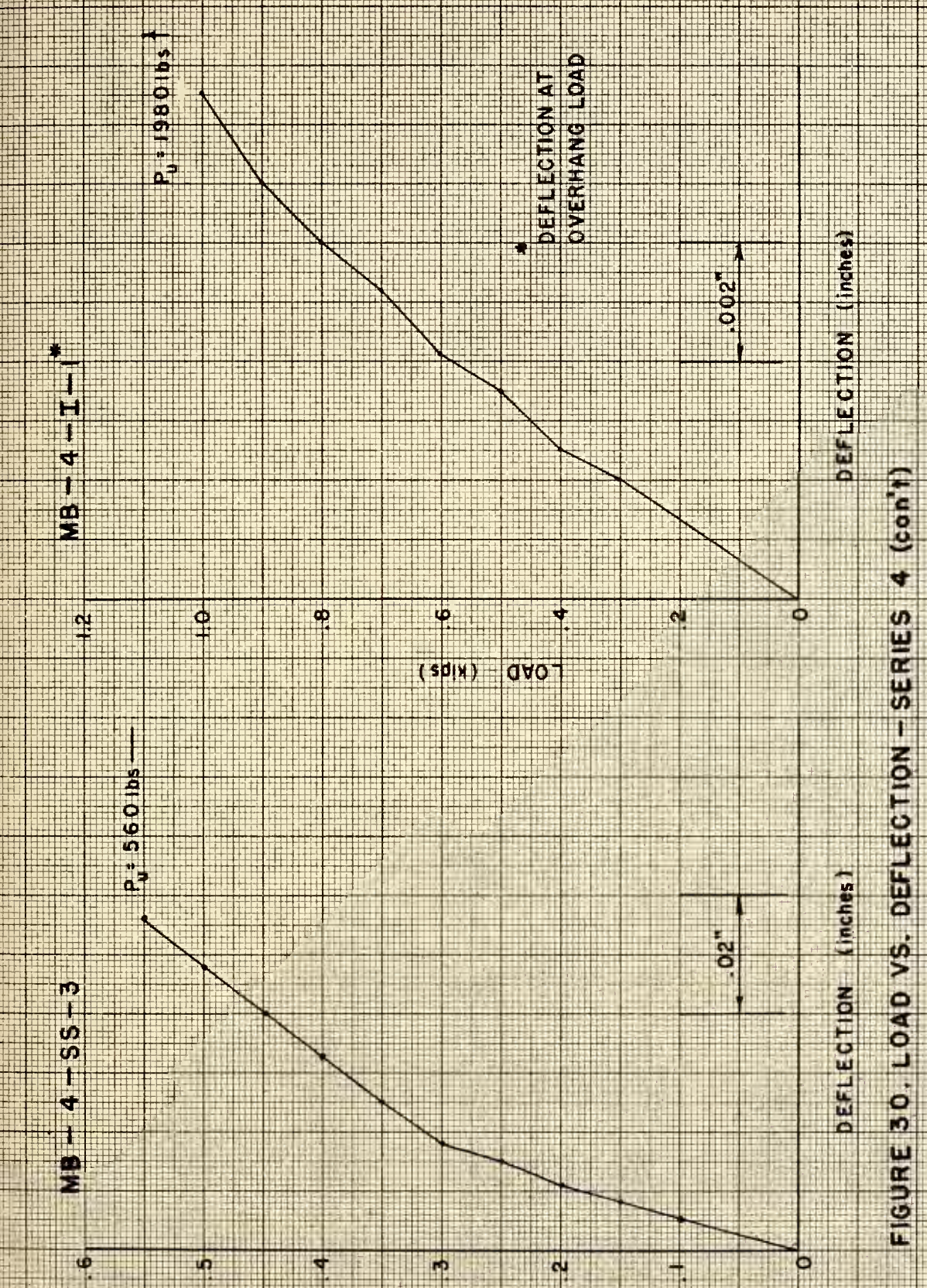

(sditx) 0v07 


\section{DISCUSSION OF TEST RESULTS}

\section{Rectangular Flexural Members}

The beams of Series 1 and 2 were all simply-supported rectangular beams loaded equally at two points equidistant from the end supports. In all cases these model bcams, made from U1tracal 30 model concrete, exhibited the same type of failures common to portland cement concrete beams subjected to similar types of loading conditions; either flexural-tension, diagonal-tension, or shear-compression failure. In each series several specimens of each type were tested to provide substantial experimental data.

The beams of these series could be categorized by the four different types of reinforcement used in them. Both threaded rod and deformed steel wire (annealed and unannealed) were used to determine which would provide the best type of model reinforcement for future use.

\section{Type "A" Reinforced Beams}

This type of beam was tested in both Series 1 and 2, as types $M B T-1$ and $M B T-2$, respectively. In general, these model beams exhibited very good bond with the formation of a large number of flexural cracks evenly spaced throughout the region of maximum moment. As loads were increased, some cracks formed within the shear spans and gradually extended 
toward the load points at a $45^{\circ}$ inclination.

Beams with high strength threaded rod did not fail suddenly, but instead failure came with gradual progression of flexural cracks to the extreme fibers of the compression zone. Generally, cracking load of these beams was at about two-thirds of the failure load. In all cases the flexural crack which extended the farthest at failure was located below one of the two load points. Immediately after the crack had reached the top of the beam it failed with the stee 1 fracturing.

Type "B" Reinforced Beams

Beams of this kind were type MBTA-2 of Series 2. The threaded rod used in these beams had been annealed, having a low yield point with a very large strain-hardening region as shown in Figure B-2 of Appendix B. Here, again, the beams failed in flexure.

In general almost no cracks formed prior to the failure load. The lack of cracks indicated that the bond strength of the threaded rod was considerably reduced by annealing. After the annealing, much of the threading had stripped off, causing the annealed rod to have a bond surface similar to smooth wire.

Those beams containing only one reinforcing rod exhibited a much higher ultimate strength than anticipated. After testing several companion beams without any reinforcement, it was found that the modulus of rupture of the 
concrete accounted for the added strength. The steel strength was so low with only one reinforcing rod that in essence the steel provided no reinforcement for the beams.

\section{Type "C" Reinforced Beams}

These beams belonged to type MBD-1 of Series 1, having unannealed, machine-straightened deformed wire for reinforcing. This reinforcing had a high yield point as shown in Figure B-3 of Appendix B. In order to increase the bond strength of these rods, they were roughened with emery cloth and then rotated after the concrete was poured.

The crack patterns for these beams closely resembled those found in larger scale reinforced portland cement concrete beams subjected to similar loading conditions. Failure for these beams came after the formation of a diagonal crack, resulting in either a diagonal-tension or shear-compression failure. It was possible to obtain good accuracy in drawing the beam crack patterns due to the size of these specimens and the smoothness of their surface.

\section{Type "D" Reinforced Beams}

Beams in this category were those of type MBDA-1 of Series 1 , having annealed, machine-straightened deformed wire for reinforcing. The properties of this steel are shown in Figure B-4 of Appendix B. In general the beams of this series behaved similarly to beams of type MBD-1. Although the annealing reduced the yield of strength of the 
reinforcing, it had little effect on the bond strength. It was felt that the reinforcing used here more closely resembled the stress-strain properties of structural steel than any of the other types tested, suggesting the use of this type model for further investigation.

\section{Rectangular Beams with Overhang}

Each beam of Series 3 involved a great deal of care in its design and manufacture. Since these beams were to duplicate specific prototype beans already tested, it was necessary to match both material properties, geometry, and test techniques very carefully. As in the case of the prototype specimens (9) excess vertical reinforcing was provided within the overhang and exterior span. This was done to ensure failure within the shear span. Unfortunately, for these models failure was not always confined to the shear span.

For those beams not failing within the shear span the failure load was often larger than expected from prototype specimens, giving credence to the idea of certain limitations for small-scale models.

The model scale for these beams was based on the ratio of area of model reinforcing to area of prototype reinforcing. Having established the scale factor, the beam size, stirrup spacing, and stirrup size were determined. The similtude problem would have been greatly reduced if more sizes of reinforcement had been available. A detailed 
discussion of this problem is made in the analysis section and calculations for determining the model scale are found in Appendix $C$.

Although the beams of this series were the largest models in this investigation, several times larger than Series 2, nevertheless they could be tested on the same test machines as the smaller beams. This indicates that a number of model sizes could be used depending on the desired information. Even if the steel had been available to model Harvey's beams to a smaller scale, this would not have been feasible due to the very small scale of vertical reinforcing.

\section{T-beam Node $1 \mathrm{~s}$}

The final series of beams, Series 4, were scaled-down $T$-beams similar to those tested by $K$. E. Wehr. As in the case of Series 3 these beams were more difficult to manufacture since they were modeled after definite prototype specimens (with the exception of beams MB-4-SS-4 and IIB-4-SS-5). Here, however the scale factor was based on a ratio of the cross-sectional areas of model and prototype specimens. A detailed discussion of this is given in the analysis as well as sample calculations in Appendix C.

Beams MB-4-SS-1, 2, and 3 exhibited failure models and ultimate loads as expected from the prototype tests. However, the results of beams MB-4-SS-4 and 5, having a lower a/d ratio, showed again the existence of a size effect as 
indicated in Series 3 . The remaining beam of this series, MB-4-I-1, failed with the formation of very few cracks. 


\section{ANALYSIS OF TEST RESULTS}

\section{Rectangular Beams in Flexure}

Comparison of the test results of Series 1 and Series 2 with Ultimate Strength Design predictions are shown in Tables 10 and 11, respectively. All theoretical values for ultimate moment and shear are based upon the ACI 1963 Code (1), using a $\emptyset$ (understrength) value of unity. Sample calculations are provided in Appendix $C$.

The governing equation for the ultimate moment on a rectangular beam from the ACI Code follows:

$$
M_{u}=\emptyset\left[A_{S} f_{y}(d-a / 2)\right] \text {, where } a=\frac{A_{S} f_{y}}{0.85 f_{c}^{\prime} b}
$$

In the preceding formula, the value of $f_{y}$, the yield strength for the longitudinal reinforcing, was taken as the value at $0.1 \%$ offset. For those types of reinforcing having a yield strength greater than $60,000 \mathrm{psi}$ the Code restricts the design yield strength to $60,000 \mathrm{psi}$ in general. However, this is merely a safety precaution for design and by using the actual yield strength a much closerestimate of the beam capacity is obtained.

The governing equation for computing the ultimate shear stress for a rectangular beam is: 


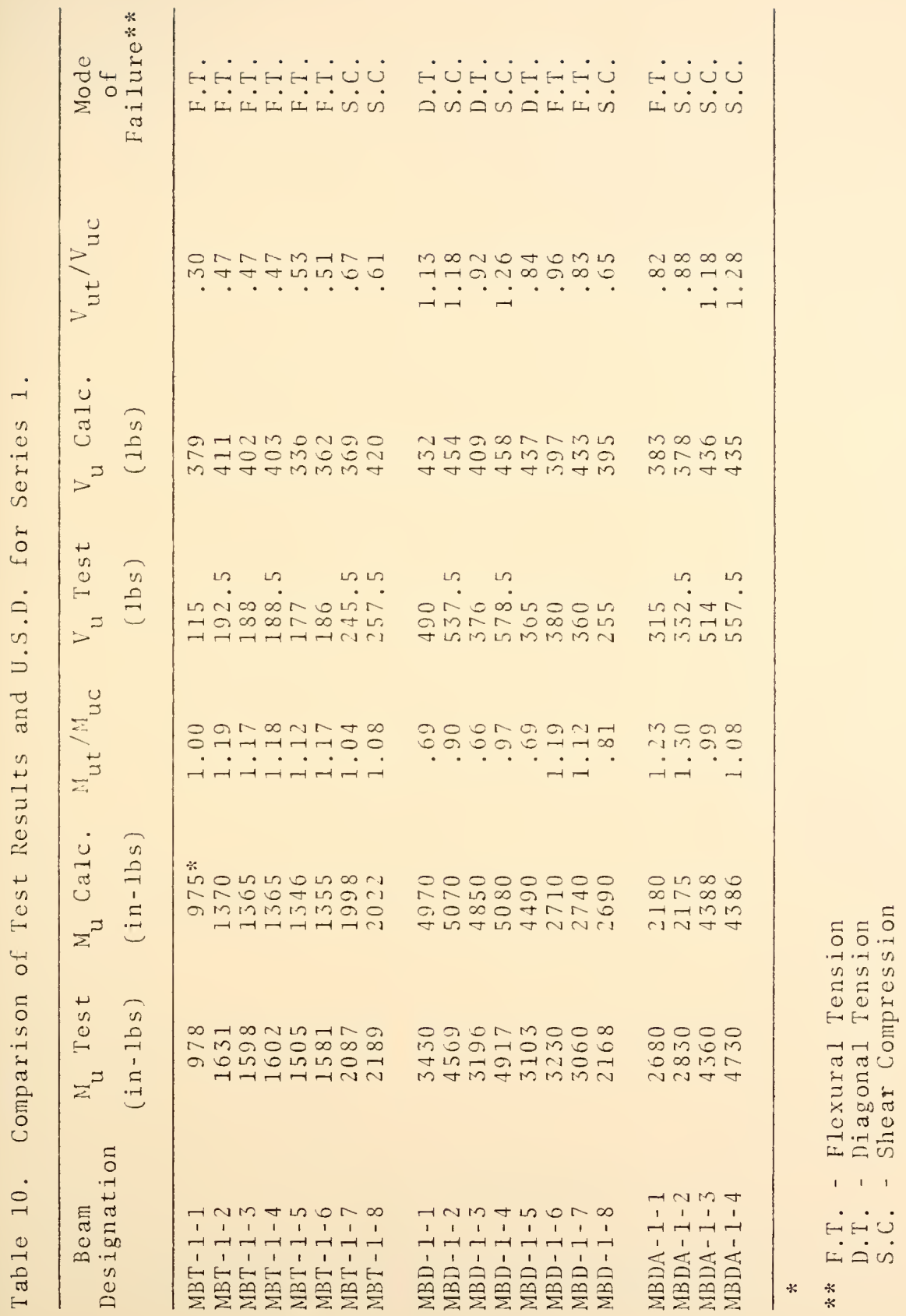




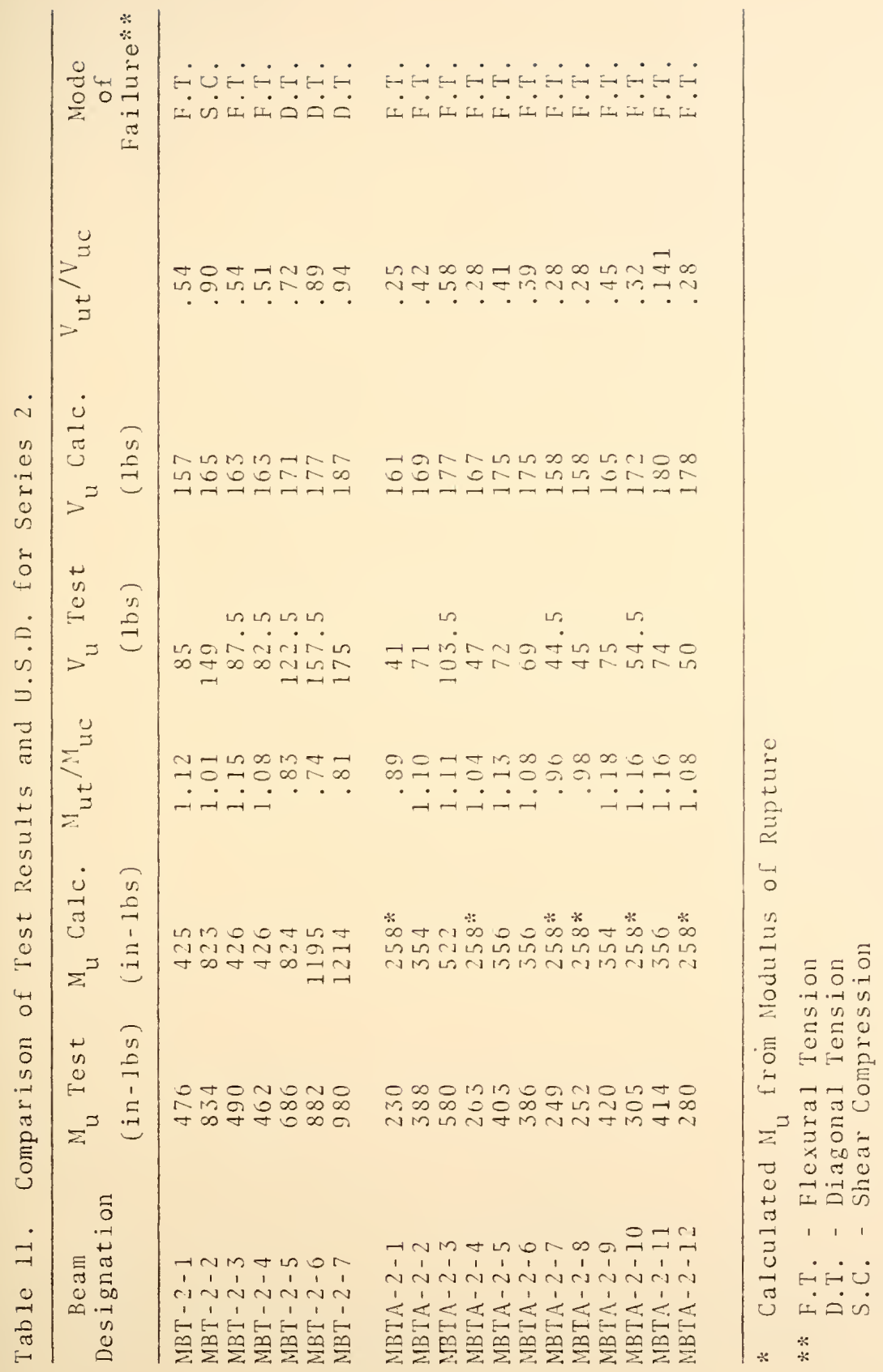




$$
v_{c}=\varnothing\left[1.9 \sqrt{\mathrm{I}_{c}}+2500 \frac{\mathrm{pVd}}{\mathrm{M}}\right] \text {, where } \mathrm{p}=\frac{\mathrm{A}_{\mathrm{s}}}{\mathrm{pd}}
$$

For this case $M$ and $V$ are taken at a section a distance $d$ from the supports, where d is the effective beam depth. Since none of the beams of these two series contained vertical reinforcement, $V_{C}$, the shear stress for the concrete alone, is then equal to $V_{u}$, the ultimate shear stress of the beam. Substituting the above relations into the previous equation for shear stress, the following simplified equation is obtained:

$$
v_{u}=1.9 \sqrt{1_{c}}+2500 \frac{\mathrm{A}_{s}}{b d}
$$

The basic difference between Series 1 and 2 is that the beams of Series 2 were smaller than those of Series 1. However, both were subjected to the same load conditions. By using two beam sizes it was possible to obtain a large number of varied specimens upon which to make comparisons with standard design theory.

Since Ultimate Strength Design is based upon numerous tests of how actual reinforced portland cement concrete beams behave, model beams that act as the theory predicts provide accurate models for actual reinforced concrete beams. The overall results of these two series of tests showed that the experimental values of the ultimate moment agreed fairly closely with the values predicted from theory, having 
an average $M_{u t} / M_{u c}$ of 1.11 for all beams of both series failing in flexure. At the same time the modes of failure were similar to those expected with larger reinforced portland cement concrete beams subjected to the same load conditions. In order to analyze every facet of this research carefully each beam type is analyzed separately in this section.

A more accurate value for the ultimate moment could have been obtained by calculating the steel strain at ultimate load based on a linear strain distribution and assuned maximum concrete strain of $0.003 \mathrm{in} / \mathrm{in}$.

The distance from the top of the compression fiber to the neutral axis, $c$, is:

$$
c=\frac{\varepsilon_{u}}{\varepsilon_{s u}+\varepsilon_{u}} d
$$

where $\varepsilon_{u}=.003$ and $\varepsilon_{\text {su }}$ is the steel strain at ultimate. From an equilibrium of forces on the section, the following expression is obtained:

$$
.7 f_{c}^{\prime} b c=A_{s} f_{s u}
$$

Combining both equations, the following equation is obtained:

$$
f_{s u}=\frac{b d}{A_{s}}\left(.7 f_{c}^{\prime}\right)\left(\frac{\varepsilon_{u}}{\varepsilon_{s u}+\varepsilon_{u}}\right)
$$

Since all quantities are known except $\varepsilon_{\text {su }}$ and $f_{\text {su }}$, this equation can be plotted on a stress-strain plot along with the stress-strain curve for the reinforcing. The intersection 
of these curves yields the value of $f_{s u}$ and $\varepsilon_{\text {su }}$. Sample calculation are shown in Appendix C. As examples, a comparison of moments calculated in this manner with test moments showed that for beam MBT-1-2, $\mathrm{M}_{u} / \mathrm{M}_{\mathrm{uc}}=1.05$, and for beam $\mathrm{MBD}-1-6, \mathrm{M}_{\mathrm{ut}} / \mathrm{M}_{\mathrm{uc}}=.967$.

Although the values from such calculations agree very favorably with the test results, it was felt that comparison between the Code formulation and test data provided close enough agreement to substantiate these tests.

For all beams which failed due to shear the average $V_{u t} / V_{u c}$ was 0.94 , showing very close agreement between the test and Code values. For those beams exhibiting a diagonal-tension failure this value was 0.91 , while for those exhibiting a shear-compression failure this value was 0.96. As was predictable the shear-compression failure in several cases occurred at a higher value than the Code formula predicted. This is also true in prototype specimens, since the formula given in the Code is based upon the shear stress at which the diagonal crack forms. In the case of three beams MBT-1-7, MBT-1-8, and MBD-1-8 shear-compression failure modes were noted, while the beams failed much below the calculated shear load. In the case of all three of these beams the test ultimate moment was close to the calculated one, indicating the beam should have failed in flexure. The average $V_{u t} / V_{u c}$ for all beams failing in shear, excluding the three mentioned above, was 1.01 . 


\section{Type MBT-1}

In general, the test results for beams of this type agreed favorably with those values based upon equations from the ACI Code. The value of $\mathrm{p}$ for these beams varied from $0.10 \%$ to $0.29 \%$. The value of $\mathrm{M}_{\mathrm{ut}} / \mathrm{M}_{\mathrm{uc}}$ for these beams was 1.14. For only those beams containing 3 reinforcing rods did the test shear at failure approach the calculated shear. The average $V_{u t} / V_{u c}$ for these, MBT-1-7 and -8 , was 0.64 .

There were two modes of failure. Those beams containing one or two reinforcing bars failed in flexure while those containing three bars exhibited a shear-compression failure. For those two beams which failed in shearcompression with the formation of a diagonal crack, beams MBT-1-7 and MBT-1-8, the shear load was considerably lower than predicted from theory. Comparison of the ultimate moments, calculated and test, indicated that the mode of failure should have been a purely flexural one for these two beams.

\section{Type MBD-1}

The results of these beams agreed favorably with the Code calculations and published data. For these beams $p$ was varied from $0.49 \%$ to $1.37 \%$. The value of $\mathrm{M}^{\prime / M}$ uc for those beams failing in flexure was 1.15 . The value of $\mathrm{V}_{\mathrm{ut}} / \mathrm{V}_{\mathrm{uc}}$ was 1.00 for those beams having a shear-type failure. 
General1y for those beams which failed in shearcompression the ultimate test shear force was considerably larger than the calculated one. This is to be expected and occurs often in prototype beams tested under the same conditions. The reason for this is that the formula given by the ACI Code for the shear strength of the beam is actually the load at which the diagonal crack forms and therefore is a conservative value for calculating the ultimate shear capacity.

Type MBDA- 1

Three of the four beams of this type failed in shearcompression. For these three beams the average $V_{u t} / V_{u c}$ was 1.12. This result is substantiated, as mentioned abore, by results from tests of reinforced portland cement concrete beams failing in shear-compression.

For beam MBDA-1-1, which failed in flexure, the value of $\mathrm{Mut}_{\mathrm{uc}} \mathrm{M}_{\mathrm{u}}$ was 1.23 . The failure mode for this beam is somewhat varied from a typical beam failure with a large horizontal piece of nodel concrete beaking off from the top surface within the mid-span.

The steel used as reinforcing for these beams most closely duplicated the stress-strain properties of structural steel reinforcing. With the exception of MBDA-1-1 the crack patterns were similar to those for large scale beans. 
Type MBT-2

The results of those beams of Series 2 containing unannealed threaded rod as longitudinal reinforcing showed that failure loads for this type of model beam closely agreed with those values obtained by use of the ACI Code Ultimate Strength Design equations. This was true for all members except MBT-2-5 for which neither the theoretical ultimate moment, nor the theoretical ultimate shear was reached.

The average $\mathrm{M}_{\mathrm{ut}} / \mathrm{M}_{\mathrm{uc}}$ value for those beams of MBT-2 which failed in flexure was 1.12. For those beams which were subjected to a shear type failure the average $V_{u t} / V_{u c}$ was 0.86 and neglecting beam MBT-2-5 this value was 0.91 .

Observations of this beam type showed that members failed in three ways, those having only one reinforcing rod failed in flexure, with some shear cracks, those with 2 rods exhibited both flexural and shear-compression failure, and those with 3 rods failed in diagonal-tension.

The value of $\mathrm{p}$ varied from $0.235 \%$ to $0.705^{\circ}$ for the beams of this type. From the crack spacing of those members which failed in flexure, it appears that the bonding of the threaded rod was excellent, producing a failure mode similar to large scale reinforced concrete beams loaded under the same conditions.

\section{Type MBTA-2}

Those beams containing annealed threaded rod failed entirely in flexure and with the exception of those beams 
containing on $1 y$ one reinforcing rod the average $\mathrm{M}_{\mathrm{ut}} / \mathrm{M}_{\mathrm{uc}}$ was 1.13. In no cases did the beams of this type ever approach their ultimate shear load and for this reason the $\mathrm{V}_{\mathrm{ut}} / \mathrm{V}_{\mathrm{uc}}$ was never critical.

For those beams which contained only one reinforcement bar further tests indicated that failure was the same as for beams without any reinforcement and that the allowable moment predicted by the ACI Code was less than the moment determined from the modulus of rupture of the material. Calculations of this moment are shown in Appendix C. A comparison of this moment with the test moment showed that the $\mathrm{Mut}_{\mathrm{uc}} / \mathrm{M}_{\mathrm{uc}}$ average was 1.02 .

\section{Mode1s of Beams Tested by W. N. Harvey}

The beams of Series 3 are compared in Table 12 with the results of prototype beams from tests performed by $W$. N. Harvey (9). The linear scale factor for this model series was 4.5. This value was obtained by averaging the steel ratios for the model and prototype specimens, $A_{s p} / A_{s m}$ and $\mathrm{A}_{\text {sp }}$ '/ $\mathrm{A}_{\text {sm }}$ ' as shown in Appendix $C$. This means of determining the scale factor was necessitated by the limited availability of model reinforcement sizes (only one size deformed wire). The yield point and modulus of elasticity of the steels used in both the prototype and model were about the same. Therefore, the ratios of both of these values, $E_{p} / E_{m}$ and $f_{p} / f_{m}$, were taken as unity. Consequently, the model load was taken as being directly proportional to the prototype load by the 
square of the linear scale factor. For this series of beams the average $\mathrm{P}_{\text {um }} / \mathrm{P}_{\text {up }}$ was 0.97 , where $\mathrm{P}_{\text {um }}$ is 20.25 times the recorded model load at failure.

Beams of this series were compared only with the results of the prototype tests, neglecting any slight variance between the concrete strengths of the model and prototype. Also, only one type of stirrup was used throughout the model beams, whereas for the prototype beam lower strength steel stirrups were used within the shear span. The stirrup spacing was adjusted so that the force carried by the stirrup steel in the model was proportional to that carried by the stirrups in the prototype.

The comparison of the model and prototype ultimate load capacities was generally good, although the actual 1ocation of the failure in the model was not confined entirely to the shear span as in the case of the prototypes. The position of the failure crack for each model beam is given in Table 12 and shown in Figure 17 .

The first two model beams were geometrically identical, the on $1 y$ difference being that beam MB-3-I-1 had a slight 1 y higher concrete strength than that in beam MB-3-I-2. The beams exhibited considerably different failure modes and ultimate load capacities. For the beam which failed in the overhang the adjusted failure load (20.25 times the actual load) was $44.6 \mathrm{kips}$, while for the other the adjusted ultimate load was $60.8 \mathrm{kips}$. In the case of the two prototype 


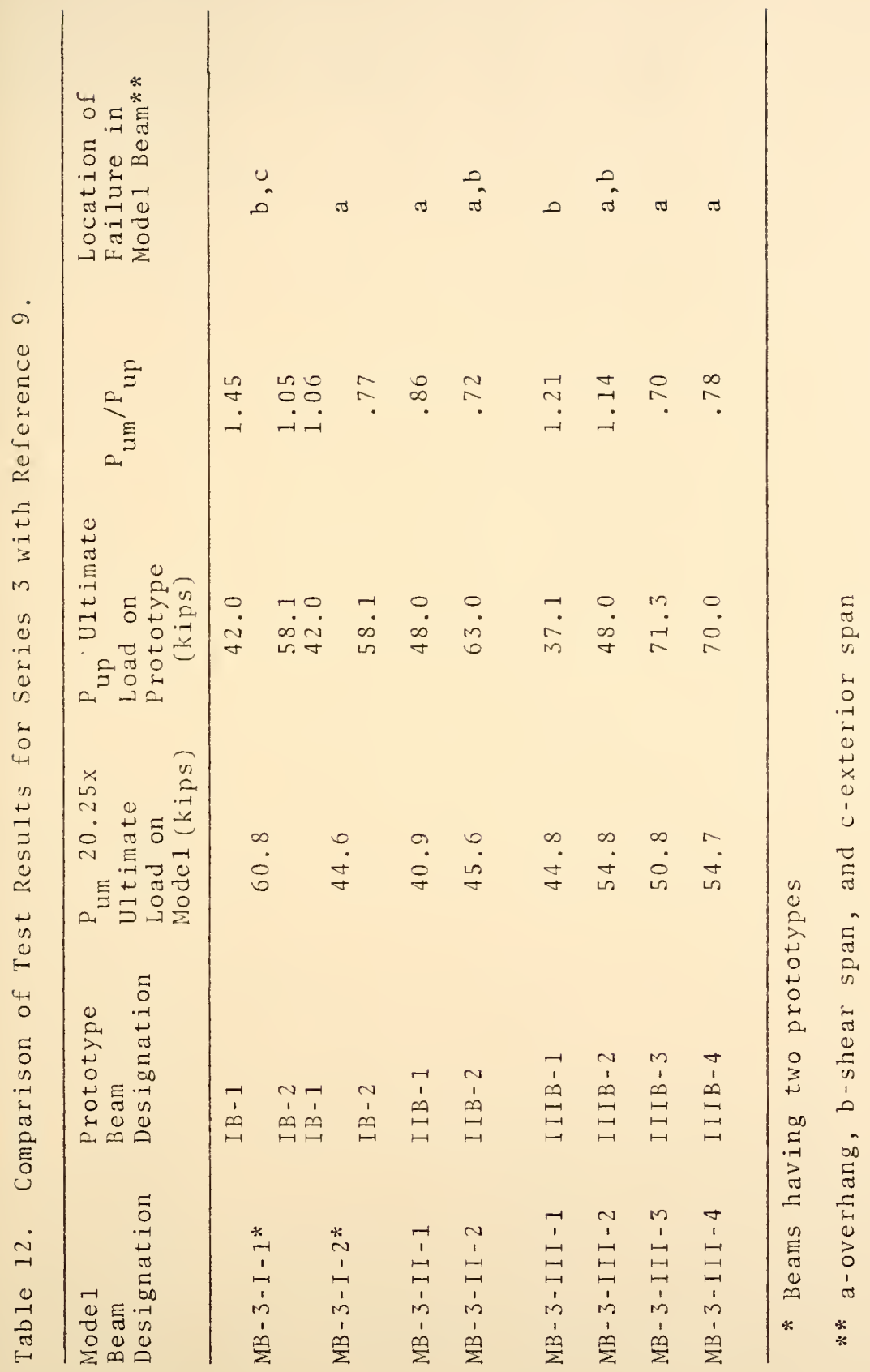


beams $I B-1$ and -2 failure loads were 42.0 kips and 58.1 kips, respectively.

For beam MB-3-II-1 the adjusted ultimate load was at 40.9 kips while its prototype beam failed at 48.0 . Here, however, failure occurred within the overhang and not in the shear span. For Beam MB-3-II-2 having stirrups at 1.33 inches within the shear span, the adjusted ultimate load was considerably lower than for its prototype, IIB-2. Here, however, the failure mode more closely resembled that of its prototype.

For these first two types of model beams the a/d was 2.2 and 2.9 , respectively. In the case of both model types, with the exception of beam MB-3-I-1, the formation of the diagonal crack within the overhang rather than within the shear span was the controlling factor. Each of the prototype specimens exhibited considerably more cracking prior to the formation of the diagonal crack, with the model cracks generally forming at higher loads than predicted from the prototype beam bests. Likewise, the diagonal cracking loads of the prototypes were such that the first two model types should have had diagonal cracks form at lower loads than they did. The occurrence of this added stiffness in the shear span of these models strongly points to the possibility of a size effect for small scale models with low a/d ratios. Additional discussion of this size effect is given in the following section on $\mathrm{T}$-beams 
At the same time that these beams were exhibiting this added restraint in the shear span, considerable cracking took place within the overhang. Although the vertical steel reinforcing was designed to prevent any large cracks from opening, it was unable to resist the formation of the diagonal crack and failure ultimately occurred. Thus, the final failure mode for these beams was determined by a combination of the location of the initial cracking and the fact that the overhang stirrups could not adequately resist the large shear in the overhang.

The third type of beam in this series, MB-3-III, contained beams with an a/d ratio of 4.0 . The amount of vertical reinforcement in the shear span increased from none in MB-3-III-1 to a maximum in MB-3-III-4. The first two beams of this type exhibited failure models very close to those of their prototypes, with the formation of the diagonal crack in the shear span. Both beams failed at loads slightly higher than those for their prototypes, but within reasonable limits for comparison. In general these models provided excellent comparison with their prototypes.

The latter two beams, MB-3-III-3 and -4, having increased amounts of vertical reinforcing in the shear span, both failed after the formation of diagonal cracks in their overhangs. Both failures came at considerably lower loads than for the corresponding prototype beams. From observation of the crack pattern, the additional amounts of vertical reinforcing in the shear span restricted the formation of 
cracks in this region with failures for these two beams occurring in a manner similar to those beams with a shorter shear span.

Although this model series generally provided a good estimate of the magnitude of the load capacity of the prototype specimens the number of cracks forming and the position where they formed varied considerably from the prototypes.

\section{$\underline{T-B e a m s}$}

Although the beams of Series 4 were models of beams tested by K. E. Wehr (14), two of the mode1 beams, MB-4-SS-4 and MB-4-SS-5, had much smaller a/d ratios than any similar prototype specimens. Comparison of model test results with prototype test results and ACI Code values is given in Table 13. There was general agreement between model and prototype tests.

The linear scale factor for this Series was taken as 6.0. After having established this value, the various geometric properties for each model were calculated as shown in Appendix C. Since the reinforcing was obtainable in only one size, it was necessary to use 2 bars for the tension steel and one bar for the compression steel, where applicable. Thus, the percentage of tension reinforcing in the mode 1 was increased from $1.33 \%$ to $1.64 \%$, and the percentage of compression stee 1 was decreased from $0.93 \%$ to $0.82 \%$. Due to this change in cross-sectional properties the tested model beams were actually distorted structural models as 


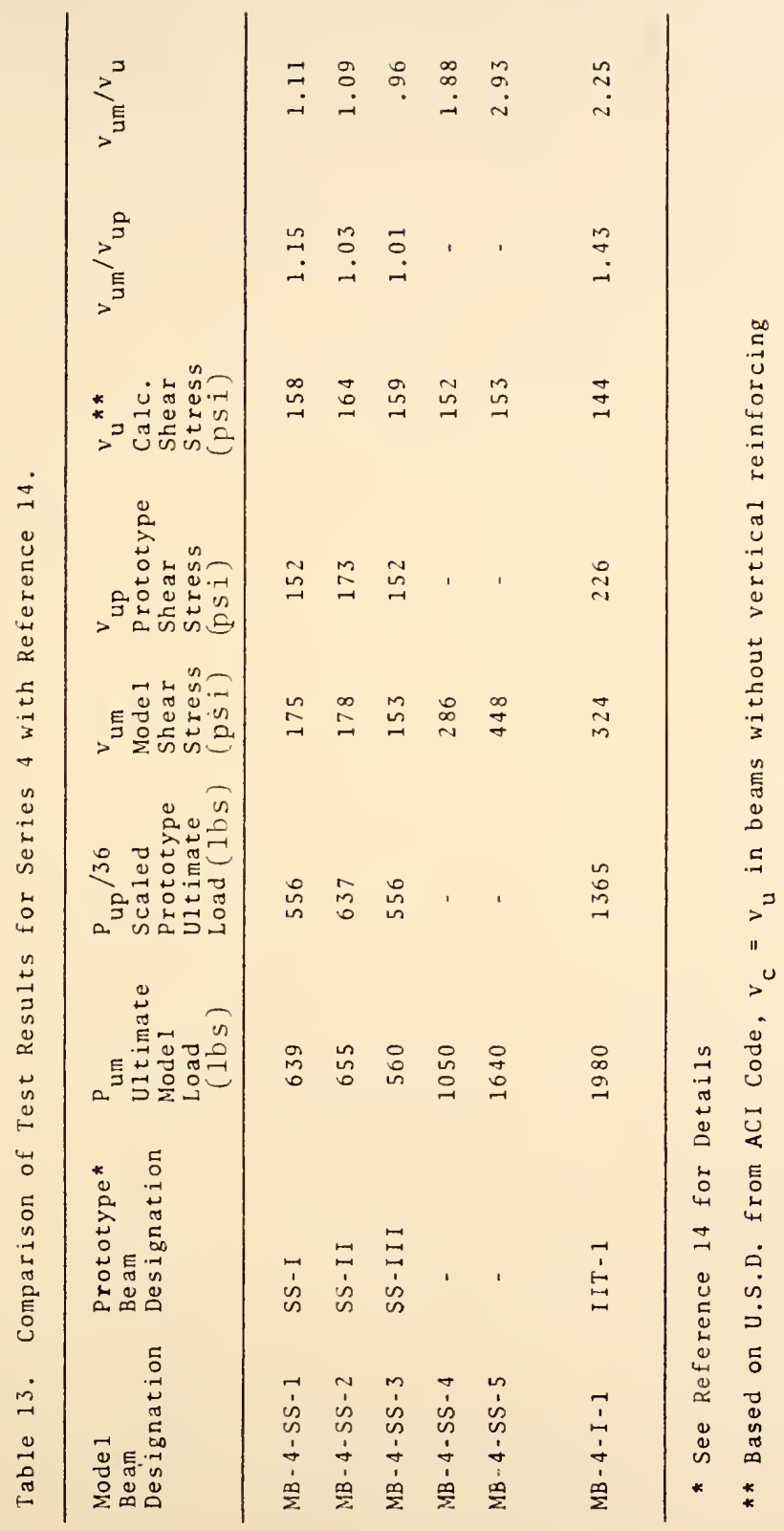


discussed previously in the introduction.

The first three model beams of type MB-4-SS were to duplicate beams -SSI, -SSII and -SSIII. In the case of both the models and prototypes, the flange width was varied in order to determine the effect of the flange width on the failure mode. Model beams $M B-4-S S-1,2$, and 3 , failed in diagonal tension as had their prototypes. Again the same ACI Code equation as discussed previously was used to calculate the ultimate shear stress for a beam without vertical reinforcement:

$$
v_{c}=\varnothing\left(1.9 f_{c}^{\prime}+2500 / \frac{p_{W} V d}{M}\right)
$$

The critical section is again taken at a distance "d" from the support for the type MB-4-SS beams.

Since diagonal-tension was the failure mode, the increase in steel percentage in the model was of little consequence for these beams as can be seen from the results of Table 13. In general the slightly lower values for the concrete strengths of the models tended to compensate for the increase in steel percentage. The resulting failure mode and ultimate shears for the models and prototypes were in excellent agreement. Multiplying the ultimate load on the model by the square (36) of the linear scale factor (6) yielded values in very close agreement with those for the prototypes.

Beams MB-4-SS-4 and -5 had the same cross section as beam MB-4-SS-2 and were loaded in the same manner. However, 
these beams had a reduced shear-span-to-depth ratio of 2.2 . The purpose of these beams was to determine the failure mode and ultimate shear in beams having $a / d=2.5$. Since no prototype beams had been tested like these models, the results were compared only with the ACI Code equation for ultimate shear. The results of the tests on both models indicated that the Code formula was highly conservative for beams having a low a/d ratio. At the same time the results indicated that, there was a definite size effect for this type of model made from ultracal 30.

The remaining beam of this series, MB-4-I-1, with a shear span-to-depth ratio of 2.9 failed at a much higher shear stress than its prototype beam IIT-1. In order to compare the rosults nf this model with standard theory, the same shear equation was used for this beam as for the other beams of this series. The only difference being that at the critical section a distance a from the support $V / M=1 /(a-d)$. Here again the test results were nuch higher than predicted from the calculations, indicating a size effect for this beam. The failure came without the formation of a diagonal crack and after the tension steel had yielded. 


\section{SURMARY AND CONCLUSIONS}

It is hoped that the work performed for this report will stimulate further interest and development of smallscale direct models for use in design and analysis of reinforced concrete structures.

The first two series of model beams verified that small models can be used to provide good indications of the ultimate capacity of larger prototype beams. It was possible to duplicate not only the ultimate capacity of the beam, but also the failure pattern.

Both those beams failing in shear and those in flexure agreed favorably when compared with the ACI Code formulas for Ultimate Strength Design.

While bond tests were not carricd out on the reinforcement used in this work, observations of crack patterns showed that bonding was fairly good, the unannealed threaded rod exhibiting the smallest crack spacing.

The fact that model's made from the Ultracal 30 could be tested in a short time was a great aid in this work. At the same time the surface smoothness of the finished models was also a great asset to the experimenter in following the cracking pattern.

The results of the third series of models, containing both longitudinal and vertical reinforcing, were compared 
with the results of their prototypes. As in the case of Series 1 and 2, both the magnitude of the failure load and the mode of failure were studied. For this series the load capacity of the models compared reasonably well with their prototype, the average ratio of model ultimate load to that of prototype being 0.97. There was, however, considerable variation in this ratio for several of these models. At the same time the model failures were not confined to the shear span as were the prototype failures.

For those beams having an a/d value less than 3.0 , initial cracks formed at higher values than predicted from prototype results. There were indications that these models were restrained from cracking within the shear span. For, although the diagonal crack did form, it was for the most part in the overhang rather than the shear span.

The beams of the last series were $T$-beams. The first Eive were loaded at their third points and supported at each end, while the last beam had an overhang, with loads applied in the overhang and interior span. The first 3 beams, MB-j-SS-1, -2 and -3 gave excellent correlation with prototype data, both type and magnitude of failure being duplicated.

The data for beams MB-3-SS-4 and - 5 was much more erratic. Although these beams were identical, there was considerable variation in their load capacity. Since the only difference between these beams and the three previous was that these had a lower a/d ratio, it appeared that for low 
a/d ralues the beams exhibited a size effect.

For the last beam, having an overhang and a/d of 2.9 , failure came after the extension of flexural cracks, rather than a diagonal tension failure as for its prototype.

Although it was not originally the purpose of this work to provide a means for aiding classroom studies of reinforced concrete design, it quickly became apparent how valuable these small models would be for such a purpose. This would be true for all courses on reinforced concrete from the beginner through the advanced stulent.

Since model beams made from Ultracal 30 can be poured and tested within a single $2+$ hour period, it is possible to aliow the student to design, manufacture, and test his own simple structure within a short period of time, helping to tie the classroom and lield together in the mind of the student. 


\section{SUGGESTIONS FOR FURTHER RESEARCH}

Due to the late development of this area of research there is ample room for more experimentation along these lines. A few suggestions for further work are apparent:

1. There is a need to develop a means for determining the strain in the model reinforcing. This means that work could be done in applying strain gages to very small reinforcing bars. Although some work has been done in this area, it is still very tedious and undeveloped.

2. ilore complicated structures should be poured and tested. At present littIe such work has been done in this country, although in the Mediterranean countries of Europe some fairly elaborate structures have been tested. This area of research is almost endiess.

3. Means for using model beams for classroom demonstrations should be carefully studied. Not only do such models act as excellent specimens, but they could even be used to physically evaluate designs developed by the students.

4. More work should be done to find and develop materials to use for models. It was only after an 
extensive survey of various steel producers that this experimentor was able to locate a small-scale reinforcing material and then it could be obtained in only one reasonable size.

5. Further work should be carried out to establish mixing, curing and testing techniques for smal1 models. Such techniques would greatly aid in dereloping more reproducible models.

6. Additional tests should be carried out, comparing molel and prototype beams subjected to various loading configurations, in order to further establish the important variables in reinforced concrete modeling. 
B IBEIOGR.IPIYY 


\section{BIBLIUGRAPHY}

1. ACI Committee 31s, "Building Code Requirements for Reinforced Concrete (ACI 318-6.5), "ACI Standard, June 1963 .

2. Alami, Z. Y. and Ferguson, Phil Mí, "Accuracy of Nodels Used in Research on Reinforced Concrete," ACI Journal, Nov. 1963, Proceedings Vol. 60, No. $11, \mathrm{p}$. 1043 .

5. Amaratunga, 1., "Tests on Piodels of Concrete Structures," Engineering, Vol. 194, No. 5021, $13 \mathrm{July} 1962$, pp. $62-03$.

4. Brock, G., "Inirect Yodels as an Aid to Reinforced Concrete Design," Lingineering, Ipril 10, 1959, pp. 408470 .

5. Brock, G., "Effect of Shear on Ultimate Strength of Rectangular Beans with lensile Reinforcements," ACl Journa1, lol. 51, No. 7, January 1960, fp. 619-637.

0. l)arics, J. D., "Models for Structural Concrete," Civil Lngineering and Public Works Review, Vol. 59, No. 693, April 1964, pp.447-451, No. 694, llay 1964, pp. 010-613.

7. Fumagal1i, E., "The Use of Models of Reintorced Concrete Structures," Magazine of Concrete Research, Vol. 12, No. 35, July 1900 , pp. 63-72.

8. Gukhman, A. A., Introduction to the Theory of Similarity, New York, Academic Press, 1905.

9. Harvey, W. X., "A Study of Diagonal Tension Failures in Reinforced Concrete Beams," M.S. Thesis, Purdue University, 1964 .

10. Johnson, R.P., "Strength Tests on Scaled-down Concretes Suitable for Models with a Note on Mix Design," Magazine of Concrete Research, Vol. 14, no. 40, Narch 1962, pp. $47-53$.

11. Langhaar, H. L., Dimensiona 1 Analys is and Theory of
Models, New York, John Wiley and Sons, Inc., 1951. 
12. Magura, D. D., "Structural Model Testing--Reinforced and Prestressed Mortar Beams," Journal of the PCA Research and Derelopment Laboratories, Vol. 9, No. 1, January 1967, pp. 2-24.

13. Murphy, G., Similitude in Engineering, New York, Ronald Press Company, 1950 .

14. Wehr, K. E., "Shear Strength of Reinforced Concrete T-Beams," M.S. Thesis, Purdue University, 1964.

15. White, R. N., "Small-Scale Models of Concrete Structures," ASCE Conference Reprint 131, October 19-23, 1904 . 
APPENDIX. MODEL CONCRETE 
APPENDIX A. MODEL CONCRETE

The model concrete was mixed using a small three-speed electric mixer in order to insure that the mix was of uniform consistency. The following mixing process was used. Initially the Ultracal 50 and water were mixed togetluer at a slow speed. The sand was gradually added within one minute at this same speed. The mixer was then turned off, the mix allowed to set for $1-1 / 2$ minutes. The mixer was then run an additional one minute at medium speed. This method seemed the most effective and produced a mix of even consistency throughout.

ilthough after mixing the concrete was very liquid in appearance, witlin ten minutes it began to set, necessitating that all pouring be done rapialy. Due to a dye added by the manufacturer, the model concrete has a light green color after being mixed.

For each batch mixed, a series of four or more $2^{\prime \prime} x^{\prime \prime}$ cylinders were poured into metal cylinder molds, the bottom ends of which were attached to metal plates. The cylinders were then filled in three layers, being rodded 25 times with each new layer. Three cylinders were then capped on top using a sulfur-castite compound. These were then tested in compression using an Emery universl test machine and a 
loading rate of 300 pounds per minute. This machine had a six inch diameter loading head that was easily adjusted. In general, there was good agreement between the results of the cylinders tested after a certain curing time, the compressive strengths varying within $10 \%$ of the average ralue. In some cases failure occurred in the cap. Observations after such failures indicated the causes to be either a large roid within the cap or a crooked cap.

After the compression tests, the remaining cylinders were then tested as shown in Figure $\Lambda-1$ in split-tension using the same machine as used in the compression tests. The results for the split-tensile tests showed more variance than those for the compressive tests, however this is generally true for portland coment concrete. For these tests the rate of loading was $1500 \mathrm{lbs} / \mathrm{min}$.

Three methods were used to determine the stress-strain propertics of this mix. Initially, dial gages were placed between the loading head and table while the capped cylinders were loaded in compression. This, however, did not give a true representation of the deformation of the specimen, but rather the amount of displacement the head of the load machine underwent. The value of the elastic modulus from these specimens was $2.2 \times 10^{6} \mathrm{psi}$.

In an attempt to improve on the first approach the cylinders were not capped, but instead were polished smooth at each end to eliminate any surface deformities. The dial 


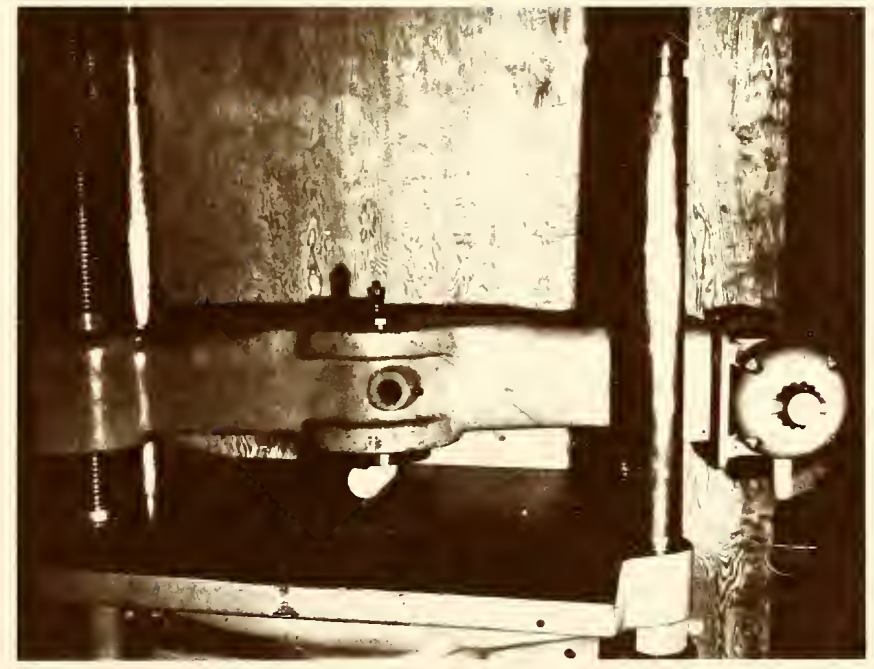

FIGUREA-1. CYLINDER SPLIT TENSILE TESTS 
gages were again placed and the cylinders loaded in compression. This method yielded somewhat more accurate values than the previous one, indicating a higher value for the elastic modulus of the Ultracal $30 \mathrm{mix}$.

Finally, SR-4 paper backed gages were applied to the test cylinders, diametrically opposite one another and located midway between the ends of the cylinder. These gages provided a very good means of determining the concrete strain. The average initial tangent modulus for a 24 -hour specimen using this method was $2.7 \times 10^{6} \mathrm{psi}$. The typical stress-strain diagram for this mix after twenty-four hours is shown in Figure $A-2$.

Figure $A-3$ indicates the increase in model concrete compressive strength with time. The curve is plotted on the basis of the average value of the cylinder test results for a particular curing time. 


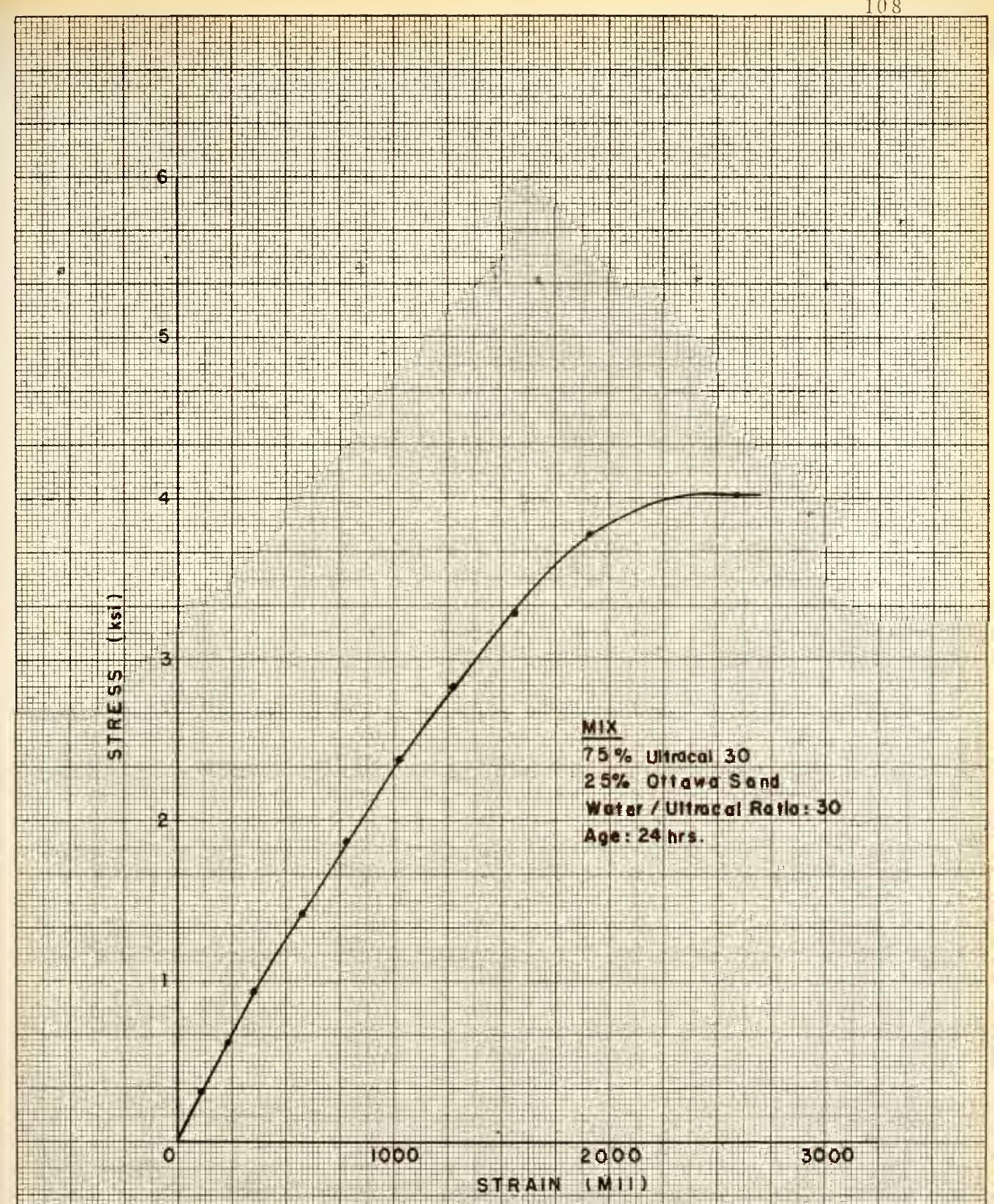

FIGURE A-2. TYPICAL STRESS-STRAIN CURVE FOR ULTRACAL MIX 


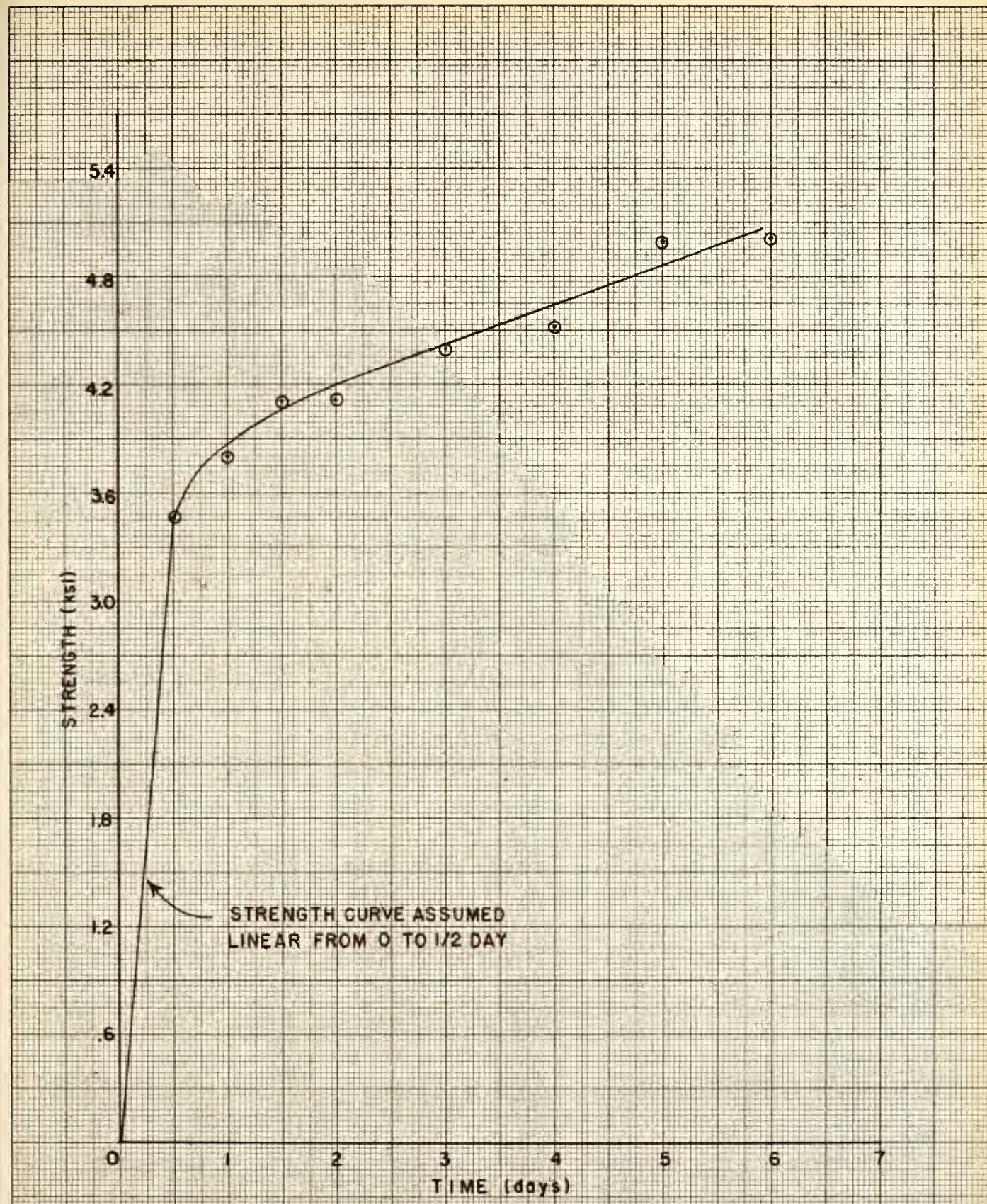

FIGURE A-3. TIME-STRENGTH CURVE FOR MODEL CONCRETE 
APPLNDIX B. MODLL REINFORCLMENT 


\section{APPENDIX B. MODEL REINFORCEMENT}

Figures $B-1$ through $B-4$ are typical stress-strain diagrams for the various types of Iongitudinal reinforcement used in the model beans. Figure $B-5$ is a stress-strain diagram for the vertical reinforcement. All of these curves are not aterage curves, hut instead are typical curves for one test coupon of each type of reinforcement used.

In all cases the stress-strain diagram was obtained by the use of an aluminum clip gage dereloped at Purdue by W. C. Kroenke and J. D. Pounds for such a purpose. Figure B- 7 shows this clip gage in detail, while Figure B-6 shows how each steel specinen was tested, with the aluminum clip gage in position. The BLI-120c strain indicator was used for recording strain in the aluminum clip gage.

The same testing machine as used for the beam tests of Series 1,3 , and 4 was used to obtain the properties of the steel reinforcement. Here again, on $1 y$ the low and middle load ranges were used. The steel specimens were secured by two templin grips. In each case before any load was applied to the specimen, the initial strain reading was taken. The coupons were each loaded in tension until the failure load was reached. For every type of reinforcement at least three coupons were tested in order to clieck the 


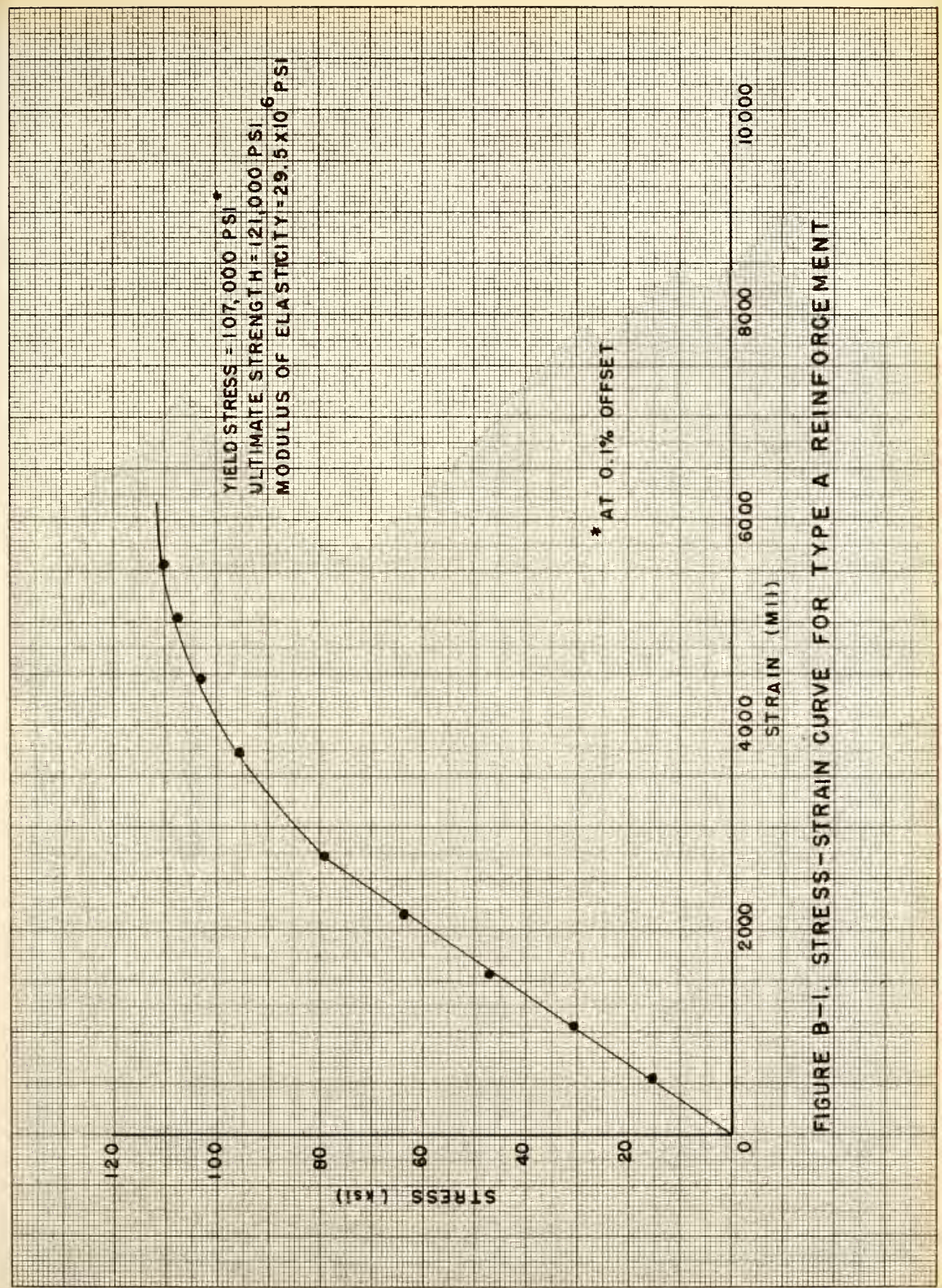




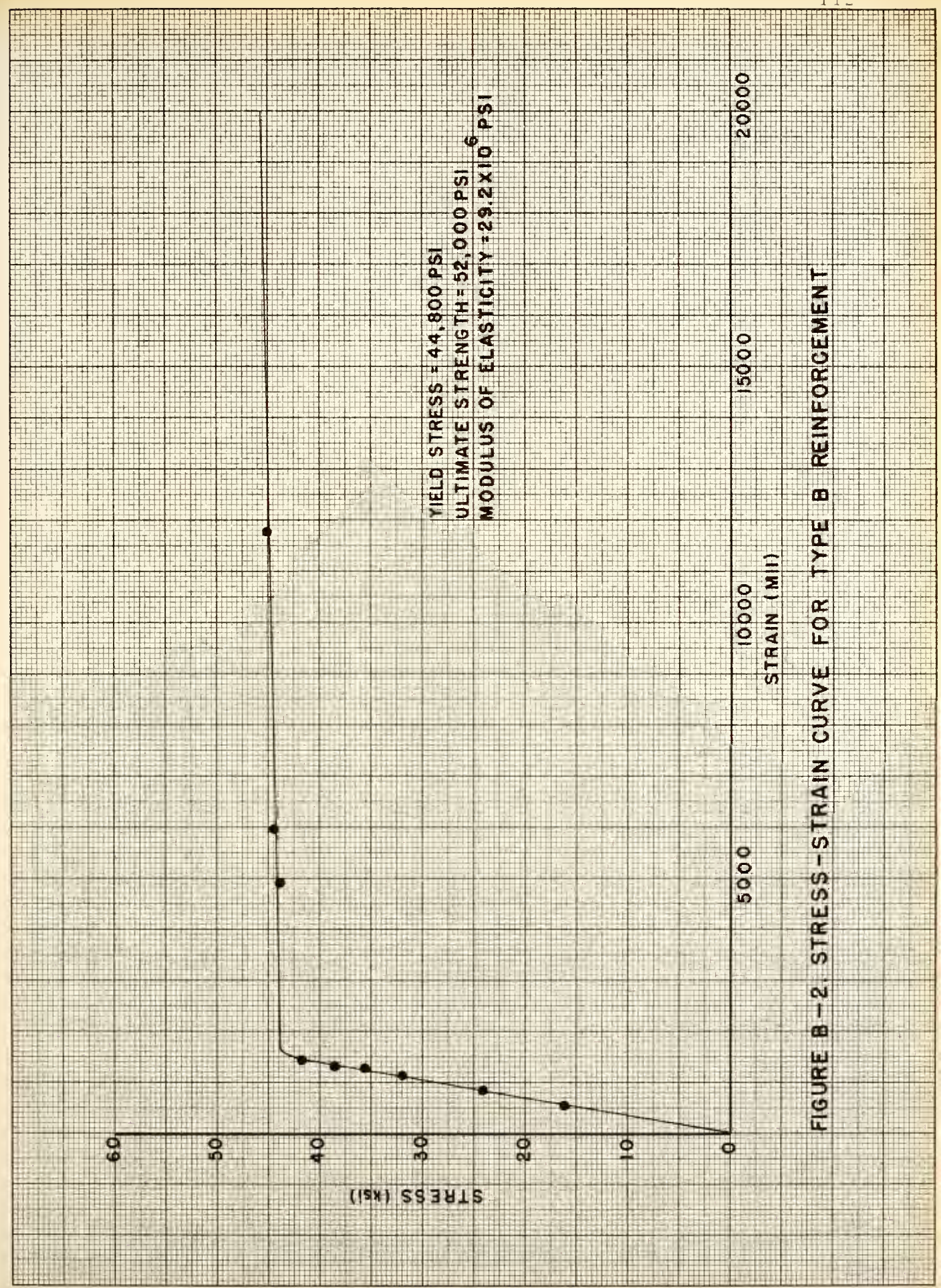




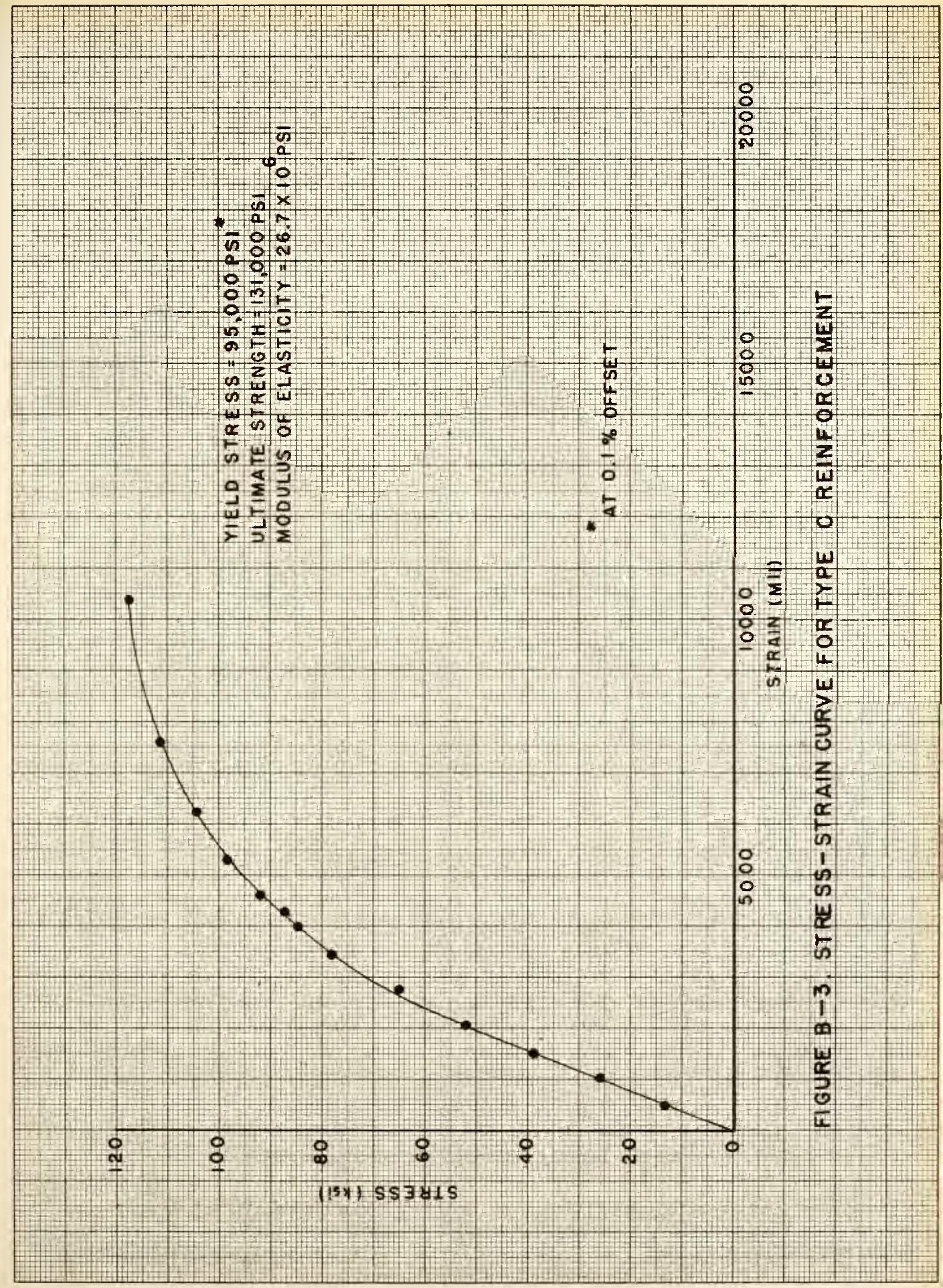




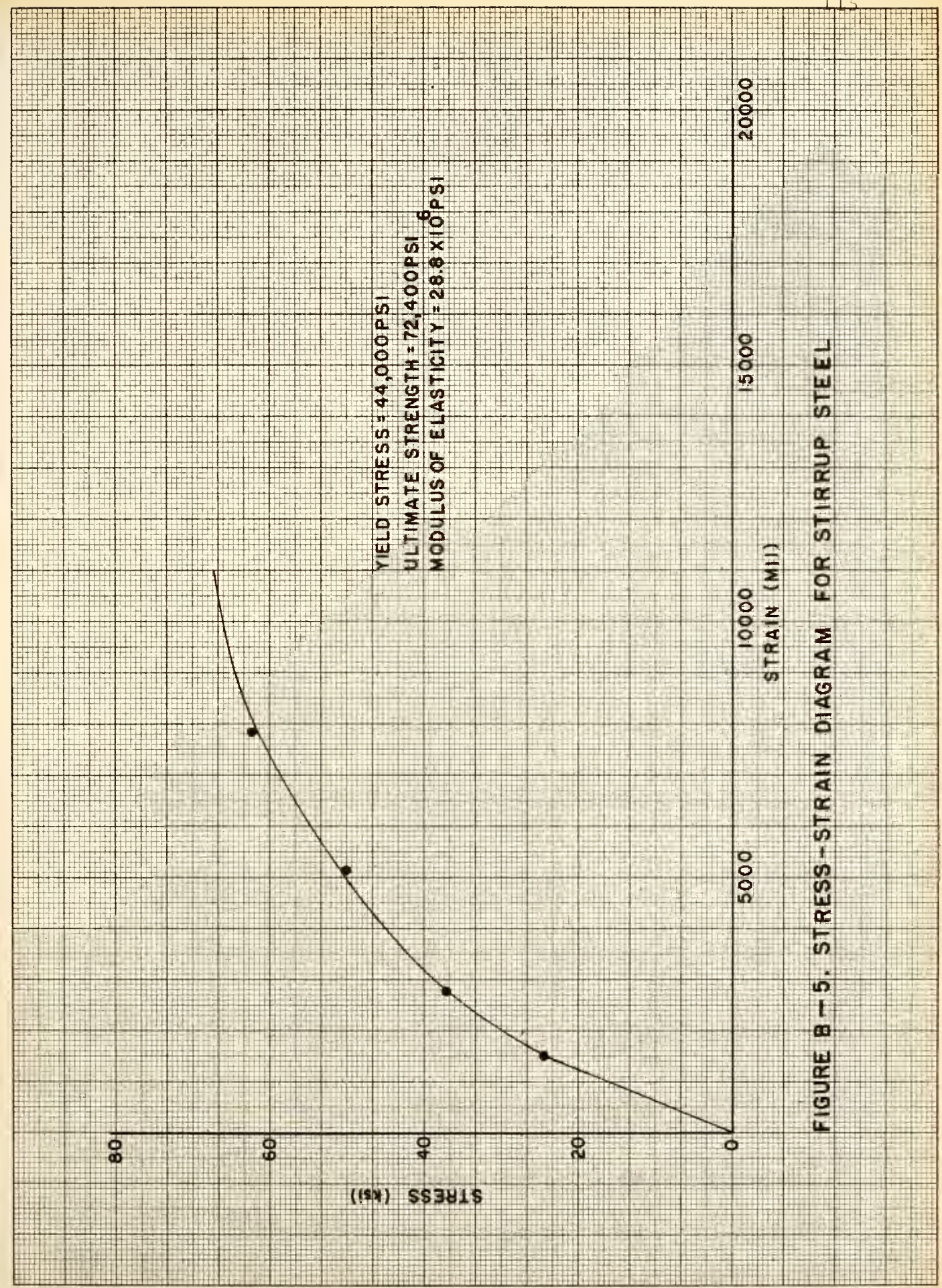




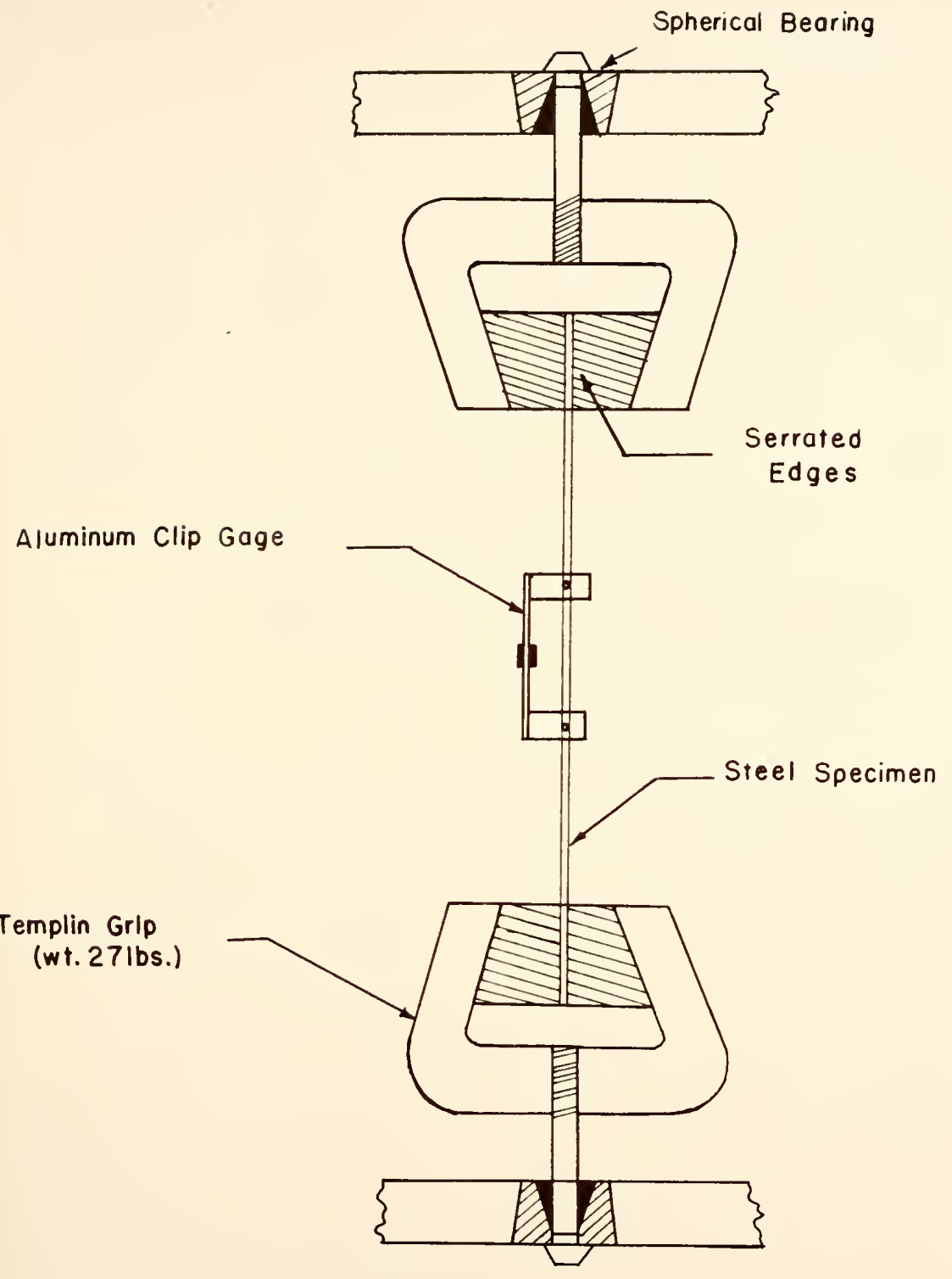

FIGURE B-6. TEST SET-UP FOR MODEL REINFORCEMENT 


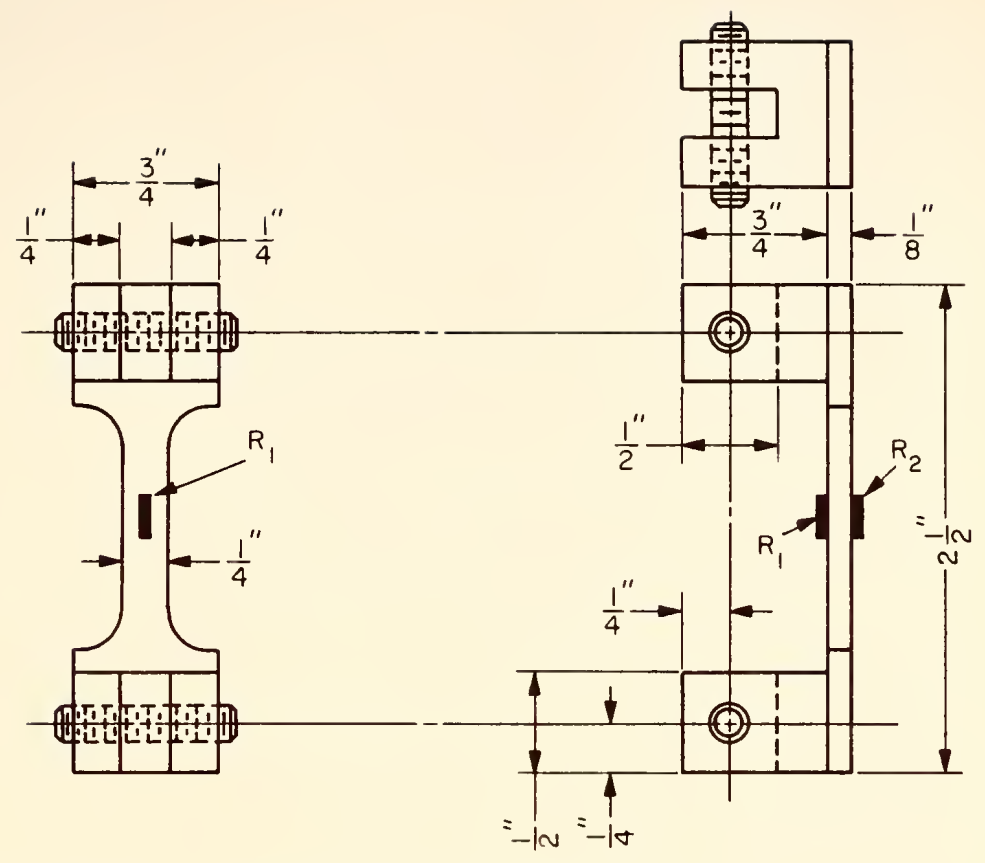

FIGURE B-7 ALUMINUM CLIP GAGE 
reliability of the test data. The first coupon in each case was tested without attaching the clip gage. This coupon provided an estimate of the yield strength of the steel in order to determine when to remove the clip gage from the other coupons. In the remaining tests the clip gage was attached and strain readings were taken at various loads. After the yield strength was passed, the clip gage was removed from the coupon.

In plotting the stress-strain curves in Figures B-3 and $B-4$, the values plotted along the abcissa are actually average stresses based on an average cross-sectional area of $0.015 \mathrm{in}^{2}$. This cross-section was established on the basis of a nominal diameter of 0.139 inches.

The annealing racks used to anneal the steel used in this project are shown in Figure $B-8$. Tension was applied to the steel by tightening nuts attached to the ends of each piece. This was very important in preventing the specimens from warping during the annealing process. Each rack was specially constructed to prevent the rack from failing during annealing. 


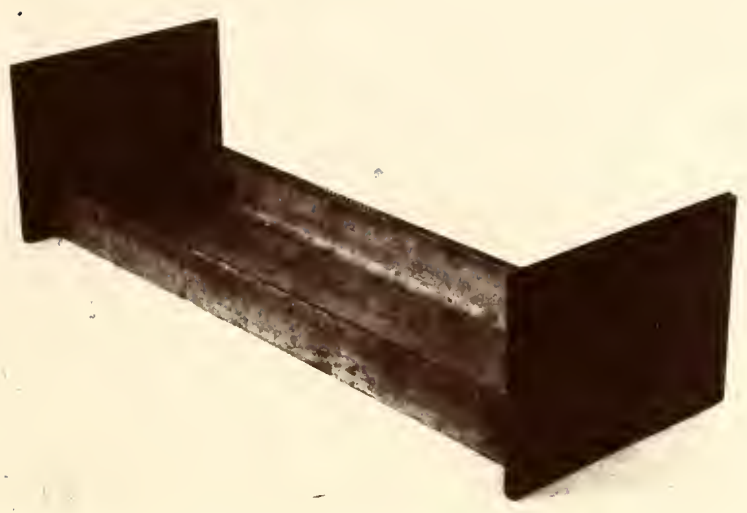

Deformed Wire

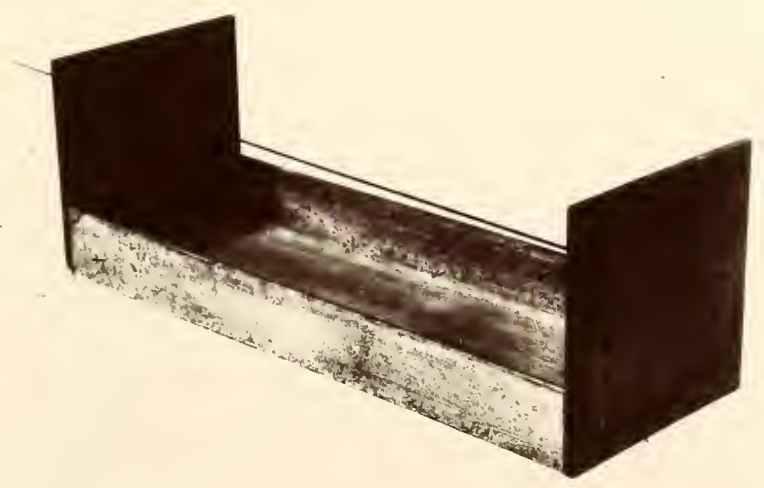

Threoded Rod

FIGURE B-8. ANNEALING RACKS 
appendix C. SAMple Calculations 


\section{APPENDIX C. SAMPLE CALCULATIONS}

\section{Series 1 and 2}

1. U1timate Moment based on ACI Code:

$$
M_{u}=A_{s} f_{y}\left(d-a^{\prime} / 2\right) \text {, where } a^{\prime}=\frac{A_{s} f}{0.85 f f^{\prime} b}
$$

For beam NBT-2-1

$$
\begin{aligned}
A_{s} & =.0031 \mathrm{in.}^{2} \\
f_{y} & =115,000 \mathrm{psi} \\
f_{c}^{\prime} & =3530 \mathrm{psi} \\
b & =1 \mathrm{in} . \\
\mathrm{d} & =1.32 \mathrm{in} . \\
\therefore a^{\prime} & =\frac{.0031(115,000)}{.85(3530)(1)}=.119
\end{aligned}
$$

and

$$
M_{u}=.0031(115,000)\left(1.32-\frac{.119}{2}\right)=449 \text { in }-1 b
$$

Ultimate Moment from Experimental Results:

$$
\begin{aligned}
& M_{u}=\frac{P_{u}}{2}(5.6)=\frac{1701 b}{2}(5.6)=476 \text { in }-1 b \\
& M_{u t} / M_{u c}=476 / 449=1.06
\end{aligned}
$$


2. Ultimate Shear Force based on ACI Code:

$$
v_{u}=v_{u}(b) d=b d\left(1.9 \sqrt{f !}+2500 \frac{A_{c}}{b}\right)
$$

For beam $M B T-2-7$

$$
\begin{aligned}
& \mathrm{A}_{\mathrm{S}}=.0095 \mathrm{in} .^{2} \\
& f_{y}=115,000 \mathrm{psi} \\
& F_{C}^{\prime}=4300 \mathrm{psi} \\
& \mathrm{b}=1 \mathrm{in} \text {. } \\
& \mathrm{d}=1.32 \mathrm{in} . \\
& v_{u c}=(1)(1.32)\left(1.9 \sqrt{(4300)}+2500 \frac{.0093}{(1)(1.32)}\right) \\
& \mathrm{v}_{\mathrm{uc}}=187
\end{aligned}
$$

Ultimate Shear Force from experimental results:

$$
\begin{aligned}
& V_{u t}=P_{u} / 2=1751 \mathrm{bs} \\
& V_{u t} / V_{u c}=175 / 187=0.94
\end{aligned}
$$

3. Modulus of Rupture:

$$
\begin{aligned}
& \mathrm{f}_{\mathrm{r}}=\mathrm{Mc} / \mathrm{I} \\
& \mathrm{M}=258 \mathrm{in}-1 \mathrm{~b} \text { (average of unreinforced specimen tests) } \\
& \mathrm{I}=\frac{\mathrm{bh}^{3}}{12}=\frac{1.0(1.5)^{3}}{12}=.282 \mathrm{in}^{3} \\
& \mathrm{C}=.75 \mathrm{in} \\
& \therefore \mathrm{F}_{\mathrm{r}}=\frac{258(.75)}{.282}=687 \mathrm{psi}
\end{aligned}
$$


4. Calculate Ultimate Moment Using Alternate Method

$$
f_{\text {su }}=\left(\frac{.7 f_{c}^{\prime}}{p}\right)\left(\frac{.003}{\varepsilon_{s u}+.003}\right)
$$

For beam MBD-1-6:

$$
\begin{aligned}
p & =.0049 \\
f_{c}^{\prime} & =3840 \mathrm{psi}
\end{aligned}
$$

$$
\text { For } \begin{aligned}
\varepsilon_{\text {su }} & =.007 \\
\varepsilon_{\text {su }} & =.017 \\
\varepsilon_{\text {su }} & =.012 \\
\varepsilon_{\text {su }} & =.010
\end{aligned}
$$

$$
\begin{aligned}
& f_{\text {su }}=164,640 \mathrm{psi} \\
& \mathrm{f}_{\text {su }}=82,320 \mathrm{psi} \\
& \mathrm{f}_{\text {su }}=109,700 \mathrm{psi} \\
& f_{\text {su }}=126,600 \mathrm{psi}
\end{aligned}
$$

Plot curve thru these points. Intersection of this curve with stress-strain curve for type " $C$ " reinforcement yields the following value:

$$
\begin{aligned}
f_{s u} & =121,000 \text { psi } \\
\therefore M_{u} & =A_{s} f_{s u}\left(d-\frac{a}{2}\right) \\
a & =\frac{A_{s} f_{s u}}{0.85 f_{c}^{1} b}=\frac{.015(121,000)}{.85(3840)(1.5)}=.401 \mathrm{in} . \\
\therefore M_{u} & =(.015)(121,000)(2.04-.20)=3340 \text { in-1bs. }
\end{aligned}
$$

5. Calculation of Model Dimensions - Series 3 Properties of Reinforcing:

$$
\begin{array}{ll}
\mathrm{f}_{\text {sp }}=75,400 \mathrm{psi} & \mathrm{f}_{\text {sm }}=76,000 \mathrm{psi} \\
\mathrm{f}_{\text {up }}=117,000 \mathrm{psi} & \mathrm{f}_{\text {um }}=87,000 \mathrm{psi}
\end{array}
$$




$$
E_{p}=30.4 \times 10^{6} \mathrm{psi} \quad E_{m}=27.5 \times 10^{6} \mathrm{psi}
$$

The ratio of yield strengths, $\mathrm{f}_{\mathrm{sp}} / \mathrm{d}_{\mathrm{sm}}=75,400 / 76,000=$ .993

$$
\therefore \text { Assume } f_{\mathrm{sp}} / \mathrm{f}_{\mathrm{sm}}=1.0
$$

\section{Areas of Reinforcement:}

a. For the Prototype

$$
\begin{aligned}
& A_{s p}=2 \text { No. } 6=.88 \mathrm{in}^{2} \\
& A_{s p}^{\prime}=2 \text { No. } 5=.62 \mathrm{in}^{2}
\end{aligned}
$$

b. For the Model

$$
\begin{aligned}
& A_{S m}=3-D A=.045 \mathrm{in}^{2} \\
& A_{S m}^{\prime}=2-D A=.050 \mathrm{in}^{2}
\end{aligned}
$$

c. Ratio of Steel Areas

$$
\begin{aligned}
& A_{s p} / A_{s m}=.88 / .045=19.6 \\
& A_{s p}^{\prime} / A_{s m}^{\prime}=.62 / .030=20.7 \\
& \text { Average of Ratios }=\frac{19.6+20.7}{2}=20.2 \\
& \therefore h^{2}=20.2 \\
& \quad h=4.49, \text { say } h=4.50
\end{aligned}
$$


Mode1 Dimensions:

$$
\begin{aligned}
b_{m}=b_{p} / h & =6 / 4.50=1.33 \text { in } \\
t_{m}=t_{p} / h & =13 / 4.50=2.89 \text { in } \\
1_{m}=1_{p} / h & =92 / 4.50=20.4 \text { in (Type MB-3-I) } \\
& =100 / 4.50=22.2 \text { in (Type MB-3-II) } \\
& =118 / 4.50=26.2 \text { in (Type MB-3-III) }
\end{aligned}
$$

6. Calculation of Model Dimensions - Series 4

Properties of Reinforcing:

$$
\begin{array}{ll}
f_{s p}=73,700 \mathrm{psi} & \mathrm{f}_{\mathrm{sm}}=76,000 \mathrm{psi} \\
f_{u p}=117,000 \mathrm{psi} & \mathrm{f}_{\mathrm{um}}=87,000 \mathrm{psi} \\
\mathrm{E}_{\mathrm{p}}=29.6 \times 10^{6} \mathrm{psi} & \mathrm{E}_{\mathrm{m}}=27.5 \times 10^{6} \mathrm{psi}
\end{array}
$$

The ratio of yield strengths, $\mathrm{f}_{\mathrm{sp}} / \mathrm{f}_{\mathrm{sm}}=73,700 / 76,000=$ 0.97

$$
\therefore \text { Assume } \mathrm{f}_{\mathrm{sp}} / \mathrm{f}_{\mathrm{sm}}=1.0
$$

\section{Lincar Scale Factor:}

$$
\begin{aligned}
\text { Assume } h & =6.0 \\
\therefore & h^{2}=36.0
\end{aligned}
$$




\section{Model Dimensions:}

$$
\begin{aligned}
& b_{m}=b_{p} / h=6 / 6.0=1 \text { in } \\
& t_{m}=t_{p} / h=13 / 6.0-2.17 \mathrm{in} \\
& t_{f m}=t_{f p} / h=3 / 6.0=0.5 \mathrm{in} \\
& b_{f m}=b_{f p} / h=30 / 6.0=5 \text { in (for } 30^{\prime \prime} \text { flange) } \\
& \left.1_{m}=1_{p} / h \quad \text { (Variable }\right) \\
& A_{s m}=A_{s p} / h^{2}=.88 / 36=.025 \mathrm{in}^{2} \\
& \because \quad \text { Use } 2-\mathrm{Da}, \mathrm{A}_{\mathrm{sm}}=.03 \mathrm{in}^{2} \\
& A_{s m}^{\prime}=A_{s p}^{\prime} / h^{2}=.62 / 36=.017 \mathrm{in}^{2} \\
& \therefore \text { Use 1-DA, } \mathrm{A}_{\mathrm{sp}}^{\prime}=.015 \mathrm{in}^{2}
\end{aligned}
$$



